\title{
Retos y perspectivas del nuevo régimen forestal en el norte amazónico boliviano
}

Wil de Jong Editor
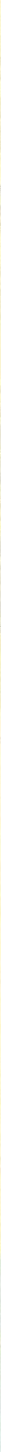


\section{Retos y perspectivas del nuevo régimen forestal en el norte amazónico boliviano}

Wil de Jong (editor) 
๑ 2004 Centro Internacional para la Investigación Forestal Todos los derechos reservados. Publicado en el 2004 Impreso por SMK Grafika Desa Putera, Indonesia

ISBN 979-3361-45-X

Publicado por

Centro Internacional para la Investigación Forestal

Dirección postal: P.O. Box 6596 JKPWB, Jakarta 10065, Indonesia

Dirección física: Jl. CIFOR, Situ Gede, Sindang Barang, Bogor Barat 16680, Indonesia

Tel.: +62 (251) 622622; Fax: +62 (251) 622100

E-mail: cifor@cgiar.org

Web site: http://www.cifor.cgiar.org 


\section{Tabla de Contenido}

Autores iv

Agradecimientos vii

Preámbulo viii

Capítulo 1

El nuevo régimen forestal en el norte amazónico boliviano 1

Wil de Jong, Michel Becker, Sergio Ruiz y Carmen Gottwald

\section{Capítulo 2}

Redistribución de los recursos forestales en el norte amazónico boliviano

Sergio Ruiz

\section{Capítulo 3}

La nueva administración de tierras y bosques en el norte amazónico boliviano

Sergio Ruiz

\section{Capítulo 4}

Participación política de comunidades forestales en el norte amazónico boliviano

Carmen Gottwald

\section{Capítulo 5}

El uso del bosque comunitario bajo el nuevo régimen forestal

Gunther Hentschel

\section{Capítulo 6}

El nuevo régimen legal y los derechos sobre tierras y bosques indígenas

Andrea Garzón

\section{Capítulo 7}

Estratégias de Medios de Vida aplicadas por los indígenas Cavineños

Johannes Stahl

\section{Capítulo 8}

Conflictos entre uso y protección de los recursos naturales,

Reserva Nacional de Vida Silvestre Amazónica Manuripi (RNVSAM)

Roberto Maldonado Kühne

\section{Capítulo 9}

Extracción forestal, procesos migratorios y deforestación

en el norte amazónico boliviano

Victor Llanque 


\title{
Autores
}

\author{
Andrea Garzón Samper
}

c/ Castillo de Jimena n.5

Jerez de la Fontera

11406 Cadiz - España

Tel: +34-856051011

E-mail: andreosky@rocketmail.com

Andrea Garzón Samper tiene un B. Sc. en Manejo de Recursos Naturales de la Universidad San Francisco de Quito, Ecuador. Se especializó con un M. Sc. en Forestería Sustentable y Uso de Tierra (énfasis en Economía y Sociedad) en la Universidad de Freiburg, Alemania (2003). Ha colaborado en diferentes estudios y proyectos comprometidos con el desarrollo sostenible y medio ambiente en la costa y amozonía ecuatoriana, en el norte de Alemania y en la amazonía boliviana.

\section{Carmen Gottwald}

Investigadora de doctorado

Universidad de Freiburg

Instituto de Política Forestal y Ambiental

Sección Mercado y Mercadeo

Tennenbacher Str. 4

79106 Freiburg - Alemania

Tel.: +49-761-2038500

Fax : +49-761-2033729

E-mail: carmengottwald@gmx.net

Carmen Gottwald recibió su título en Estudios Superiores de Economía, Política y Ámbitos Culturales en la Universidad de Passau (1999). Actualmente es estudiante doctoral en la Universidad Freiburg en el Instituto de Política Forestal y Ambiental, Sección Mercado y Mercadeo. Su tesis doctoral examina la acción y reacción de comunidades campesinas en la Amazonía Boliviana frente a cambios legales con enfoque a aspectos socio-históricos en el uso de los recursos naturales, organización y capital social.

\section{Johannes Stahl}

Investigador de doctorado

Universidad Humboldt de Berlín

Instituto de Economía Agrícola y Ciencias Sociales

Grupo de Investigación de Relaciones de Tierras Post Socialistas

Luisenstr. 56

10099 Berlín - Alemania

Tel: +49 30-2093 6240

Fax: +49 30-2093 6427

E-mail: johastahl@yahoo.de 
Johannes Stahl recibió su M.A. en Antropología Social en la Universidad de Friburgo (2003). Actualmente es estudiante doctoral en la Universidad Humboldt de Berlín en el Instituto de Economía Agrícola y Ciencias Sociales. Su tesis doctoral examina los efectos de la reforma agraria en comunidades rurales en Albania.

\section{Michel Becker}

Director de la Sección "Mercado y Mercadeo", Instituto de Política Forestal y Ambiental, Universidad de Freiburg

Tennenbacher Str. 4

D-79085 Friburgo - Alemania

Tel (direct): +49-761-2033708; Tel (org): +49-761-2033707

Fax: +49-761-2033729

E-mail: markt.marketing@ifp.uni-freiburg.de

Michel Becker dirige un programa de investigación y ensenanza superior que en Europa analiza los cambios estructurales que afectan a la empresas forestales y al comercio de madera y derivados. En los trópicos la Sección investiga aspectos económicos, sociales e institucionales del aprovechamiento forestal (maderables y no maderables) en América Latina y África.

\section{Roberto Maldonado Kühne}

GOPA Consultants

Rural Development and Environment

Robert Koch Str. 94

72800 Eningen u.A. - Alemania

Tel: +49-6171-923500

Fax: +49-671-2909281

E-mail: maldonador@gmx.de

Roberto Maldonado Kühne recibió su M. Sc. en Ciencias Forestales de la Universidad Albert Ludwigs en Freiburgo, Alemania (2003). Después de trabajar en el ambito de productos forestales no maderables y realizar un estudio socio económico para CIFOR, está trabajando para COPA Consultans apoyando en el proyecto de cooperación técnica en el ambito de mecanismos de desarrollo limpio (CDM), manejo de áreas protegidas así como desarrollo rural.

\section{Sergio Antonio Ruiz}

Candidato a Doctor

Proyecto de investigación "Developing institutions for sustainable use of NonTimber Forest Products" patrocinado por BMZ/CIFOR

Universidad de Freiburg, Instituto de Política Forestal y Ambiental, Sección de Mercado y Mercadeo

Tennenbacher Str. 4

D-79085 Freiburgo - Alemania

Tel: +49-761-2038495

Fax: +49-761-2033729

E-mail: sergioantonioruiz@hotmail.com 
Sergio Antonio Ruiz es ingeniero agrónomo Zamorano con maestría en Planificación Regional en Karlsruhe, Alemania. Desde el 2000 se dedica a investigar los cambios de los derechos de propiedad en el uso del bosque amazónico y los conflictos sociales emergentes. Cuenta con una experiencia de 5 años trabajando en proyectos de cooperación internacional en Latinoamerica dirigidos hacia el manejo y conservación de los recursos naturales, ordenamiento territorial y conflictos por el uso de los bosques.

Wil de Jong

Científico

Centro para la Investigación Forestal Internacional

P.O. Box 6596 JKPWB

10065 Yakarta - Indonesia

Tel: $+62-251-622622$

Fax: $+62-251-622100$

E-mail: w.de-jong@cgiar.org

Wil de Jong tiene un Ph.D. de la Universidad Agrícola de Wageningen, Holanda. Ha trabajado más de 20 años haciendo investigación sobre el uso de los recursos naturales por pequeños agricultores y grupos indígenas en Bolivia, Perú, Zimbabwe, Indonesia y Vietnam. Actualmente supervisa y ejecuta proyectos de investigación en Bolivia, Perú y Vietnam.

\section{Gunther Hentschel}

Forest Policy Advisor

Timber Trade Federation UK

Clareville House

26/27 Oxendon Street

SW1Y 4EL Londres - Inglaterra

g_hentschel@web.de

Gunther Hentschel concluyó sus estudios de Ciencias Forestales y Medio Ambientales en el 2003 en la Universidad de Friburgo, Alemania. Actualmente trabaja como asesor forestal en la organización matriz del comercio de maderas de Gran Bretaña. Su trabajo se concentra en el desarrollo de políticas ambientales para la adquisición de maderas, en el comercio ilegal de la madera y en la elaboración de análisis de riesgo en los países participantes. 


\section{Agradecimientos}

Este libro es producto de un proyecto de investigación que se llevó a cabo con el apoyo financiero del Ministerio Federal de Cooperación Económica y Desarrollo de Alemania (BMZ) y la Agencia Suiza para el Desarrollo y la Cooperación (SDC). CIFOR expresa su agradecimiento a estas dos agencias.

El proyecto de investigación fue un proyecto en colaboración entre el Centro para la Investigación Forestal Internacional (CIFOR), el Instituto de Política Forestal y Ambiental a través de su Sección de Mercados y Mercadeo, el Programa de Manejo de Bosques de la Amazonía Boliviana (PROMAB) y el Centro de Investigación y Promoción del Campesinado (CIPCA).

El proyecto también contó con la amplia colaboración de varias organizaciones en Bolivia: El Servicio Nacional de Áreas Protegidas de Bolivia; La ONG Herencia, con sede en Cobija; La oficina en Pando del Servicio Holandés de Cooperación Técnica (SNV); El Instituto Nacional de Reforma Agraria y La Superintendencia Forestal. El CIFOR también expresa su agradecimiento a estas organizaciones.

Agradecemos el valioso trabajo de Luis Valencia en la edición y diagramación de este libro y a Andrea Garzón Samper por revisar la versión final y hacer valiosos comentarios. Agradecemos también a todos aquellos que colaboraron para la realización de este libro. 


\section{Preámbulo}

Bolivia, como muchos países con bosque tropical, está viviendo un tiempo de cambio. El país tiene una economía débil, resultando en altos índices de pobreza. Muy relacionado a estos está la frágil estabilidad política. El gobierno, las asociaciones civiles y el sector privado están gestionando cambios, a veces colaborando, a veces en conflicto entre ellos. Hay suficiente razón para ser optimista que el proceso de cambio llevará al país a una mejor situación. Una mejora de la economía será un resultado de esta mejora, pero es también una condición clave para este resultado.

Al sector forestal se le ha asignado un rol importante en la estrategia boliviana para la reducción de la pobreza. La gran variedad de recursos forestales en el país justifica esta esperanza. Bolivia tiene muchos recursos forestales, y un sector forestal muy activo. Además, la última frontera forestal del país, el norte amazónico boliviano, una vez terminada la carretera bi-oceánica, estará dentro de una región por donde pasará el intercambio económico entre Brasil, Perú y Chile. En términos generales, no puede haber mejores condiciones que estas para reactivar el sector forestal. El país ha reconocido esto y ha iniciado una reforma forestal, como parte de una reforma legal más amplia, con la cual se espera aumentar la contribución del sector a la economía nacional, pero también se espera que pueda contribuir significativamente en la reducción de la pobreza.

El presente libro hace un balance del impacto del nuevo régimen legal boliviano, en el norte amazónico de Bolivia. Región remota y aislada, que hasta hace poco no fue tomada en cuenta por el oficialismo nacional y que fue poco considerada cuando se formuló este nuevo régimen. Irónicamente, es una región que está cambiando fuertemente y de manera acelerada. $Y$ el efecto del nuevo régimen forestal sobre los bosques en Bolivia se sentirá más en esta región, a pesar de no haber sido diseñado para ella.

Queremos compartir este libro con todos aquellos que tienen un compromiso con los bosques tropicales, y con los pobladores que viven en ellos y que aspiran a una vida mejor. Esperamos que sea de utilidad en sus esfuerzos y luchas.

Wil de Jong

Científico

Centro para la Investigación Forestal Internacional 


\title{
Capítulo 1
}

\section{El nuevo régimen forestal en el norte amazónico boliviano}

\author{
Wil de Jong, Michel Becker, Sergio Ruiz y Carmen Gottwald
}

\section{INTRODUCCIÓN 1}

La preocupación mundial sobre los problemas de pobreza y el uso sostenible de los recursos naturales, como los bosques tropicales, está muy relacionada con temas de gobernabilidad. Con gobernabilidad entendemos los procesos formales e informales para la toma de decisiones en que están involucrados diferentes actores que pueden o no tener los mismos intereses, o en el peor de los casos intereses opuestos. En estos tiempos la gobernabilidad de los recursos naturales está ampliamente redefinida en muchos países por procesos de descentralización y reformas políticas y legales. Con descentralización se entiende la transferencia de autoridad para la toma de decisiones y disponibilidad de recursos, desde niveles jerárquicos más altos hacia niveles más bajos. Esto generalmente coincide con una reubicación geográfica de dicha autoridad desde el centro donde se ubica la autoridad, hacia lugares más remotos. Descentralización, sin embargo, en muchos casos es parte de una reforma más amplia de gobernabilidad de recursos forestales, los que en muchos casos incluyen una redefinición de los derechos de propiedad sobre los recursos, y democratización de la participación política. Muchos países han reconsiderado la importancia del sector forestal en la perspectiva para un desarrollo económico y en las estrategias para reducir la pobreza, lo cual está reflejado en reformas políticas y legales relacionadas. 
En Bolivia, una profunda reforma política y legal fue iniciada durante la década de 1990. Esta reforma fue una respuesta a las políticas económicas neo-liberales de los años 1980 (Ruiz, Capítulo 2, Pacheco y Mertens 2004). Un proceso de municipalización que delegó autoridad, responsabilidades y recursos a los municipios, era parte de esta reforma. Estos cambios afectaron fuertemente la gobernabilidad de los bosques bolivianos. El eje central de la reforma política fue la promulgación de un paquete de leyes, incluyendo la Ley de Participación Popular (1994), la Ley de Descentralización Administrativa (1995), la Ley de Municipalidades (1999), la Ley del Servicio Nacional de Reforma Agraria (Ley INRA), y la nueva Ley Forestal (1996). Estas leyes tuvieron enfoques y objetivos distintos, pero todas han de una u otra manera contribuido a una reconfiguración de la gobernabilidad de los recursos forestales. Evidencia de esto es en parte cómo al momento de formularlas, estas leyes tuvieron que adecuarse una a la otra. Así, la Ley Forestal tuvo que adecuarse a la Ley de Participación Popular, y de igual manera, la Ley INRA tuvo que considerar el marco de la Ley Forestal.

En muchas oportunidades se habla del nuevo régimen forestal de Bolivia, un término definido en la Ley Forestal. En este libro, sin embargo, consideramos el impacto del nuevo régimen forestal y las demás leyes mencionadas, además de las políticas de varios sectores oficiales y no estatales, que afectan el manejo de los recursos forestales en Bolivia. A este le llamamos el nuevo régimen legal de Bolivia. Consideramos aquí parte este nuevo régimen que es relevante para entender el cambio de la gobernabilidad forestal en el norte amazónico boliviano: la Ley Forestal, las revisiones de la constitución que crea los Territorios Comunitarios de Origen (TCOs), la Ley INRA que crea las bases para el manejo comunitario forestal y la Ley de Participación Popular que da la opción de obtener personería jurídica a muchos asentamientos forestales en el norte amazónico boliviano.

En este libro presentamos resultados de diferentes estudios que analizan el impacto de este paquete de reformas sobre el sector forestal y los diferentes usos que da la población rural a los bosques en el norte amazónico boliviano. Los estudios son el resultado de un proyecto de investigación en el que participaron el Centro Internacional para la Investigación Forestal (CIFOR), el Instituto de Política Forestal y Ambiental, Sección de Mercados y Mercadeo de la Universidad de Freiburg, el Programa de Manejo de Bosques de la Amazonía Boliviana (PROMAB), el Centro de Investigación y Promoción del Campesinado (CIPCA), y otras organizaciones colaboradoras de la región. Este proyecto de investigación enfocaba aspectos económicos y sociales relacionados con las industrias forestales en la región, y en los últimos años, temas relacionados con el impacto de los procesos de la reforma legal y política. 
El presente capítulo de introducción presenta los capítulos de este libro, e intenta mostrar una síntesis del impacto que ha tenido el nuevo régimen legal en la actualidad sobre la región. A continuación sigue una sección que nos introduce brevemente la historia económica de la región. Después, el capítulo presenta una sección que relaciona el caso boliviano con tendencias internacionales de gobernabilidad forestal. Aquí se introducen los temas claves que abarcan los capítulos del libro, y se resumen las contribuciones de ellos a cada tema. La siguiente sección analiza los logros y desafíos del paquete de reforma que analizamos aquí, seguido por una sección que hace un balance de esta misma.

\section{EL NORTE AMAZÓNICO BOLIVIANO}

El norte amazónico boliviano es un área de bosque continuo de aproximadamente $100,000 \mathrm{~km}^{2}$ que cubre el departamento de Pando, la provincia Vaca Diez, en el departamento del Beni, y una parte de la provincia de Iturralde, departamento de La Paz. La región limita con el departamento de Madre de Dios (Perú) y con los estados de Acre y Rhondônia (Brasil). Es una región aislada de Bolivia, debido a que no hubo ninguna conexión de carretera a esta región. El transporte era solamente por ríos.

En la región se recolectaba quinina (Cinchona spp.) desde mediados del siglo XIX. La región fue uno de los principales centros productores de caucho (Hevea brasiliensis) desde 1880. En el norte de Bolivia la producción de caucho se reduce drásticamente desde 1910, pero recién a finales de los años 1980 se deja de exportar caucho desde esta región (Stoian 2000a). La recolección y exportación de castaña se da con mayor frecuencia a partir de 1930, pero se hace más importante desde los años 1980 cuando aumentan las plantas de procesamiento (beneficiadoras) en la región. Entonces, la castaña (Bertholletia excelsa) se convierte en el motor de la economía regional. El valor de las exportaciones de castaña creció de US\$3 millones en 1985 a US\$30 millones entre los años 19961997 (Stoian 2000a), un nivel que se ha mantenido más o menos estable desde entonces.

La situación social en la región es precaria desde el punto de vista económico, político y social. Gran parte de estas condiciones tienen que ver con su aislamiento geográfico. En el 2001 cerca del 70\% de la población de la región era pobre, usando los indicadores de necesidades básicas satisfechas. Además la región tiene índices de violencia intrafamiliar muy altos. Las relaciones entre los diferentes grupos sociales de la región son muy problemáticas, resultado de una historia de relaciones económicas, laborales y de poder que favorecía a los grupos económicos y políticos más fuertes. Las relaciones laborales hasta hace poco eran semi- 

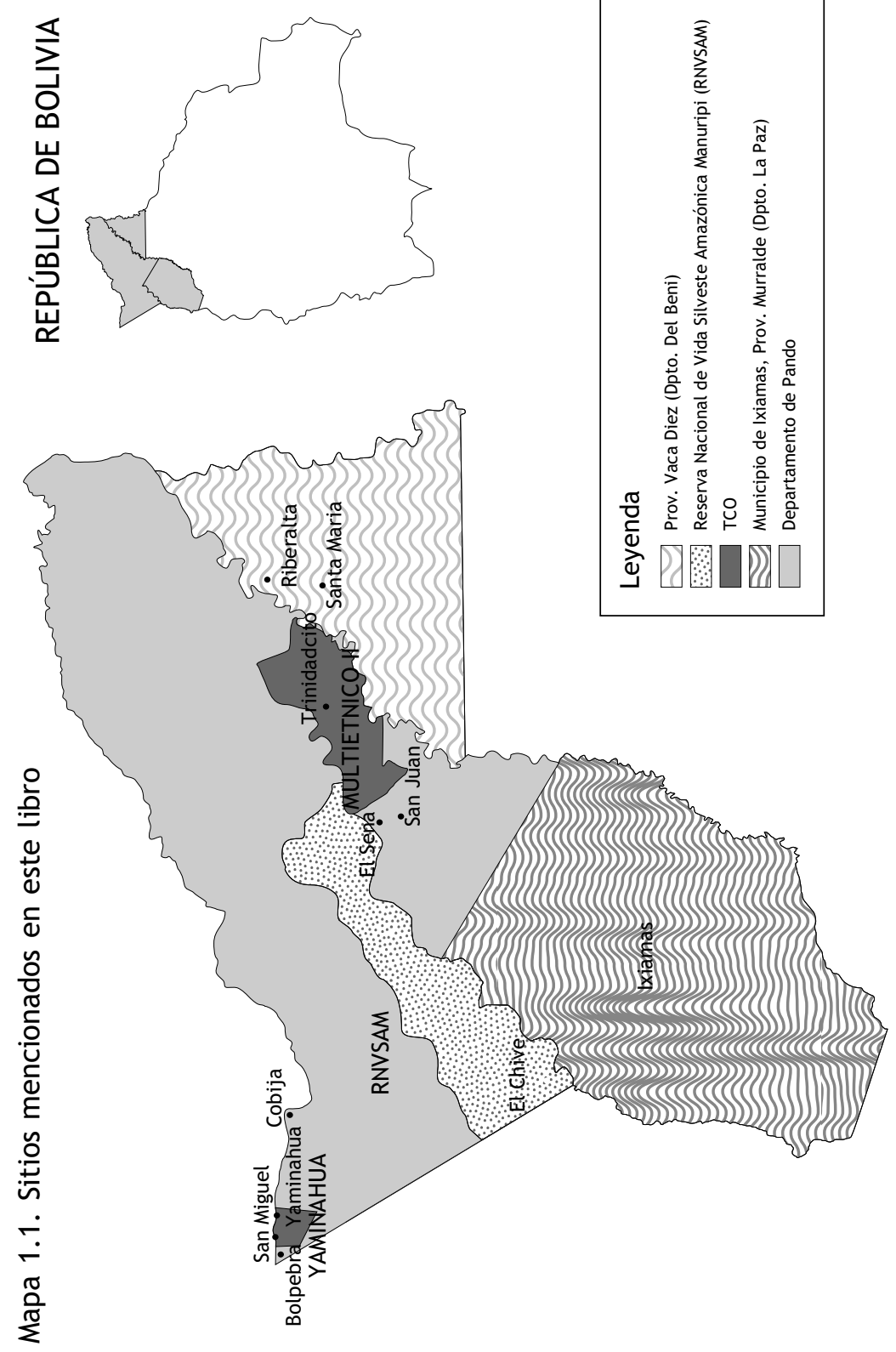
feudal ya que muchos patrones tenían trabajadores en una dependencia casi completa. Bojanic (2001) menciona la cultura de desconfianza y de engaños como típica de la región.

Actualmente, las actividades vinculadas a la recolección y procesamiento de castaña ofrecen trabajo a casi la mitad de la población económicamente activa de Riberalta, la ciudad más grande de la región, y son un generador de otras actividades económicas (Bojanic 2001). Durante los años 1990 hubo un pequeño auge del palmito (el cogollo de la palma Euterpe precatoria), cayendo su venta drásticamente después de la crisis económica del Brasil. Durante esta década la extracción de madera se incrementó siendo el segundo producto de importancia en la economía regional y es muy probable que esta importancia aumente en el futuro. En 1999, por ejemplo, la extracción de madera contribuye en US\$10 millones a la exportación (Bojanic 2001).

La región está experimentando grandes cambios en parte porque se están mejorando sus vías de acceso; desde los centros económicos de Bolivia, pero sobretodo por el aumento del comercio con Brasil. A principios de los años 1990 finalmente se estableció una conexión vía carretera desde Riberalta hacia La Paz. A pesar de la poca transitabilidad de esta carretera durante las épocas de lluvia, ella permitió por ejemplo, que la castaña (Bertholletia excelsa) y la madera que produce la región pueda ser exportada a través del puerto de Arica (Chile). En la actualidad la comercialización de ambos productos se puede realizar a través de Brasil o Chile y no como antes que dependía exclusivamente de los mayoristas brasileños.

La conexión por carretera ha facilitado el comercio de castaña. Anteriormente tenía que ser transportada por río, teniendo que pasar por Belem (Brasil), su comercialización fue controlada por unas pocas familias de Belem quienes además controlaban gran parte del comercio internacional de la castaña (Bojanic 2001). Estos cambios económicos generaron fuertes migraciones intra-regionales y la reubicación de una parte importante de la población de la región (Llanque, Capítulo 9). Muchos pobladores cambiaban fundamentalmente sus actividades económicas, coincidiendo con un reasentamiento desde el campo hacia las ciudades o desde las barracas, que es la figura regional de propiedad sobre áreas forestales, hacia nuevas comunidades rurales independientes (localmente llamadas comunidades libres) de la región. Durante esta misma época, el palmito, llegó a ocupar un lugar importante en la economía regional, llegando a exportarse US\$8 millones en 1998. Un cambio fuerte de la propiedad de barracas acompañó el cambió de la economía regional. Los propietarios de las fábricas de procesamiento de castaña (localmente llamadas beneficiadoras) durante los últimos años han comprado barracas de los dueños anteriores. Al 
mismo tiempo, la conexión que la región tiene con Brasil por medio de la carretera que una Acre y Manaus, está progresivamente integrando la economía del norte amazónico boliviano con una economía internacional. Según informantes locales, ya existe venta de madera de la región hacia China. Esta tendencia aumentará cuando se complete la carretera bioceánica, prevista para dentro de dos años, y que pasará muy cerca de la región.

Todos estos cambios ocurrieron sin mayor influencia del nuevo régimen legal que estamos analizando aquí. Como mostraremos en este volumen, el nuevo régimen legal y su implementación gradual en la región también están contribuyendo a estos procesos de cambio.

\section{EL CONTEXTO INTERNACIONAL Y EL NUEVO RÉGIMEN LEGAL BOLIVIANO}

Son varios los procesos que han resultado en una nueva filosofía compartida por muchos actores sobre gobernabilidad de bosques en un gran número de países. Ya desde los años 1950 creció la preocupación mundial sobre la pobreza en muchos países, y cómo eso podría afectar la estabilidad política mundial. Como consecuencia de un crecimiento económico muy amplio durante los años 1970 y 1980 se explotó excesivamente los recursos no renovables, lo que tiene por consecuencia una preocupación mundial por los efectos negativos sobre el ambiente. Estas preocupaciones eran analizadas, por ejemplo, en los reportes del Club de Roma. En cierto modo, estos dos últimos acontecimientos tienen su reflejo en dos procesos similares, pero más recientes. En los años 1980 nace el discurso de desarrollo sostenible, que es esencialmente una redefinición del discurso de desarrollo de los años 1950 y 1960, pero que incorpora las ideas claves del Club de Roma. Este discurso, entre otros, reubica el enfoque de desarrollo desde el nivel macro-económico y estructural, hacia un enfoque local, participativo y de tecnología apropiada. Un paralelo de la preocupación sobre la sobre-explotación de los recursos no renovables es también la amplia atención que recibe la deforestación tropical, sobretodo durante los años 1980 y 1990. Por último, ya desde los años 1970 , pero con mayor fuerza durante la siguiente década, surgen muchas iniciativas de grupos indígenas que reclaman sus derechos originarios sobre sus tierras y bosques, cuando estos estaban siendo acaparados por empresas forestales, proyectos de plantaciones u otro tipo de iniciativas de expansión de grupos económicos poderosos.

Estos factores explican los cambios en el pensamiento sobre quién es, o debería ser el dueño de los bosques, quién debe aprovecharse de los beneficios de los bosques, y qué tipo de propiedad y de aprovechamiento contribuye mejor a salvaguardar los servicios de los bosques que gozan los usuarios no directos. Esto coincide con que los bosques tropicales son considerados, 
cada vez más, como una propiedad común internacional, y no solamente nacional. Desde los años 1990, la propuesta de que los bosques tropicales sean manejados por las mismas comunidades indígenas y que éstas reciban una parte importante de los beneficios es más aceptada. Los bosques tropicales pasan a tener una función social y medio-ambiental, además de tener una función económica nacional. Muchos países adecuan su legislación y políticas a esta nueva filosofía sobre el rol nacional e internacional de los bosques tropicales.

Los diferentes procesos descritos anteriormente se reflejan en el nuevo régimen legal boliviano. Propuestas de reforma desde el gobierno, inspiradas por el auge de la descentralización, democratización y participación, además de la incorporación de las demandas de los grupos campesinos e indígenas resultaron en las nuevas leyes como parte de la reforma. Bolivia reformuló su Constitución, y en ella se consideran los derechos originarios de los pueblos indígenas, habitantes de los bosques tropicales (Garzón, Capítulo 6). La nueva Ley Forestal tiene objetivos conservacionistas, ya que promueve un aprovechamiento forestal sin llegar a una degradación del bosque. Otro punto importante de esta ley es que democratiza el sector forestal boliviano (Ruiz, Capítulo 2), creando la opción de aprovechamiento forestal en tierras comunitarias indígenas y campesinas, y crea una nueva figura legal, las Asociaciones Sociales del Lugar (ASLs), que permiten a grupos locales, no empresariales, solicitar concesiones forestales. Además, la misma ley reorganiza la administración y la fiscalización de las tierras forestales. No sólo pone a cargo una agencia estatal que pueda operar independiente de las fuerzas políticas de turno, sino que también asigna el $20 \%$ de los bosques públicos de los municipios para que sean administrados por los gobiernos municipales. Contribuye así al proceso de descentralización promovido por el Estado, aunque responsabilidades claves todavía quedan a nivel central (Pacheco 2004). Como consecuencia de las movilizaciones campesinas e indígenas se declara el Decreto Supremo 25848, que crea la opción de que se asignen áreas forestales significativas a las comunidades campesinas en el norte amazónico boliviano. Adicionalmente, la Ley de Participación Popular crea la base para el reconocimiento formal de todas las organizaciones bolivianas con base territorial, entre ellas los habitantes del bosque, y crea un mecanismo para que ellos participen en la planificación del gasto público municipal y fiscalicen la toma de decisiones. Por estas razones la reforma boliviana que estamos analizando ha sido considerada como una de las reformas más progresistas que actualmente existe (Ribot 2002), aunque esta es una opinión no compartida por todos (P.ej. Pacheco 2004).

Tomando esto como punto de partida, nuestra preocupación central en el presente libro es saber qué efecto está teniendo en el norte amazónico boliviano el nuevo régimen legal. Esto nos interesa por varias razones. 
Primero, porque el Centro Internacional para la Investigación Forestal y el Instituto de Políticas Forestales y de Medioambiente, con su Sección Mercados y Mercadeo vienen colaborando con instituciones regionales desde 1996 en la región. Los resultados de estos trabajos nos han permitido conceptuar algunas conclusiones interesantes sobre cómo está evolucionando la economía de esta región y qué opciones sobre intervención existen (ver Stoian 2000a, b, Stoian y Henkemans 2000, Bojanic 2001). El efecto de la reforma tratado aquí recién empezó a sentirse a finales de la década de 1990. Nos interesa saber qué impacto tiene el nuevo régimen legal sobre la región, para alcanzar sugerencias que podrían contribuir a una mejor implementación. Siendo instituciones de investigación, también nos interesa saber si el paquete de leyes que formuló Bolivia puede o no contribuir a lograr los objetivos subyacentes. Esta inquietud es relevante porque, como ya explicamos, y como se explica en los demás capítulos de este libro, las condiciones del norte amazónico boliviano son especiales y diferentes a las condiciones de las demás regiones tropicales de Bolivia. El paquete de leyes fue formulado para atender las necesidades de todo el país, pero la realidad forestal en regiones como Santa Cruz ha tenido una gran influencia por ejemplo en la formulación de la Ley Forestal sin considerar la realidad de la región norte. Es importante preguntarnos hasta qué punto el nuevo régimen legal es adecuado o no para esta región.

\section{Temas abordados en el libro}

Con estos objetivos concretos, entonces surge la interrogante qué temas se deberá investigar para evaluar esta reforma. Los objetivos de fondo que deberá lograr una reforma de la gobernabilidad de los recursos forestales son una mejora directa de la situación de los menos privilegiados por medio de una mayor equidad en el acceso a los recursos forestales y en hacer uso efectivo de estos recursos para aumentar sus beneficios económicos. Además, debería resultar una mejora del estado del bosque, o por lo menos una condición de ello. Estos, sin embargo son resultados muy indirectos que no se pueden esperar inmediatamente después de una reforma de gobernabilidad. Existen pasos intermedios, que podrán ser resultados más directos de la reforma, y que, supuestamente deberían eventualmente resultar en estos otros objetivos de fondo. En el presente libro hemos escogido algunos temas de enfoque como indicadores para evaluar el progreso hacia las metas originalmente previstas cuando se formuló el nuevo régimen legal.

Primero, revisaremos el efecto que ha tenido la redistribución de los derechos de propiedad bajo el nuevo régimen legal. Algunos no consideran que una redefinición de derechos de propiedad es esencial para una mejora de la gobernabilidad de los recursos naturales (P.ej. Ribot 2002). Los proponentes de los diferentes componentes del nuevo régimen legal de Bolivia claramente 
han pensado que una redefinición de los derechos de propiedad sobre tierras y bosques es muy importante para lograr los objetivos de fondo. En condiciones de una zona remota y forestal como es el norte amazónico boliviano, el hecho de quién tiene derechos de propiedad, y en qué consisten, es de suma importancia. Por ser una zona remota, y por ser un área mayormente cubierta con bosque, los derechos de propiedad no están bien definidos, o los de facto derechos de propiedad son sobretodo resultado de pugnas entre diferentes grupos de interés, y fuertemente influenciados por quienes tiene poder político y económico. Por eso, en la medida que una reforma de gobernabilidad logre redefinir los derechos de propiedad tiene gran influencia sobre su éxito. En el capítulo 2, Ruiz analiza la redistribución de los derechos de propiedad sobre los recursos forestales en el norte amazónico boliviano, principalmente como resultado de la Ley Forestal y Ley INRA.

Un siguiente tema que consideramos clave para completar este capítulo es el análisis de la administración de tierras y bosques. La administración y fiscalización de tierras y bosques tiene mucho que ver con la propiedad, ya que una administración adecuada permite una entrega de derechos de propiedad como estipula la ley. Una administración adecuada de tierras y bosques permite el cobro de impuestos y la distribución de fondos. La nueva legislación define, por ejemplo, que los municipios obtendrán una parte importante de la patente forestal que se cobra a cualquier usuario que cuenta con un Plan de Manejo Forestal (PMF). Estos fondos, por lo menos en el caso de los municipios de la región norte, son una de las principales fuentes de ingreso, y por lo tanto influyen en la gestión municipal. Es allí donde existe un nexo importante entre la administración de tierras y bosques y el éxito de la reforma forestal en el norte amazónico boliviano. La administración y la fiscalización también son importantes para el cumplimiento de las normas técnicas, como por ejemplo los PMFs, igual como para la atención adecuada a los usuarios del sector civil, que quieren beneficiarse de las opciones que ofrecen las leyes. Ruiz en el Capítulo 3, al igual que Hentschel (Capítulo 5) y Garzón (Capítulo 6) discuten temas relacionados con la administración y fiscalización forestal en el norte amazónico boliviano.

Una reforma de gobernabilidad sobre los recursos naturales, debería incluir la participación democrática de los más pobres, vulnerables y aquellos quienes por mucho tiempo no fueron considerados en la toma de decisiones. El paquete de reformas legales de los años 1990 tenía previsto estos objetivos. Algunos de los elementos claves, por ejemplo la Ley de Participación Popular, tiene como objetivo garantizar la participación activa de las comunidades más remotas en el proceso político y administrativo del Estado. En el Capítulo 4, Gottwald estudia dos comunidades campesinas cinco años después de haberse promulgado diferentes leyes que tenían como objetivo garantizar 
la participación de los pobladores, en los procesos democráticos, en regiones como el norte amazónico boliviano. Los temas que abarca este capítulo son el conocimiento de las nuevas leyes, cómo estas han afectado la vida de los pobladores y la participación de la comunidad en los mecanismos democráticos establecidos por la Ley de Participación Popular.

Como lo mencionamos anteriormente, la nueva Ley Forestal intenta democratizar el aprovechamiento forestal más allá del uso tradicional del bosque. Crea la oportunidad para que grupos locales no empresariales también participen en el aprovechamiento comercial de la madera, sea en concesiones en tierras fiscales, organizándose como ASLs, ya sea en tierras comunales campesinas o en TCOs. No deberá sorprender que esta oportunidad todavía tiene muchos obstáculos. Es un mecanismo totalmente nuevo que todavía no ha sido comprobado, mientras que comunidades no tienen mayor experiencia con actividades que requieren semejante cantidad de gestiones formales. En el Capítulo 5, Hentschel analiza en detalle los desafíos que enfrentan comunidades que inician actividades de aprovechamiento maderable. Según como evolucione la participación de los grupos no tradicionales en el aprovechamiento de este recurso tendremos mayores implicaciones sobre cómo evolucionará el sector forestal en el norte amazónico boliviano, en qué medida se podrán aprovechar de este los grupos más pobres de la región, y cómo todo eso afectará el estado del bosque.

Los Capítulos 6 y 7 (Garzón y Stahl) enfocan su estudio en un grupo de pobladores forestales que han tenido una posición especial en toda la reforma legal; los grupos indígenas de la región. Los derechos sobre los territorios indígenas eran reconocidos en la Constitución Boliviana, mucho antes de que se empezara a definir los diferentes elementos de la reforma que afecta el sector forestal (Garzón, Capítulo 6). Sin embargo, completar los trámites para definir una TCO al igual que el manejo de las TCOs son procesos complicados. Garzón analiza el proceso que ha tomado definir la TCO Yaminahua-Machineri en el municipio de Bolpebra. Además, como muestra Stahl en el Capítulo 7, con las tierras aseguradas, los demás procesos de cambio que está viviendo la región, afectan de igual manera o tal vez en mayor medida a los grupos indígenas que viven en las TCOs.

Desde el Capítulo 2 hasta el Capítulo 7 estudiamos el impacto social del nuevo régimen legal en el norte amazónico boliviano. Sin embargo, como mencionamos, el objetivo de las diferentes leyes es asegurar la conservación del bosque amazónico, para así poder prestar en forma sostenible los servicios de medio ambiente y biodiversidad que actualmente brindan los bosques bolivianos. Por lo tanto, Maldonado analiza en el Capítulo 8 el impacto del nuevo régimen legal sobre el manejo de áreas protegidas, enfocándose especialmente en el caso de la Reserva Nacional de Vida Silvestre 
Amazónica Manuripi, ubicada en los municipios de Filadelfia y Puerto Rico de Pando.

El libro concluye con un enfoque en el impacto colateral del nuevo régimen legal boliviano. En el Capítulo 9, Llanque contempla los procesos migratorios en los tiempos modernos, pero relacionando estos con una historia de migraciones que ya tiene más de 100 años. La región del norte amazónico boliviano ha adquirido importancia social y económica debido a la migración de grandes grupos hacia la región. Las migraciones más significantes se dieron durante el auge del caucho, finales del siglo $\mathrm{XIX}$ e inicios del siglo XX. Sin embargo, los procesos migratorios en la región son muy complejos e incluyen inmigraciones extra regionales, emigraciones desde las zonas rurales hacia las ciudades, migraciones intrarurales, y migraciones desde la ciudad hacia zonas rurales. Tampoco hay duda de que el factor migración será muy importante en la región, y que la reforma legal y los demás procesos de cambio tienen un fuerte impacto sobre los procesos de migraciones. Sin embargo es difícil anticipar las futuras tendencias migratorias así como sus impactos.

\section{LOGROS Y DESAFIOS DEL NUEVO RÉGIMEN LEGAL EN EL NORTE AMAZÓNICO BOLIVIANO}

En esta sección presentamos un breve resumen de los efectos que ha tenido el nuevo régimen legal sobre el norte amazónico boliviano. Usamos cuatro indicadores que coinciden estrechamente con el contenido de los siguientes capítulos. Veremos primero cómo la participación democrática en los procesos políticos y administrativos ha cambiado. Segundo, presentamos reflexiones sobre los cambios en los derechos de propiedad sobre bosque y tierras. Tercero, analizamos cómo evoluciona la administración y fiscalización de los recursos forestales, y por último, veremos cómo todo eso está impactando en los indicadores más esenciales: el bienestar de la población rural y el estado del bosque en el norte amazónico boliviano.

\section{Participación democrática}

Los primeros cambios en el norte amazónico boliviano, consecuencia de la nueva reforma, fueron resultados de la Ley de Participación Popular. De mucha importancia para la región fue el estatus legal que dio esta ley a un gran número de asentamientos humanos, sean ellos comunidades libres que no tenían personería jurídica, o centros de acopio en barracas de castaña con una población permanente. En el proceso del reconocimiento de la personería jurídica de estos asentamientos, también se consolida el proceso de representación democrática a través de las Organizaciones Territoriales de Base (OTBs), que es el organismo formal de toma de 
decisiones políticas administrativas y que es el equivalente a una directiva comunal. Además se establece el Comité de Vigilancia, un organismo en el que participan todos los sectores de un municipio, y que supervisa el gobierno municipal. Durante esta época los municipios han asumido nuevas responsabilidades y han tenido que afrontar una serie de problemas (P.ej. Garzón, Capítulo 6, Maldonado et al. 2004).

A pesar del avance obtenido con la participación popular en los procesos políticos y administrativos en el norte amazónico boliviano, el proceso todavía está lejos de ser perfecto. Como indica Gottwald en el Capítulo 4 , un proceso de participación popular no puede llevarse a cabo fácilmente cuando un porcentaje importante de la población no está registrada oficialmente. Según un censo realizado en 77 comunidades que hizo CIPCA Norte (citado por Gottwald, Capítulo 4), casi la mitad de la población no está registrada en ningún registro civil; un poco más de la mitad no tiene partida de nacimiento, y más del $80 \%$ no tiene documento de identidad. Atender esta deficiencia no está previsto en ninguna de las leyes promulgadas en los años 1990.

En las comunidades rurales de la zona, los mecanismos de representación democrática todavía están en proceso de consolidación. La representación democrática es susceptible de ser dominada por élites locales, mientras que representantes para cargos municipales y nacionales prestan atención a comunidades rurales en la medida en que estas les aseguren su voto. Estos resultados no son ninguna sorpresa, ya que son síntomas de procesos de democratización y descentralización donde mecanismos de retro alimentación que puedan corregir semejantes deficiencias todavía no se han establecido.

Un problema fundamental, previsto por Gottwald (Capítulo 4), es el conocimiento limitado de la nueva legislación y las posibilidades que esta ofrece a los pobladores rurales en el norte amazónico boliviano. La ley más conocida es la Ley INRA, y por lo menos en los ejemplos discutidos por Gottwald, las comunidades han iniciado acciones claras, respondiendo a una situación donde las tierras comunales han pasado el proceso de saneamiento y titulación formal. A pesar de que los pobladores conocían la Ley de Participación Popular y la participación y representación democrática, queda mucho por mejorar.

\section{Propiedad de tierras y bosques}

Uno de los objetivos clave que tenía previsto la Ley INRA era por un lado consolidar la propiedad de tierras, es decir, lograr un reconocimiento y registro formal de la propiedad existente, adicionalmente se buscó una redistribución de tierras (Gottwald, Capítulo 4). En el norte amazónico 
boliviano esta implementación tuvo dos enfoques. Por un lado, se había definido un número de TCOs en la región (Martinez 2000). La consolidación de la TCO Yaminahua-Machineri, que es una de ellas, fue un proceso relativamente lento y largo, debido a que requirió adaptaciones organizativas de los grupos interesados y del INRA que al momento de la implementación todavía no contaba con los instrumentos técnicos y legales necesarios (Garzón, Capítulo 6, Martinez 2000). Un problema que se tuvo que resolver, al igual que en casi todas las TCOs en Bolivia, eran los reclamos de derechos de propiedad de terceros sobre partes de la TCO. En el caso de Yaminahua-Machineri, eso se pudo resolver sin muchas dificultades, y actualmente las comunidades Yaminahua-Machineri tienen sus tierras bien definidas y reconocidas por el Estado boliviano. Lo mismo es cierto para varios grupos que viven en la TCO Multi-étnico II, que es una TCO con una extensión de casi medio millón de hectáreas (Martinez 2000). En otras TCOs problemas con reclamos sobre propiedad de terceros resultan mucho más difíciles de resolver.

Otro tipo de problemas relacionados con las TCOs se están haciendo evidentes. Algunos de ellos tienen soluciones menos complicadas que otros. Los que podrán solucionarse son los problemas de gobernabilidad internos que tienen por lo menos dos TCOs del norte boliviano. Ruiz (Capítulo 2) menciona los desacuerdos entre los mismos miembros de la TCO para autorizar a sus dirigentes las negociaciones relacionadas con los recursos maderables. Igualmente, Garzón (Capítulo 6) menciona la falta de coordinación en la toma de decisiones entre los Yaminahua y los Machineri, resultado de largas distancias y falta de un mecanismo adecuado para la toma de decisiones. Maldonado et al. (2004) hace una evaluación similar y observa que como consecuencia 50 familias Machineris migraron al Brasil.

Relacionado a este último fenómeno, se puede prever que, por lo menos en algunos casos, la aceptación pública de las TCOs podría entrar en una severa crisis. Maldonado et al. (2004) no sólo menciona la migración de las 50 familias a Brasil, también observa la reubicación de los grupos habitantes de la TCO Yaminahua-Machineri hacia el norte de la TCO, dejando gran parte del sur despoblado. Este no sólo resultará en un aumento de la explotación ilegal de los recursos, también incrementará los nuevos asentamientos de pobladores no indígenas ilegales. Ni el Estado, y aun menos los mismos indígenas, tienen, o tendrán, capacidad y recursos adecuados para controlar territorios tan extensos, y así limitar la explotación ilegal. Con las posibilidades reales de un aumento de inmigraciones hacia la región (Llanque, Capítulo 9) se puede esperar que iniciativas para desalojar invasores cada vez sean menos aceptadas. En el clima político de Bolivia de los últimos años se puede prever que eso podrá ser causa de serios problemas políticos y sociales en la región. 
No está claro si se tendrán semejantes problemas con las tierras comunales campesinas, o los otros tipos de propiedades pequeñas, una vez que el proceso de saneamiento esté terminado. A pesar de que algunas comunidades con un área comunal en base a 500 ha por familia serán muy extensas, las comunidades son relativamente estables y en muchos casos la población está en aumento (Gottwald, Capítulo 4). Al mismo tiempo, se observa un proceso de urbanización en la región. Probablemente no habrá problemas de abandono de tierras comunales, aunque es muy probable que se tenga problemas de tala ilegal de madera con personas ajenas a las comunidades. Una vez establecidas, con muy alta probabilidad ocurrirán semejantes problemas como en las TCOs, que líderes, ciertas familias, u otros grupos intentarán excluir a otros de los nuevos beneficios que ofrece el nuevo régimen legal. Aún más porque la nueva estructura política favorece el surgimiento de un pequeño grupo de dirigentes que conoce las gestiones administrativas que requiere cualquier aprovechamiento forestal (Hentschel, Capítulo 5). También porque muchas comunidades fueron establecidas en centros de acopio de barracas antiguas, y todavía están acostumbrados a un sistema de autoridad dominado por un patrón (Maldonado, Capítulo 8).

Sin embargo, se deja prever, que completar el saneamiento, y la asignación de derechos de propiedad claros y definidos, como lo establece la nueva legislación, tomará todavía mucho tiempo. Los problemas centrales que necesitan solución estarán entre la propiedad barraca y las tierras comunales. Los barraqueros son un grupo diverso que reclama propiedad sobre áreas forestales con castaña, una propiedad que hasta ahora fue reconocida localmente. Muchas de estas áreas coinciden con las que serán tierras comunales campesinas e indígenas. La nueva legislación favorece la propiedad comunal, y solamente permite como aprovechamiento del bosque la extracción de castaña con un mecanismo administrativamente muy complicado (Ruiz, Capítulo 2). El nuevo régimen legal simplemente no está concebido para solucionar una situación como la del norte de Bolivia. La nueva legislación intenta por un lado reconocer y consolidar la propiedad tradicional sobre tierras y bosques, pero por otro lado también llegar a una distribución equitativa de estos recursos. La propiedad no formal de las barracas, es por un lado una forma de propiedad muy antigua, que se ha adaptado al cambio de la realidad económica de la región. Existe una percepción de que las barracas son el equivalente de los latifundios de otras regiones de Bolivia, lo cual es parcialmente cierto. Un tipo de barraqueros controla áreas forestales muy grandes para asegurar el abastecimiento de la materia prima para sus fábricas de procesamiento de castaña. Sin embargo, también existen propietarios que tienen áreas menores. Gran parte de las tierras comunales campesinas ya identificadas en el proceso de saneamiento, coinciden con estas barracas. Los barraqueros se han opuesto al proceso de saneamiento, y están llevando estos reclamos a las calles de las 
ciudades de la región y a los representantes políticos en La Paz. Algunas soluciones frente a esta aparente injusticia social podrían ser el reconocimiento formal de un área máxima de barraca por propietario, tratando de ubicarla fuera de tierras comunales campesinas y TCOs. También se debería crear la opción de concesión de castaña, y ubicar esto en tierras fiscales. Los propietarios de barracas muy extensas deberán renunciar a estas, cuando coincidan con tierras comunales campesinas $u$ otra propiedad comunal $o$ indígena, igual como se procedió con las concesiones forestales (Ruiz, Capítulo 2). Sin embargo, el tema de las barracas es sumamente volátil y politizado. Cualquier solución que se proponga tiene que ser presentada, discutida y socializada con mucho cuidado. Mientras tanto, la situación no resuelta de las barracas posiblemente quedará como obstáculo para completar la asignación de los diferentes derechos de propiedad, previstos en el nuevo régimen legal.

Un tema no muy discutido y que requiere de reflexión y atención es la transferencia de derechos. Como varios autores en este libro señalan (Ruiz, Capítulo 2, Garzón, Capítulo 6), hay un gran número de expertos que argumentan que las limitaciones para la transferencia de los derechos sobre las tierras impiden que se abra un mercado de tierras, y esto causará un estancamiento de la economía local. Los argumentos a favor de estas limitaciones son que el libre mercado de tierras aumentará la desigualdad, dadas las circunstancias de desigualdad actuales (Ruiz, Capítulo 2). El argumento más fuerte a favor de una ampliación de los derechos de transferibilidad es la existencia de mercados de tierras no formales. Esto demuestra que existe la necesidad y el deseo de transferir, y que esto se da de manera independiente al mecanismo que permite hacerlo legal. El argumento más fuerte para mantener las restricciones de compra y venta es el riesgo de nuevos compradores que podrían entrar en este mercado, atraídos por las perspectivas de especulación o de otro tipo de uso de tierras resultado de la carretera bi-oceánica entre Brasil y Perú que está por terminarse y que pasa muy cerca del norte amazónico boliviano. Este hecho posiblemente traerá nuevos compradores, quienes en poco tiempo dejarán un gran número de pobladores rurales sin tierras. A nuestro modo de ver, en vez de cambiar las estipulaciones en la ley sobre transferibilidad de derechos sobre TCO y de comunidad campesina, será mejor buscar soluciones específicas para la región. Allí se debería pensar en mecanismos en el ámbito comunal que permitan asignaciones temporales de derechos y transferibilidad limitada de estos derechos. Al mismo tiempo hace falta crear opciones de créditos, y buscar garantías de cumplimiento de pago o mecanismos de compensación cuando la cancelación no se cumple. Estos podrán ser mecanismos que sí favorecen un crecimiento económico, mientras que se evita los riesgos de desapropiación de tierras y el empobrecimiento de un sector importante de la población regional. 


\section{Administración y fiscalización}

La administración y fiscalización relacionada a bosque y tierras, como estipula el nuevo régimen legal en el norte amazónico boliviano, todavía está por establecerse. En una situación ideal, una administración efectiva y eficiente tendrá un registró claro de tierras, un debido cobro de pagos e impuestos para los diferentes derechos que se otorga, un procedimiento administrativo correcto del sector civil, cumpliendo las directivas técnicas y administrativas, y una atención eficiente y transparente a las necesidades de este sector civil.

Al momento de escribir este capítulo todavía se está lejos de una administración y fiscalización eficaz y eficiente. Hasta que el proceso de saneamiento no esté terminado, no se puede tener un catastro de tierras. A pesar de que el catastro de tierras es responsabilidad del INRA, se llevará en el ámbito municipal, y muchos de los municipios no cuentan con las facilidades técnicas y la capacidad humana para establecer o mantener este catastro. Los municipios, además, no serán capaces de registrar las propiedades de usuarios individuales en las comunidades campesinas, donde mucha de la propiedad es informal, y muchas veces muy dinámica. Esto implica que los municipios podrán tener catastros generales de las áreas de comunidades campesinas, una vez que el proceso de saneamiento termine, pero que el registro de propiedades individuales, formales o informales, de alguna manera deberá ser definido en el ámbito comunal. El registro de concesiones, sea de madera o en algún momento de castaña en las tierras fiscales forestales municipales, también se deberá llevar a cabo en los municipios, cuando estos tengan la capacidad instalada para hacerlo. El registro de otro tipo de concesiones, es decir, en tierras que no son parte de tierras fiscales forestales municipales, seguirían siendo responsabilidad de la Superintendencia Forestal.

Relacionado con el cumplimiento de trámites administrativos como exige la ley, el presente libro muestra problemas que están surgiendo. Uno de ellos es la preparación de los Planes de Manejo Forestal (PMFs). Hentschel (Capítulo 5) describe con mucho detalle los desafíos que encuentran los pobladores de comunidades campesinas para preparar un PMF. Los procedimientos son complicados y costosos, y fuera de las capacidades de la mayoría de las comunidades en la región. De igual modo, las exigencias de los PMFs para la explotación de castaña significan un procedimiento con un costo por hectárea demasiado alto, comparando con los ingresos por hectárea que se obtiene de la extracción de este fruto. En resumen, los diferentes requisitos administrativos que el nuevo régimen legal impone para el sector privado promueven un no-cumplimiento y hasta un recurrir a la ilegalidad. La mayoría de los concesionarios forestales de la 
región no pagan su patente forestal, porque no pueden recuperar los costos con el aprovechamiento de las pocas especies valiosas que se pueden explotar económicamente en la región. Todavía no existe ningún PMF comunal completamente aprobado, aunque si hay planes parcialmente aprobados. Mucho del aprovechamiento de madera en tierras comunales que ocurre formalmente todavía es ilegal. El hecho que más llama la atención es la extracción de castaña, principal fuente de ingresos de la región. Esta actividad no está respaldada por ningún dispositivo legal, ni con PMFs aprobados, y por eso según la legislación debería ser considerada como una actividad ilegal.

Varios de los actores están acomodándose a este problema legal. Hay una nueva tendencia por parte de las empresas forestales de alejarse de las concesiones forestales y dedicarse solamente a la compra de madera en troza. En parte porque se asocian con comunidades campesinas que de alguna manera no tienen oportunidades para el aprovechamiento de este recurso. Por eso Ruiz (Capítulo 2) concluye que: "... en un futuro cercano los aserraderos de la región pasarán a ser protagonistas principales del manejo forestal comercial". No queda claro cómo se desarrollará el aprovechamiento de castaña con las nuevas reestructuraciones de propiedad y requerimientos para preparar los PMFs. Siguiendo las sugerencias de la sección anterior, un escenario posible es que en un futuro cercano la mayoría de los bosques con castaña estará en manos de comunidades campesinas e indígenas. Se deberían acomodar las exigencias técnicas a una situación así, y de esta manera obviar que los pequeños barraqueros tengan que preparan un PMF demasiado costoso. La parte débil de este escenario es que no atiende a la necesidad de los propietarios de las fábricas de transformación de castaña quienes durante la última década han tratado de conseguir control sobre extensas áreas boscosas con castaña para así asegurar el abastecimiento de la materia prima. Posiblemente se deberá pensar en semejantes arreglos como entre las empresas forestales o las comunidades campesinas, para que las beneficiadoras puedan asegurarse el abastecimiento de materia prima.

\section{Beneficios y conservación}

Al final de esta sección enfocamos en qué medida los logros y desafíos del nuevo régimen legal señalados anteriormente han contribuido mejorando los ingresos de la región en general, de los pobres de la región y en qué medida han contribuido a la conservación del bosque tropical del norte amazónico boliviano.

El principal efecto es que la región se beneficia sobretodo de la reforma descentralizada que ha ocurrido en todo el país. Con la Ley de Participación Popular los municipios reciben fondos importantes del tesoro público a través 
de la coparticipación tributaria. Estos fondos están a la disposición de los municipios quienes invierten estos, bien o mal, en obras públicas, salud, educación y otros (Maldonado et al. 2004). A pesar de que actualmente existe una seria de problemas con la ejecución de las nuevas responsabilidades por parte de los municipios, y por ejemplo, varios municipios tienen sus cuentas congeladas por la falta de rendición de cuentas adecuadas (Maldonado et al. 2004), se considera que existe un efecto positivo de esta reforma.

Un segundo factor de importancia es la redistribución de la patente forestal que paga cualquier usuario del bosque. Según la nueva Ley Forestal, se cobra una patente de US\$1 por hectárea por año a las concesiones forestales, y el $25 \%$ de esta patente va a los municipios donde están ubicadas estas concesiones, mientras que otra parte va a la prefectura. Varios municipios en el norte han obtenido ingresos importantes bajo esta figura, algunos más que por la coparticipación tributaria (Ruiz, Capítulo 3). Sin embargo, en el tiempo, probablemente estos ingresos disminuyan. Por un lado, muchas concesiones no pagan esta patente, y la SIF no tiene la capacidad para exigir el pago de la misma. Visto estas dificultades, se ha promulgado el Decreto Supremo 27024, que reduce el pago a sólo un pago por área aprovechada, y ya no a la totalidad de la concesión. Por último, el proceso de saneamiento implica que en algunos municipios las áreas de concesión forestal están siendo reducidas drásticamente, ya que según la Ley Forestal y Ley INRA, propiedad comunal tiene preferencia sobre concesión forestal. Como explica Ruiz (Capítulo 3) Bolpebra, como varios otros municipios de la región, recibió en el año 1999 un ingreso por patente forestal más alto que el ingreso obtenido por la coparticipación tributaria. Este mismo municipio, sin embargo, ha perdido buena parte de este ingreso cuando el saneamiento fue completado.

La reforma legal de Bolivia no ha tenido mucho impacto sobre el ingreso familiar, como explican Ruiz (Capítulo 3), Gottwald (Capítulo 4), Hentschel (Capítulo 5) y Stahl (Capítulo 7). Las posibilidades de una más alta participación en una economía forestal regional sí existen, cuando las comunidades toman un rol mayor en el aprovechamiento de la castaña o madera. Sin embargo, estas posibilidades todavía están por realizarse.

Por último, Ruiz (Capítulo 3) y Maldonado (Capítulo 8) expresan reservas sobre el impacto conservacionista del nuevo régimen forestal. Ruiz (Capítulo 3) y Llanque (Capítulo 9) señalan que la deforestación en la región todavía es muy baja. Sin embargo, Ruiz menciona que existe poco control y fiscalización para cumplir regulaciones que tienen el objetivo de contribuir al uso sostenible de los recursos naturales y de los bosques en general. Maldonado (Capítulo 8) observa que existe el riesgo de un manejo y una protección ineficaz de áreas protegidas en la región por un lado por 
la falta de aprovechamiento de los recursos según lo establecen las normas técnicas, y porque no existen mecanismos de negociación y resolución de conflictos entre la administración de áreas protegidas (El Sistema Nacional de Áreas Protegidas o sus representantes) y los usuarios de estas áreas. El nuevo régimen forestal es conservacionista en nombre, pero no cuenta con respaldo técnico y financiero para atender este aspecto. El impacto del aprovechamiento sobre el bosque ha sido bajo y esto se debe a que todavía se aprovecha muy pocas especies, y todavía no son rentables otras actividades agropecuarias. Estas dos condiciones podrían cambiar fuertemente una vez terminada la carretera bi-oceánica. El aprovechamiento forestal, la especulación por tierra y actividades agropecuarias en áreas mucho más extensas podrían convertir el norte amazónico boliviano en una nueva frontera agrícola, siguiendo una trayectoria deplorable como lo han conocido tantas otras regiones en la olla amazónica (Browder y Geoffrey 1997).

\section{UN BALANCE DEL NUEVO RÉGIMEN LEGAL}

La reforma que inició Bolivia en los últimos 10 años ha tenido un impacto claramente identificable en el norte del país. El balance positivo es que en el norte se ha dado seguridad jurídica a las comunidades. Esto permite que ellas puedan aprovechar los recursos y gozar de las facilidades que brinda el proceso de descentralización a los municipios. El nuevo régimen legal ha contribuido a una redistribución de las tierras y recursos forestales. Cuando el proceso de saneamiento en el norte esté terminado, cerca de 2 millones de hectáreas tendrán el estatus legal de tierra comunal indígena o campesina, estimado por Ruiz (por publicarse). Las comunidades tendrán la oportunidad exclusiva del aprovechamiento económico de los recursos forestales en estas tierras. El nuevo régimen ha creado una nueva figura legal, la de ASL que permite a otros grupos sociales que anteriormente no tenían esta oportunidad beneficiarse de la democratización del sector forestal en Bolivia. También ha logrado una distribución más equitativa de la patente forestal. El cobro de patente forestal es por área, y ya no por volumen. Los mismos municipios donde se efectúa el aprovechamiento forestal y las prefecturas, reciben un porcentaje predefinido de la patente, y estos fondos pueden ser destinados a acciones de desarrollo forestal entre otras. Por último, el nuevo régimen ha encargado a una agencia independiente, La Superintendencia Forestal (SIF), implementar los aspectos del nuevo régimen estipulados en la nueva Ley Forestal.

Sin embargo, la implementación del nuevo régimen legal en el norte amazónico boliviano todavía está lejos de lograr los objetivos para lo cual ha sido formulado. Esto se debe a que la implementación ha sido inadecuada, pero también a que el régimen tiene deficiencias estructurales. Comenzando con que el proceso de democratización y participación todavía no ha logrado 
que la mayoría de los pobladores de la región sean ciudadanos legales. Sin embargo, esta no es una deficiencia del nuevo régimen, pues son otras las leyes que regulan estos temas. Por otro lado, se hubiera podido planificar adecuadamente una aplicación de la Ley de Participación Popular en el norte, también considerando la deficiencia de los registros poblacionales. Más importantes, los problemas con la representatividad, en el ámbito comunal, municipal y nacional, no son resultados de deficiencias estructurales, sino de implementación.

El nuevo régimen legal ha entregado derechos de ubicación y aprovechamiento sobre tierras y recursos forestales a poblaciones originarias y comunidades campesinas, pero no entregó mayores opciones de transferencia de estos derechos. Estas limitaciones por un lado dan seguridad a los pobladores rurales, pero a la vez limitan su actuación económica. Todavía no está claro si el impacto de estas limitaciones es positivo o negativo. Como hemos señalado, es posible que las TCOs muy extensas, relacionadas con el número de pobladores, sufra en algún momento la falta de aceptación de otros sectores que tienen necesidad de tierras. La legislación al respecto no ha previsto que tener en propiedad extensas áreas de tierras implica un costo económico de monitoreo y protección. No se ha previsto estos temas en la asignación de tierras. Esto se podría consolidar como una deficiencia estructural del nuevo régimen legal.

El nuevo régimen legal ha ignorado a un grupo de usuarios de los bosques del norte amazónico boliviano. Todos los barraqueros fueron categorizados como latifundistas, una clase de propietarios no formales para los cuales en la Bolivia moderna ya no hay lugar. No se ha considerado que existan usuarios de bosques que practican la extracción de castaña como actividad empresarial familiar, y cuál es el tamaño mínimo de área para que esta empresa forestal familiar pueda rendir económicamente. El mismo cálculo sí se hizo para una familia rural que vive de producción integrada de agricultura y extracción forestal mixta, ya que en base a esto se propuso el Decreto Supremo 25848. Queda claro que el derecho de aprovechamiento de áreas boscosas con castaña cambiará radicalmente en los siguientes años, pero todavía no está claro qué implicaciones tendrá esto sobre la economía de la castaña en la región.

El nuevo régimen legal ha modificado de manera importante la industria maderera. Cambios centrales son el pago por área en vez de un pago por volumen, la creación de la figura legal de ASLs y la opción que comunidades indígenas y campesinas participen en el aprovechamiento de madera en tierras que son de ellos. Estos cambios han logrado una verdadera democratización del sector forestal en Bolivia. Sin embargo, nos preguntamos si estos cambios, y nuevas opciones en el caso del norte amazónico boliviano están empujando al sector forestal a continuar en la 
ilegalidad. El cambio del pago por volumen hacia el pago por área tenía la intención de reducir el área bajo concesión, promover el uso de especies no tradicionales, y así mejorar la contribución del sector forestal a la economía nacional. El mecanismo de cobro y distribución de patentes debería garantizar control y fiscalización.

Este escenario todavía no se ha implementado. El aprovechamiento forestal de madera en el norte sigue muy limitado por los precios de las maderas en el mercado nacional e internacional, y por los altos costos de transporte. Esto hace que el aprovechamiento de otras especies de menor valor comercial no sea rentable. Esto, en los últimos años ha tenido como consecuencia que la mayoría de los concesionarios no han pagado la patente forestal. La patente forestal es destinada a la SIF, que es la agencia encargada de controlar y fiscalizar infracciones. Por el bajo pago de la patente forestal en Bolivia, la SIF no está en condiciones de ejecutar un control adecuado. Además debido a la extensa área que ocupa la región es difícil realizar un control eficaz por los altos costos que implica. En la actualidad con la crisis que afronta el sector forestal en Bolivia, y la posible reducción de la patente a sólo el área aprovechada anualmente, el financiamiento de la SIF se reducirá más. Esto aparentemente crea un círculo vicioso, para el cual es difícil encontrar una solución.

Como consecuencia, según Ruiz (Capítulo 2) la empresa forestal que se abastece de madera de concesiones forestales disminuirá un 50\%. No queda muy claro cuál será la alternativa. Un escenario optimista es que comunidades campesinas e indígenas tengan completo control sobre sus asuntos forestales, que manejen sus áreas forestales con un buen Plan de Manejo Forestal, que tengan la capacidad gerencial instalada para hacer la planificación, negociación, y administración necesaria, y que garanticen una distribución e inversión adecuada de los ingresos forestales. Este cuadro, sin embargo, todavía está lejos de poder realizarse. Lo más probable, por lo menos a corto plazo, es el escenario como lo han presentado varios autores en el presente libro. En este escenario las empresas forestales se asocian con las comunidades, en la mayoría de los casos en relaciones en que las empresas dominan las iniciativas, y tienen influencia excesiva sobre las condiciones de esta colaboración. Vista la historia de la región requiere poca imaginación para ver relaciones de dependencia que, como dice Gottwald (Capítulo 4) son estructuras de poder antiguas acomodadas a una realidad diferente.

Por último, la implementación de las diferentes oficinas de asistencia, control y fiscalización está avanzando en forma muy lenta. Ya señalamos los problemas que encuentra la SIF con un financiamiento inadecuado en un escenario de no-cumplimiento del pago de la patente forestal. Poco se ha previsto de 
cómo establecer las Unidades Forestales Municipales que son propuestas en la Ley Forestal y que deben atender aspectos técnicos dentro del municipio. Los municipios de la región cuentan con poco apoyo en el establecimiento de estas unidades, y ellos también tendrán problemas de financiamiento cuando el sistema de patente no sea implementado como ha sido previsto. Por último, los procesos administrativos que deberán regir cualquier uso forestal parecen requerir conocimientos y capacidades que muchos de los posibles usuarios no tienen, y de añadir costos de transacción que fácilmente podrán convertir en no rentables a ciertos tipos de aprovechamiento forestal. Para parafrasear a Gottwald (Capítulo 4) el nuevo régimen legal en el norte amazónico boliviano, esta cambiando la vida de los pobladores más pobres de la región, aunque el progreso es muy lento. El bosque mismo no estará adecuadamente protegido frente a los nuevos saqueos que le tocará a la región.

\section{CONCLUSIONES}

Una de las deficiencias del nuevo régimen boliviano, considerando la situación actual del norte amazónico boliviano, es que no toma muy en cuenta los vínculos entre la redistribución de los derechos de propiedad y el cambio en la participación en la toma de decisiones que este requiere, para así, dentro de un marco de descentralización, mejorar la gobernabilidad de los recursos forestales (Pacheco, com. per. 2004). La redistribución de tierras y recursos y la democratización no caminan en forma paralela. Los nuevos derechos de propiedad sobre los recursos están limitados al aprovechamiento económico pero no permiten un mecanismo de representación democrática más allá de la comunidad, o del grupo de interés, que permita influenciar la toma de decisiones que afectan a más de un grupo de actores. Esta situación impide que diferentes intereses y conflictos son resueltos por medio de un mecanismo democrático y no por medio de acciones civiles.

Tampoco queda claro cómo se debería resolver esta debilidad. Principalmente es resultado de una desigualdad de relaciones de poder, y una falta de confianza (capital social) que existe desde muchos antes de las reformas. Modificaciones tan fundamentales como una redistribución de derechos de propiedad son difíciles también en una situación más favorable que la del norte amazónico boliviano. Hasta que no se resuelva esta deficiencia en el mecanismo democrático, que debería institucionalizarse por medio de modificaciones legales que consideran mejor las particularidades de la región, no va a funcionar. La desigualdad de relaciones de poder y falta de confianza posiblemente pueden ser atendidas cuando se negocia los puntos contundentes. Estos son, por ejemplo, las tierras forestales que son reclamadas por comunidades y barracas. Representación democrática, y atención a las necesidades de 
las comunidades. Ineficiencia en la atención a usuarios del bosque por el oficialismo. Cumplimiento de los usuarios con los requisitos de la ley. En una fase inicial, el oficialismo debe ser uno de los actores con que se negocia, y no necesariamente uno de los facilitadores del proceso. Esto permitirá también atender las deficiencias que señala este volumen en los servicios que este actor presta, por ejemplo a las comunidades que intentan de formular su PFM. Además de crear capital social por medio de la facilitación de negociaciones, será necesario invertir mucho en crear la capacidad que permite a varios de los actores claves cumplir mejor sus nuevas responsabilidades, pero también lograr condiciones de negociación más equitativas.

En resumen, atender los problemas de gobernabilidad que observa este libro requiere una estrategia amplia. El marco legal, que ha sido nuestro enfoque principal en nuestras investigaciones, es solamente un elemento que influye en la gobernabilidad de los recursos forestales en el norte amazónico boliviano, también es un elemento clave y de suma importancia. Hemos señalado que el marco legal que actualmente existe tiene fuerzas importantes pero también deficiencias estructurales. Algunas de ellas se pueden atender, pero semejantes medidas en aislamiento no tendrán el efecto requerido. Tiene que estar acompañada por medidas más amplias, que crearan la capacidad y disposición adecuada de los diferentes actores para implementar una gobernabilidad mejor, permitida por un régimen legal adecuado a las condiciones de la región.

\section{NOTA}

${ }^{1}$ Agradecemos los comentarios de Pablo Pacheco y Roberto Maldonado Kühne sobre versiones anteriores de este capítulo.

\section{REFERENCIAS}

Agrawal, A y Ostrom, E. 2001. Collective action, property rights and descentralization in resource use in India and Nepal. Politics and Society 29: 485-514.

Bojanic, A. 2001. Balance is beautiful: Assessing sustainable development in the rain forests of the Bolivian Amazon. PROMAB Scientific Series 4. $255 \mathrm{Pp}$.

Browder, J.O y Geoffrey, B. 1997. Rainforest cities: Urbanization, development and globalization of the Brazilian Amazon. Columbia University Press, $424 \mathrm{Pp}$.

Maldonado, R., Haches, R., De Jong, W., Fuentes, D., Cronkleton, P. y Becker, M. 2004. Pobreza y Descentralización en los Municipios de la Amazonía Boliviana: Estudio de caso de los Municipios Bolpebra y El Sena en el departamento de Pando. Informe interno, CIFOR, Bogor. 
Martinez J.A. (ed.) 2000. Atlas territorios indígenas en Bolivia: Situación de las Tierras Comunitarias de Origen (TCOs) y proceso de titulación. Centro de Planificación Territorial Indígena, Confederación de Pueblos Indígenas de Bolivia. 263 Pp.

Pacheco, P. 2004. What Lies behind Decentralization? Forest, Powers and Actors in Lowlands Bolivia. European Journal of Development Research 16: 90-109.

Pacheco P. y Mertens, B.2003. Land use change and agriculture development in Santa Cruz, Bolivia. Enviado a Bois et Forêt des Tropiques.

Ribot, J.C. 2002. Democratic Decentralization of Natural Resources. Institutionalizing Popular Participation. World Resource Institute, Washington, D.C, 35 Pp.

Ruiz, S.A. Por publicarse. Cambios en los derechos de propiedad y conflictos sociales por el uso del bosque en el norte amazónico boliviano.

Stoian, D. 2000a. Shifts in forest products extraction: The post rubber era in the Bolivian Amazon. International Tree Crop Journal, Vol 10. pp 285-299.

Stoian, D. 2000b. Variations and dynamics of extractive economies: the rural-urban nexus of non-timber forest use in the Bolivian Amazon. Tesis de doctorado, Universidad de Friburgo, Alemania. 390 Pp.

Stoian, D. y Henkemans, A. 2000. Between extractivism and peasant agriculture: Differentiation of rural settlements in the Bolivian Amazon. International Tree Crops Journal, Vol.10. pp 299-319. 


\title{
Capítulo 2
}

\section{Redistribución de los recursos forestales en el norte amazónico boliviano}

\author{
Sergio Ruiz
}

\section{INTRODUCCIÓN}

Entre los años 1980 y 1985 Bolivia experimentó una de sus más fuertes crisis económica, política y social. Producto de ello, a partir de los años 1990 los gobiernos sucesivos han coincidido en llevar a cabo una de las más ambiciosas reformas estatales ocurridas en Latinoamérica. ${ }^{1}$ Un momento clave en el proceso de descentralización del Estado boliviano fue la aprobación de la Ley de Participación Popular (1994) y la Ley de Descentralización Administrativa (1995). En cuanto al manejo de los recursos naturales las principales leyes que consolidan la nueva estructura estatal son: la Ley General del Medio Ambiente, la Ley Forestal y la Ley del Instituto Nacional de Reforma Agraria (conocida como Ley INRA). Estas dos últimas leyes han sustituido la Ley Forestal de 1974 y la Ley de Reforma Agraria de 1956.

La región del norte amazónico boliviano está conformada por el departamento de Pando, la provincia Vaca Diez en el departamento del Beni y la parte norte del municipio de Ixiamas, perteneciente al departamento de La Paz. La superficie aproximada del norte amazónico es de $100,000 \mathrm{~km}^{2}$. En esta región habitan en la actualidad aproximadamente 170,000 habitantes (INE 2001), de los cuales el $70 \%$ se concentra en las tres ciudades más grandes de la región: Riberalta (64,511 habitantes), Guayaramerín (33,095 habitantes) y Cobija $(20,820$ habitantes). La 
extracción de Productos Forestales No Maderables (PFNM) como la goma (Hevea brasiliensis) en el pasado y la castaña (Bertholletia excelsa) en la actualidad, son las principales fuentes de trabajo e ingresos en la región (Stoian 2000). También se considera la extracción de madera como otra de las actividades económicas importantes a nivel regional, así como la ganadería y agricultura en menor medida. En 1998 del total de productos forestales exportados por Bolivia, aproximadamente el $26 \%$ de la madera aserrada, junto con el $40 \%$ de la producción de palmito y el $100 \%$ de la producción de castaña provenían de la región en estudio (Bojanic 2001:47).

A falta de un Estado normativo, la región desarrolló su propio sistema “legal”. El régimen de ocupación territorial y explotación forestal más conocido y producto de estas normas y derechos tradicionales son las barracas. La barraca es el espacio forestal destinado al aprovechamiento de los recursos forestales, principalmente goma y castaña. En el pasado varias normas públicas reconocieron el derecho de los barraqueros. Entre 1890 y 1915 varias leyes nacionales intentaron normar la explotación de goma en el norte amazónico, tomando en cuenta siempre a la barraca como la unidad productivo-económica. Por ejemplo existió la ley "Explotación de la Goma" del 12 de diciembre de 1895 y su decreto reglamentario "Estradas Gomeras" aprobado el 30 de junio de 1896. Actualmente el término "Barracas" no se encuentra explícito en ninguna norma legal. El "régimen barraquero" normó en su momento el aprovechamiento de los recursos naturales influyendo en las relaciones sociales, económicas y administrativas de la región.

Con la aplicación de la reforma y principalmente con el establecimiento de los municipios propuestos por la Ley de Participación Popular, el Estado boliviano inicia su presencia con autoridad en el norte amazónico, este es el punto de partida del presente capítulo, que tiene como objetivos aclarar cuáles son los cambios en los derechos de propiedad para el manejo de los recursos forestales introducidos por la Ley Forestal y Ley INRA.

La metodología de investigación aplicada se basa en revisiones bibliográficas, tanto de las normas vigentes que rigen los derechos para manejo de los bosques, como en la revisión de documentos técnicos y científicos relacionados con el tema. Debido a que en Bolivia el manejo de los recursos forestales está subordinado al régimen agrario, el análisis de los cambios institucionales se concentra en la comparación del Decreto Ley Forestal 11686 de 1974 con la Ley Forestal 1700 de 1996. De igual forma se comparan las disposiciones de la Ley de la Reforma Agraria de 1956 con la Ley del Instituto de Reforma Agraria de 1996.

Toda la información disponible fue complementada con los resultados obtenidos de las entrevistas realizadas a los diferentes grupos de interés 
regional y con las observaciones directas durante el estudio de campo en la región amazónica entre los meses de agosto del 2001 y junio del 2002.

El presente capítulo está dividido en seis secciones. La segunda sección discute el tema de los derechos de propiedad sobres bosques en general, mientras que la tercera sección analiza los derechos de la población rural sobre ellos. Después sigue una discusión sobre el impacto de la Ley INRA, seguido por una discusión sobre la transferibilidad de los derechos sobre tierras y bosques bajo el nuevo régimen legal. La última sección concluye.

\section{DERECHOS DE PROPIEDAD SOBRE BOSQUES}

Enmarcado en los artículos 136 y 165 de la Constitución Política del Estado (CPE), la nueva Ley Forestal reconoce el derecho de propiedad estatal sobre los recursos forestales (artículo 4). El Decreto Ley de 1974 reconocía este derecho estatal (artículo 2) sin cerrar la posibilidad de otorgar propiedad privada sobre los bosques (artículos 9 incisos a y b, 10, 19, 22, 45, 70 y 80). Los empresarios forestales, sin embargo brindaron poca importancia a esta oportunidad. Una de las principales razones fue porque la figura de la suscripción de contratos de aprovechamiento otorgaba a los empresarios, acceso rápido a los bosques y con menores costos de implementación técnica y jurídica. Por otro lado, al optar por la propiedad privada, las empresas forestales renunciaban a dos de las más grandes ventajas del sistema de usufructo: acaparar grandes superficies boscosas ilimitadas, y realizar una extracción selectiva de las especies más valiosas del mercado. Otra de las ventajas comparativas la constituía el bajo costo de los derechos de monte, que al mismo tiempo era fácilmente evadido por las empresas forestales. En resumen, el derecho a título de propiedad privada sobre los bosques dictado en 1974 nunca fue realmente implementado. La Ley 1700 pone fin al acto de otorgar propiedad privada sobre bosques del Estado.

La Ley 1700 introduce tres nuevas clases de derecho forestal: la concesión forestal en tierras fiscales, la autorización de aprovechamiento en tierra de propiedad privada y el permiso de desmonte (ver Tabla 2.1). Con una concesión forestal la Superintendencia Forestal (SIF) otorga a personas o comunidades el derecho de aprovechamiento de los recursos forestales en un área delimitada de tierras fiscales (Ley Forestal, 1996:art. 29-I). En resumen, seis atributos diferencian los tipos de derechos del Decreto Ley de 1974 de la Ley Forestal 1700: a) la Superintendensia Forestal (SIF) es la única instancia a nivel nacional encargada de otorgar las concesiones,

b) las concesiones se otorgan únicamente a largo plazo, 40 años, c) existe la posibilidad de transferencia de concesiones a través de la suscripción de contratos subsidiarios, d) el pago de la patente forestal se basa en una unidad de superficie, hectárea, e) las concesiones presentan 
Tabla 2.1. Derechos forestales para el corte de madera y de los PFNMs

Decreto Ley Forestal 1168 (1974)

(art. 25-I-III)

Autorización de aprovechamiento único

Autorización anual de corte

Autorizaciones a corto, mediano y largo Permiso de desmonte plazo

Autorizaciones para cosechar productos forestales secundarios
Ley Forestal 1700 (1996)

(art. 28 y art. 29 II)

Concesión Forestal en tierras fiscales

Autorización de aprovechamiento en tierra de propiedad privada

Concesiones para recursos forestales no maderables

límites claros y fijos y f) el nuevo régimen forestal promueve el aprovechamiento de especies forestales alternativas. Las diferencias entre las clases de derechos normadas por ambos regímenes forestales están resumidas en la Tabla 2.2 .

Históricamente el gobierno ha otorgado concesiones para el aprovechamiento de la castaña. En la década de 1940, la entonces Corporación Boliviana de Fomento, era la instancia encargada de convalidar dichas concesiones en beneficio de algunos grupos económicos. El Decreto Ley de 1974 delegaba al Centro de Desarrollo Forestal (CDF) el otorgamiento de autorizaciones de cosecha para productos forestales secundarios (DHV 1993 a,b). ${ }^{2}$ Bajo la Ley Forestal, el propietario de una concesión forestal puede traspasar el derecho de extracción de los PFNMs a terceros, a través de la suscripción de contratos subsidiarios, previa aprobación de la SIF. En el artículo 31 (I) se da prioridad a los usuarios tradicionales, comunidades campesinas y Agrupaciones Sociales del Lugar (ASL) ${ }^{3}$ en el proceso de solicitud de concesiones forestales en áreas destinadas a la extracción de PFNMs. En la práctica ambas formas de derecho legal para la extracción de los PFNMs fueron difícilmente implementadas por los usuarios del bosque amazónico.

La Ley 1700 corrige errores del pasado, como por ejemplo, reduce la posibilidad de que un mismo espacio territorial sea otorgado a dos dueños o por lo menos evita que en el futuro se den casos en que dos diferentes intereses se encuentren superpuestos en un mismo predio, tal como se observó en la región del Chore, ubicada al norte de Santa Cruz (Ruiz 1996). En la práctica, esta normativa se ve reforzada por el proceso de saneamiento de la tierra. El saneamiento de la tierra es el proceso técnico jurídico que incluye varias actividades en el terreno y en gabinete. Su objetivo principal es regular y consolidar el derecho de la propiedad agraria. La Ley INRA estipula que el proceso de saneamiento en todo Bolivia se completará en el año 2010. 
Tabla 2.2. Diferencias entre autorizaciones de corte y concesiones forestales

\begin{tabular}{l} 
Autorizaciones de Corte \\
(Decreto Ley Forestal, 1974) \\
\hline Según el tipo de autorización, su \\
aprobación precisaba de tres \\
diferentes tipos de instrumentos \\
legales: Las autorizaciones del \\
Centro de Desarrollo Forestal (CDF), \\
para los contratos a corto plazo; \\
Resolución Ministerial ${ }^{5}$ para los \\
contratos a mediano plazo; Decreto \\
Supremo ${ }^{6}$ para los contratos a largo \\
plazo (art. 30)
\end{tabular}

Norman tres diferentes plazos de aprovechamiento según el tipo de contrato: Corto plazo (3 años); Mediano plazo (10 años); y Largo Concesiones Forestales (Ley Forestal, 1996)

La SIF mediante resolución administrativa es la única organización responsable de otorgar las concesiones forestales (art. 29 I y III) plazo (20 años) (art. 30)

En teoría no se contempla el atributo de ser bienes transferibles

Pago de patentes establecida por volúmenes (Reglamento de la Ley General Forestal, 1977 art. 71)
Establece un plazo único de concesión de 40 años, renovable cada cinco años (art. 29 III c.)
Puede transferirse los derechos totales o parciales a terceros a través de la suscripción de contratos subsidiarios (art. 29 I; III e.)
Pago de patente forestal establecida por superficie, tomando en cuenta la hectárea como unidad de medida. A la fecha se ha establecido como patente mínima el monto de US\$1 por hectárea por año (art. 36)

Las autorizaciones contenían límites superficiales poco claros, porque valía más el principio de aprovechamiento por volumen que por superficie. Era muy común observar superposiciones totales y parciales entre los contratos aprobados

El sistema de aprovechamiento estaba orientado a ser selectivo, debido a las características temporales y espaciales de los contratos
Se entiende que las concesiones deben ser áreas sólidas, con límites bien catastro y control, que no generen áreas enclaustradas o casi enclaustradas ni bloques artificiosamente vinculados entre sí, porque en razón de ellos se procede al pago de la patente forestal (art. 80)

El sistema promueve el aprovechamiento del área en concesión en su totalidad al delimitar el accionar de la empresa en un área específica y al exigir el pago de patente por superficie definidos, fácilmente sometidas al 
La Ley Forestal otorga derechos forestales con prioridad a los dueños de los predios agrarios. Esto significa la directa exclusión de terceros para realizar aprovechamiento forestal dentro de las propiedades privadas o comunales tituladas. Esta nueva figura de derecho se implementa a través de las autorizaciones de aprovechamiento en tierra de propiedad privada. Esta figura legal es muy importante en el norte amazónico, ya que los pobladores de una comunidad campesina o TCO (Tierra Comunitaria de Origen), gozarán del aprovechamiento exclusivo de los recursos forestales.

\section{LA DEMOCRATIZACIÓN DE LOS BOSQUES EN BOLIVIA}

El Decreto Ley de 1974 excluye del acceso a los recursos forestales a cualquier usuario del bosque que no esté constituido como empresario forestal. El artículo 4 (d) es uno de los pocos párrafos de esta norma que hace referencia de manera general y poco convincente a la incorporación de la clase campesina a los beneficios de la producción forestal. Respecto a los grupos indígenas la norma de 1974 los denomina como tribus silvícolas, encargando su protección al Centro de Desarrollo Forestal (CDF) para garantizar su supervivencia (art. 119-120).

Bajo el nuevo régimen, adicionalmente a la figura de concesiones forestales a largo plazo, los usuarios del bosque teóricamente pueden acceder a los recursos forestales adoptando tres formas legales: a) solicitud de concesiones forestales como ASL, b) aprovechamiento forestal en TCO y c) aprovechamiento forestal en propiedades privadas y comunales. La primera figura legal de las ASLs ha sido establecida directamente por la Ley Forestal, mientras que la segunda y la tercera mantienen estrecha relación y concordancia con la Ley INRA y la Ley de Participación Popular.

Las ASLs fueron creadas para permitir el acceso formal al bosque de los grupos de usuarios de bosque "ilegales", que estaban constituidos por el grupo de "motosierristas" y comerciantes de madera. Una ASL es un grupo de personas organizadas que goza del reconocimiento de su Municipio mediante personería jurídica. Las ASLs pueden estar compuestas por usuarios tradicionales, comunidades campesinas, pueblos indígenas y otros usuarios del lugar que utilizan recursos forestales (Reglamento General de la Ley Forestal, D.S. 24453, 1996: art. 1-II a). Para tal efecto, las municipalidades podrán declarar Áreas de Reserva Forestal Municipal (ARFM) a una superficie no mayor al 20\% de los bosques públicos dentro de su jurisdicción y licitar en concesiones a ASLs (Ley Forestal, 1996: art. 25a). A nivel nacional existen 15 ASL con derechos forestales vigentes, que ocupan un total de 407,721 hectáreas (SIF 2002:8). La segunda forma legal se enmarca en el artículo 32 (II) de la Ley Forestal y el artículo 3 (III) de la Ley INRA y se refiere al manejo forestal en TCO. 
Estos artículos garantizan a los pueblos indígenas la exclusividad del aprovechamiento colectivo forestal dentro de sus tierras. Hasta la anterior gestión del 2001, la SIF había otorgado a nivel nacional 11 permisos de aprovechamiento forestal en TCOs, que hacen un total de 444,406 hectáreas. La Ley Forestal ha desafiado a los indígenas a realizar un aprovechamiento forestal sobre sus TCOs, debido a las fuertes demandas en términos técnicos, financieros y administrativos que representa (Real 2002:vii).

La figura de comunidad rural es representada en la Ley de Participación Popular. Esta ley establece que el requisito básico para convertirse en comunidad campesina o indígena es la solicitud de la personería jurídica. Una vez que la comunidad obtiene este trámite cuenta con el derecho exclusivo de acceder a los recursos forestales dentro de los límites de sus predios. Adicional a lo estipulado en la Ley Forestal sobre comunidades campesinas, el Decreto Supremo 25848, en el marco de la Ley INRA, define que las comunidades campesinas en el norte amazónico boliviano, en regiones forestales, tienen derecho a un área comunal de un mínimo de 500 ha por familia residente en la comunidad. Como consecuencia de este decreto, en un futuro próximo esta figura legal puede producir una verdadera "reforma forestal", en caso que las comunidades campesinas decidan incursionar en el manejo forestal, ya que la presencia de 6,800 familias podrían implicar un mínimo de 3.4 millones de hectáreas bajo manejo comunitario (Orduna 2000).

El cambio de actores legales que pueden acceder a los bosques ha tenido su impacto sobre la distribución de áreas forestales bajo manejo. Bajo el antiguo régimen, el $40 \%$ de la superficie boscosa del país (aproximadamente 21 millones de ha) se encontraba en manos de 50 empresas forestales, bajo el otorgamiento de 173 contratos de aprovechamiento (Contreras y Vargas 2001:4, Pacheco 2000:8, Bojanic 2001:42). Desde 1996 se produjo una reducción drástica de la superficie de aprovechamiento forestal. Entre los años 1997 y 2001 la superficie otorgada a las empresas forestales tiende a reducirse, mientras que la superficie bajo manejo de los nuevos usuarios forestales va en aumento (ver Gráfico 2.1). Según informe de la gestión 2001 de la SIF, un $12 \%$ del total de la superficie de bosques de Bolivia (aproximadamente 6.5 millones de hectáreas) está siendo legalmente aprovechada por nuevos usuarios del bosque. Aunque las concesiones a las empresas forestales son el instrumento legal más difundido (78\%), el $7 \%$ de la superficie total está siendo manejada bajo TCOs, $6 \%$ en ASLs, $4 \%$ en propiedades privadas y comunales y el resto en concesiones destinadas a la investigación o en Reservas Privadas de Patrimonio Natural (RPPN) (ver Gráfico 2.2). 
Gráfico 2.1. Superficie forestal regulada por la SIF (1997-2001)

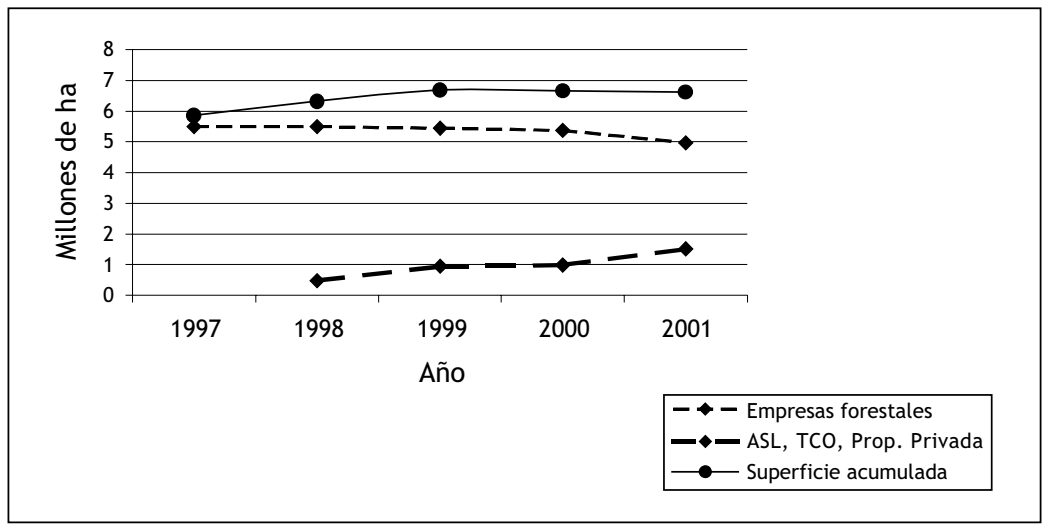

Fuente: Llanque y Zonta 2002. En base a estadísticas de la SIF

Gráfico 2.2. Distribución de los recursos forestales en Bolivia (Gestión 1997-2001)

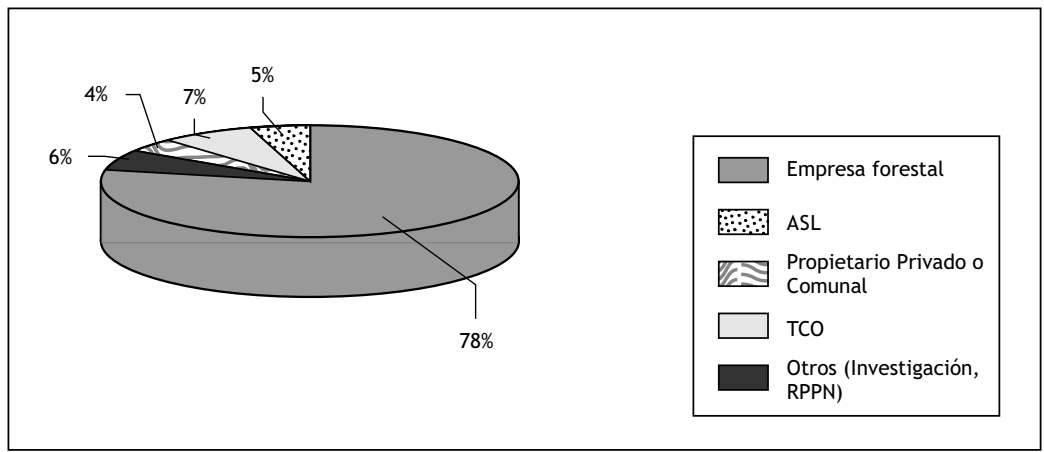

Fuente: Superintendencia Forestal 2002:8

\section{El efecto de la democratización forestal en el norte amazónico boliviano}

La experiencia en constitución de ASLs en el norte amazónico boliviano es muy pobre. Únicamente cuatro ASL fueron establecidas en la provincia Vaca Diez (dos en el Municipio de Riberalta y dos en el Municipio de Guayaramerín). Específicamente en el caso de Riberalta, el proceso de consolidación del Área de Reserva Forestal Municipal (ARFM) se inicia en 1997 con la inmovilización de aproximadamente 513,000 hectáreas (Ordenanza Municipal 25/97). Su consolidación se efectúa recién dos años después, en julio de 1999 con una superficie de 147,200 hectáreas (Ordenanza Municipal 51/99). Para la demarcación geográfica de la ARFM 
el municipio recibió ayuda técnica del Proyecto BOLFOR. ${ }^{7}$ Este proceso ha sido muy cuestionado por varios grupos de actores sociales, como comunidades campesinas, barraqueros y propietarios individuales que atribuyen contar con derechos anteriores a dicha demarcación. A esta situación de sobre posición de intereses se añade el hecho que ninguna de las dos ASL del municipio cuenta con la aprobación del Ministerio de Desarrollo Sostenible para emprender actividades de explotación forestal.

El caso específico de la Asociación de Productores Exportadores Forestales Amazónicos (APEFA) constituida en Riberalta (1998), ha recibido el visto bueno del gobierno municipal de Riberalta para manejar un área aproximada de 30,000 hectáreas. En el año 2002 los miembros de la APEFA elaboraron un Plan Operativo Anual Forestal (POAF) que abarca una superficie de 1,000 hectáreas. Hasta la fecha la SIF ha aprobado parte del POAF 2002, lo que ha permitido a los miembros de APEFA iniciar el proceso de negociación de la madera con los aserraderos de Riberalta. Esta situación no sólo ha desalentado el interés de trabajar en Asociación a muchos de los miembros de la APEFA, sino que también les ha obligado a seguir extrayendo madera de forma individual, actividad que en la mayoría de los casos recurre al uso de mecanismos ilegales de aprovechamiento forestal. Su salvación fue la institucionalización del programa de abastecimiento de madera para la construcción en Riberalta, estipulado por la SIF, que a la vez sirvió para mejorar el control del aprovechamiento forestal en la zona y recaudar fondos por concepto del pago de la patente forestal por volumen de las especies aprovechadas. Dicho programa aprueba el aprovechamiento de hasta 2,000 pies de especies "blancas" en un máximo de 6,000 pies de madera anuales por persona.

En el departamento de Pando, el establecimiento de ASLs está más atrasado, debido a que no existe ninguna asociación conformada. Sólo se tiene identificado de forma preliminar y en gabinete a seis ARFM, ${ }^{8}$ gracias al apoyo técnico del PANFOR. ${ }^{9}$ El proceso de demarcación de las ARFMs y posterior creación y consolidación de las ASLs ha sido paralizado de igual manera, hasta que se concluya el saneamiento de la tierra, proceso que tiene como principal objetivo garantizar la seguridad jurídica y técnica sobre las propiedades.

En el norte amazónico boliviano, hasta el año 2001 fueron tituladas dos TCO: Multiétnico II y Yaminahua-Machineri, con superficies de 289,470 hectáreas y 26,470 hectáreas respectivamente. A la fecha ninguna de estas TCO ha solicitado al Estado el derecho para aprovechar sus recursos forestales. Al igual que las ASL, el aprovechamiento forestal normado por la Ley 1700 al interior de una TCO requiere cumplir con numerosas condiciones técnicas y legales que representan altos costos de transacción ${ }^{10}$ para los 
usuarios. En este sentido, los pueblos indígenas, pero también las comunidades campesinas, siguen siendo dependientes del apoyo técnico y de los fondos financieros de empresas forestales, o en su defecto de algunas organizaciones no gubernamentales (ONGs) o gubernamentales.

Otro elemento que impide el manejo forestal dentro de las TCOs son los desacuerdos entre sus miembros. Los habitantes de las TCOs no se atreven a incursionar en el aprovechamiento forestal por el riesgo que este representa, pudiendo convertirse en una fuente permanente de conflictos sociales al interior de sus comunidades. Esta situación se mantendrá mientras no se mejoren las asimetrías en el acceso a la información entre los propios habitantes de las TCOs y mientras las reglas de juego se mantengan confusas respecto a la contribución de los recursos de cada uno de los actores y a la distribución de las ganancias. En la TCO Multiétnico II la mayoría de las comunidades están de acuerdo en impedir a sus dirigentes cualquier tipo de negociación de sus recursos forestales maderables, sin el consentimiento previo de todos sus habitantes y de la Central Indígena de la Región Amazónica Boliviana (CIRABO). ${ }^{11}$

Esta situación junto al Decreto Supremo 25848 ha contribuido a aumentar las expectativas hacia los derechos de las comunidades rurales. Muchas de las solicitudes planteadas al INRA no mantienen ninguna relación entre el número de familias dentro de la comunidad con las 500 hectáreas inicialmente propuestas por las organizaciones regionales. El problema del Decreto Supremo 25848 es que en realidad no limita un número máximo de superficie de dotación. Un ejemplo ilustrativo en la provincia Vaca Diez es el caso de la comunidad Santa María, donde sus 87 familias aspiran a consolidar aproximadamente 100,000 hectáreas, aunque muchos de sus miembros no comprenden en realidad por qué sus representantes aspiran duplicar el área a la que tienen derecho (Hentschel, Capítulo 5). Ante esta incertidumbre en una reunión del Comité de Saneamiento del Norte Amazónico, el 20 de febrero del 2002, el Director Nacional del INRA acordó con los representantes de las organizaciones campesinas de la región y con las ONGs presentes, dotar un máximo de hasta 560 hectáreas por familia campesina.

\section{LA LEY INRA Y PROPIEDAD DE TIERRAS}

\section{Clasificación de la Propiedad Agraria}

El régimen agrario nacional estipulado en la CPE constituye la base para la formulación de la Ley INRA. Los artículos 1 y 171 de la Constitución declaran a Bolivia como país multiétnico y pluricultural y reconocen el derecho al uso y aprovechamiento de sus recursos naturales sobre sus TCOs. 
Para evitar contradicciones con los lineamientos sobre el otorgamiento de derechos de los recursos naturales establecidos en la CPE, la Ley INRA enfatiza el término tierra antes que suelo o territorio. ${ }^{12}$ De esta manera el Estado da título de propiedad sobre la capa superficial de la tierra y reserva el derecho de usufructo sobre los bosques y los recursos del subsuelo.

La Ley INRA conserva inalterable las cuatro categorías de derecho de propiedad individual, introduciendo cambios únicamente en las dos categorías restantes correspondientes al régimen de propiedad comunal (Tabla 2.3). La forma de distribución de la tierra a comunidades rurales normada por la Ley INRA, continúa siendo a través de la unidad familiar. La familia es considerada como una organización clave e influyente en el acceso a la tierra en gran parte de los países latinoamericanos (Gordillo y Boening 2000).

Tabla 2.3. Clasificación de la propiedad agraria

Ley Reforma Agraria (1956)

Solar campesino (art. 6)

Propiedad Pequeña (art. 7)

Propiedad mediana (art. 8)

Empresa agrícola (art. 11)

Comunidad indígena (art. 9)

Propiedad agraria cooperativa (art. 10)
Ley INRA (1996)

Solar campesino (art. 41)

Pequeña Propiedad (art. 41)

Mediana Propiedad (art. 41)

Empresa agrícola (art. 41)

Tierra Comunitaria de Origen (art. 41)

Propiedad Comunitaria Campesina o

Indígena (art. 41)

La introducción parcial del concepto territorio indígena,$^{13} \mathrm{a}$ través de la figura legal de una TCO, es el cambio más trascendental dentro de las clases de derechos de propiedad comunal. De las seis demandas solicitadas en 1996 en el norte amazónico boliviano, existen dos TCO tituladas (Multiétnico II y Yaminahua-Machineri) y cuatro demandas en diferentes estados administrativos de ejecución (Chacobo-Pacahura, Cavineño, Araona y Tacana II). ${ }^{14}$ De esta forma han sido incorporados los derechos solicitados de los nueve pueblos indígenas que habitan la región del norte amazónico boliviano.

Las comunidades indígenas pueden acceder a la propiedad de la tierra a través de las dos clases de derechos comunal, es decir TCO o propiedad comunitaria. Según De Vries (1998:13) la diferencia jurídica entre TCO y Propiedad Comunal es mínima. De facto la TCO tiene dos ventajas comparativas frente a la figura de propiedad comunal: Primero, se permite la titulación de TCO sobre zonas determinadas como Áreas Protegidas (AP) por ejemplo: Parque Nacional y Territorio Indígena Isiboro Sécure, Reserva de la biósfera y Territorio Indígena Pilón Lajas (Ley General de Medio Ambiente, 1992: art. 64, Decreto Supremo 25906, 22 de setiembre del 
2000: art. 8). Segundo, la TCO no limita la superficie ni requiere un número mínimo de familias.

En el caso del área en estudio, estas dos ventajas se consideran poco significativas. A dos años de ejecución del proceso de saneamiento se tiene conocimiento que únicamente una demanda indígena ha optado por la clasificación de propiedad comunal (Comunidad de Mapajo, ubicada en el área del Bolsón de Rapirrán). La conformación de una TCO dentro de la Reserva Nacional de Vida Silvestre Amazónica Manuripi no ha sido posible, debido a que la población originaria fue disminuida durante el periodo del auge gomero (Salm y Marconi 1992). Maldonado (2002), de acuerdo a datos demográficos del último censo nacional, señala que a pesar de la existencia de descendientes de las nueve etnias regionales y de otras etnias del país dentro del AP, ninguna de las comunidades rurales allí establecidas ha solicitado el acceso a tierras bajo la figura de TCO, pero si como propiedad comunal. En cierto modo, la aprobación del Decreto 25848 ha neutralizado las solicitudes de TCO dentro de la región, debido a que las familias campesinas tienen acceso a 500 ha bajo esta clasificación.

Muchos de los habitantes de las comunidades campesinas comparten la opinión que la propiedad comunal contribuye a reducir conflictos internos, que pueden ser originados principalmente en TCOs multiétnicas. Los conflictos se originan por las diferencias en concepciones sobre la gestión territorial. Por ejemplo, en el Multiétnico II, ${ }^{15}$ los Esse-ejjas no tienen restricciones para que los Tacanas establezcan sus viviendas, desarrollen actividades agrícolas o extraigan castaña dentro de su espacio otorgado. Es decir, los Esse-ejjas reconocen a la TCO como una gran comunidad. Por su parte los Tacanas, al no compartir la misma percepción territorial, han optado por poner límites geográficos tanto al interior como al exterior de sus comunidades, limitando así el acceso a otros habitantes que comparten la misma TCO.

El cambio más significativo en la historia del norte amazónico boliviano fue la dotación de un mínimo de 500 hectáreas a cada familia campesina o indígena que habite en una comunidad rural (Decreto Supremo 25848, 2000: art. 1). Este es un cambio bastante significativo, pues la Ley de 1956 se limitaba a otorgar en concesión los árboles de goma y castaña, hasta un máximo de dos estradas ${ }^{16}$ y la adjudicación de una pequeña propiedad en lugar adecuado para desarrollar actividades agrícolas (art. 70 a). Esta modificación ocasionó polémica incluso a nivel nacional por los mismos campesinos del oriente y occidente del país, los cuales recién han logrado acceder a un máximo de 50 hectáreas de tierra, bajo la modalidad de pequeñas propiedades agrícolas en las zonas tropicales y subtropicales de Bolivia. (art. 15 y 75). 
Vale la pena aclarar que la pequeña propiedad agrícola para el norte amazónico sigue siendo de 50 hectáreas y la pequeña propiedad ganadera es de 500 hectáreas. Estas dos formas individuales de propiedad agraria aún poseen un alto grado de aceptabilidad en la región, debido a sus características de independencia en la toma de decisiones para el uso de los recursos naturales y también por su alto grado de transferencia. En los dos polígonos del departamento de Pando donde el proceso de saneamiento de tierras esta más avanzado, de los 58 predios mesurados, el $40 \%$ ha optado por la pequeña propiedad agrícola y el $27 \%$ por la pequeña propiedad ganadera (INRA 2002a,b).

\section{TRANSFERENCIA DE LOS DERECHOS FORESTALES Y AGRARIOS}

Como transferencia de derechos se entiende cualquier tipo de acción que puede tomar un individuo para ceder o traspasar su derecho sobre un bien a terceros. Con el objetivo de evitar la división de los predios que han provocado en el pasado minifundios, o la acumulación de tierras que conlleven a la consolidación de latifundios, la normativa vigente es más precisa en normar las posibles formas de transferencia de los derechos agrarios y forestales a terceros.

Un tema bastante controversial relacionado con la transferencia de los derechos de propiedad, es el papel que debe jugar el Estado para proteger o liberar el intercambio de bienes de las propiedades comunales. Las leyes en análisis se acercan más a la idea de un Estado protector sobre los derechos adquiridos por las comunidades rurales frente a los posibles intentos de otros grupos de interés en acaparar sus tierras. La transferencia de derechos sobre las diferentes clases de tierras está bastante restringida, como se muestra en la Tabla 2.4.

En el área de estudio muchas de las buenas intenciones estatales están limitadas debido a las siguientes causas: a) carencia de medios técnicos y financieros de las instancias de gobierno, que garanticen un efectivo control de las instituciones públicas aprobadas, b) alta dependencia de los grupos campesinos e indígenas ante las élites económicas locales en cuanto al acceso de los recursos y a la venta de los mismos en los mercados regionales, y por último, c) la actual crisis económica que obliga a los habitantes rurales a renunciar a sus bienes adquiridos. Durante el estudio de campo se han identificado cuatro tipos de mercado de bienes, los tres primeros pueden considerarse netamente informales (el de las barracas, el de los predios ocupados por los habitantes brasileros y el de las parcelas al interior de las comunidades rurales) y el último semi-formal (de las concesiones forestales). 
Tabla 2.4. Transferencias de derechos agrarios y forestales

\begin{tabular}{|c|c|c|}
\hline Régimen & $\begin{array}{l}\text { Clases de } \\
\text { Derecho }\end{array}$ & $\begin{array}{l}\text { Posibilidades de } \\
\text { Transferencias }\end{array}$ \\
\hline \multirow[t]{7}{*}{ Agrario } & Propiedad & Severamente limitado: \\
\hline & Comunal & - No se puede vender \\
\hline & & - No es hipotecable \\
\hline & $\begin{array}{l}\text { Tierras } \\
\text { Comunitarias } \\
\text { de Origen }\end{array}$ & $\begin{array}{l}\text { - } \text { - Las sucesiones hereditarias se mantendrán } \\
\text { para todos los casos bajo régimen de indivisión } \\
\text { forzosa } \\
\text { - Es imprescriptible }{ }^{17}\end{array}$ \\
\hline & $\begin{array}{l}\text { Solar } \\
\text { Campesino }\end{array}$ & $\begin{array}{l}\text { Limitado: } \\
\text { - Se puede vender, en tanto que la ley no lo prohíbe } \\
\text { - No es hipotecable } \\
\text { - No es embargable }\end{array}$ \\
\hline & $\begin{array}{l}\text { Pequeña } \\
\text { Propiedad }\end{array}$ & $\begin{array}{l}\text { - Las sucesiones hereditarias se mantendrán } \\
\text { para todos los casos bajo régimen de indivisión } \\
\text { forzosa }\end{array}$ \\
\hline & $\begin{array}{l}\text { Mediana } \\
\text { Propiedad } \\
\text { Empresa } \\
\text { Agropecuaria }\end{array}$ & $\begin{array}{l}\text { Abierto: } \\
\text { - Se puede vender } \\
\text { - Se puede hipotecar } \\
\text { - Se puede dar en prenda } \\
\text { - Es embargable } \\
\text { - Es sujeto de herencia }\end{array}$ \\
\hline Forestal & $\begin{array}{l}\text { Concesión } \\
\text { Forestal }\end{array}$ & $\begin{array}{l}\text { Limitado: } \\
\text { - Es posible ceder los derechos de forma total y } \\
\text { parcial, con la debida autorización de la SIF, } \\
\text { previa auditoría de cumplimiento } \\
\text { - Los términos y condiciones de la transferencia } \\
\text { total o parcial de la concesión serán libremente } \\
\text { convenidos entre las partes interesadas. Es } \\
\text { decir, se deja abierta la posibilidad de agregar } \\
\text { plusvalía al bien por concepto de mejoras } \\
\text { introducidas o condiciones de mercado } \\
\text { - No es hipotecable } \\
\text { - Las sucesiones hereditarias son posibles en } \\
\text { tanto que se consideran las concesiones como } \\
\text { parte de un patrimonio empresarial. }\end{array}$ \\
\hline
\end{tabular}




\section{Transacciones de las barracas}

El régimen privado de las barracas, no reconocido en la disposición legal contemporánea, ha permitido realizar todo tipo de transacciones de derechos sin necesidad de contar con los títulos ejecutoriales. De facto las barracas eran vendidas, heredadas, puestas en prenda, intercambiadas por inmuebles, alquiladas o hipotecadas ante organizaciones crediticias de los mismos empresarios de la región (Torrez 1930:246-249). En la actualidad, sin embargo se nota una disminución drástica del mercado informal de barracas en la región, debido a la inseguridad jurídica, al sinnúmero de casos de superposición de intereses y a la consecuente pérdida del valor de mercado. Por ejemplo, antes la barraca era considerada como un bien hipotecario en el sistema de habilito, ${ }^{19}$ ahora las beneficiadoras de castaña prefieren pedir únicamente inmuebles a los pequeños barraqueros para financiar la recolección de castaña. Esto no significa que las transacciones de barracas en la región han desaparecido. Muchos barraqueros optan por dividir sus tierras y traspasar en herencia a sus futuras generaciones o transferir parte de sus bienes a terceros (principalmente a otros barraqueros que viven en el lugar e incluso a miembros de comunidades rurales).

\section{Transacciones de predios de habitantes brasileros}

De igual manera, se ha podido constatar la presencia de un mercado informal de tierras internacional, ejecutado por habitantes ubicados en las zonas fronterizas con Brasil y Perú. Por ejemplo, predios ubicados en Bolivia, manejados por ciudadanos brasileros, son transferidos a terceros en ciudades fronterizas, como Capixaba del Brasil. Dichas transferencias no demandan ninguna condición, por el simple hecho que la mayoría de sus poseedores no cuentan con documentos o planos que acrediten su propiedad y ubicación. Este tipo de intercambios también ha disminuido desde que el INRA ha iniciado el proceso de saneamiento de tierras en el polígono 10, en febrero del 2001. Muchas de estas transferencias de compra y venta o alquiler, no necesariamente ocurrían con dinero, especialmente en la zona fronteriza con el Brasil. Es muy común vender las tierras a cambio de especies (goma, castaña, asaí, animales, madera, etc).

\section{Transacciones de parcelas de comunidades rurales}

Las parcelas dentro de propiedades comunales, igualmente son ofrecidas en un mercado informal de bienes que posibilita vender, alquilar, intercambiar e incluso poner en prenda los bienes adquiridos individualmente. Al igual que las dos anteriores, antes de la aplicación del régimen agrario, estas transferencias eran muy populares en la región. 
Actualmente, las transferencias al interior o exterior de la comunidad están siendo discutidas por sus miembros afiliados, observándose un proceso de cambio institucional de sus normas privadas (Gottwald, Capítulo 4).

\section{Transacciones de las concesiones forestales}

Cuatro de las 19 concesiones forestales oficialmente entregadas en 1997 (Los Indios, Río Negro, San Joaquín y Selva Negra) han sido transferidas a dos aserraderos establecidos en Riberalta. Las cuatro concesiones transadas se encuentran en el extremo noreste del departamento de Pando, región que contempla bajos índices de densidad poblacional, y por ende menores conflictos sociales entre usuarios del bosque. La principal razón de la transferencia de estas concesiones es porque las empresas originalmente adjudicadas no estaban aprovechando los recursos y tenían demoras en el pago de la patente forestal.

Este tipo de transacciones no debe considerarse como un logro del nuevo sistema forestal, ni atribuirse a la plusvalía de los bienes transados, ya que en el anterior régimen se dieron de igual manera transacciones similares entre empresarios forestales. El avance cualitativo en relación al pasado es el control que asumen las organizaciones públicas al momento de aprobarse los acuerdos.

\section{CONCLUSIONES}

La implementación del sistema legal boliviano sigue tropezando con la idea de considerar a la ley como un instrumento normativo general que requiere para su aplicación la aprobación de reglamentos específicos. Para el norte amazónico boliviano, se confirma que parte de los contenidos de las leyes analizadas son muy generales llegando a ser ajenos a su realidad (Gottwald, Capítulo 4). En este sentido, la implementación de las instituciones públicas dependió del proceso de adecuación de la reforma que logró incorporar los intereses de los actores regionales y las características de la región. Este proceso es mucho más joven que la aprobación de las leyes nacionale ${ }^{20} y$ se encuentra fuertemente influenciado por las iniciativas, relaciones de poder y estrategias de los grupos de interés. Durante el proceso de adecuación de las normas públicas se aprobaron una serie de decretos supremos, resoluciones ministeriales, resoluciones administrativas por parte del INRA y de la SIF, ordenanzas municipales, etc., sin las cuales la reforma hubiera quedado en el papel. En teoría, el problema de la implementación legal en Bolivia podría comenzar cuando las normas específicas sean difícilmente aprobadas, ya sea por negligencia, olvido o carencia de voluntad política o por la resistencia que ejercen los grupos de interés antagónicos. Otro problema de las normas específicas que afectaría la implementación de las 
leyes, es su bajo nivel jerárquico legal, que determina su alto grado de vulnerabilidad y flexibilidad hacia el cambio y corta duración.

Respecto a las transacciones de bienes, en la región del norte amazónico boliviano al igual que en el resto del país, los bienes se transfieren fundamentalmente intra-estrato en los mercados de tierra informal, es decir, la venta o alquiler de los mismos ocurre entre usuarios del bosque con características socioeconómicas similares. Sin embargo, no se descarta a futuro la posibilidad de trasferencias extra-estrato en la región, debido al sinnúmero de necesidades socioeconómicas que tienen los campesinos e indígenas. En este mismo orden de ideas, no se descarta un aumento en el número de transferencias por parte de miembros de las comunidades rurales.

Debido a la tendencia de manejo forestal y la distribución de tierras en propiedades comunales, se prevé en el futuro que las autorizaciones de aprovechamiento en tierras de propiedad privada se constituirán en la figura legal más popular aplicada en el norte amazónico boliviano. Esta situación demandará mayor control por parte de las instancias regionales, que en la actualidad carecen de medios financieros y técnicos para afrontar estos desafíos. Bajo esta misma óptica de análisis, se prevé también un aumento en la consolidación de contratos mixtos de aprovechamiento forestal entre aserraderos y comunidades rurales o con ASLs. Los contratos privados serán legitimados por la SIF al aprobar los PMFs. De facto el interés que persiguen los usuarios del bosque se orientará al aprovechamiento selectivo de especies comerciales, dejando muchas veces de lado los criterios propios de un sistema moderno de aprovechamiento forestal sostenible. Esto significa que en un futuro muy próximo los aserraderos de la región pasarán a ser protagonistas principales del manejo forestal comercial. En el campo social se prevé el aumento de conflictos sociales al interior de las comunidades rurales y no se descarta la tendencia de que el aprovechamiento forestal ilegal siga ganando espacio, sobretodo por parte de las familias campesinas y grupos de usuarios de bosque afectados por los conflictos sociales, o por aquellas personas que no compartan intereses con lo estipulado en los acuerdos firmados en los contratos comerciales.

Si bien la actual situación conflictiva en la que se encuentra el norte amazónico no es responsabilidad única de las reformas aplicadas, mucho de su contenido ha servido para aflorar los conflictos sociales existentes en el pasado. De todas formas, la redistribución de recursos forestales en el caso del área de estudio se ha mantenido en el orden de un proceso pasivo, hecho que permite la discusión e inclusión por otras regiones de Bolivia e incluso por otros países del continente que persiguen iniciativas similares. 


\section{NOTAS}

${ }^{1}$ La Reforma ejecutada en Bolivia ha sido considerada por muchos expertos como la más profunda y ambiciosa en el ámbito latinoamericano (ver Birle 1996:9-14, Antelo 2000:5, Crespo 2000:9-11, Loayza O.J.: 115, Real 2002:80).

2 En la práctica las Corporaciones de Desarrollo Regional de Pando, del Beni y La Paz asumen responsabilidades sobre la extracción de los PFNMs. 3 Una forma de organización social que define la ley forestal. Como ASL se pueden reconocer ciertos grupos locales que no tienen otro reconocimiento legal.

${ }^{4}$ Las autorizaciones de corte a corto plazo llevaban la firma del Director Regional del CDF y del Jefe departamental de Industria y Comercio de la misma organización.

${ }^{5}$ La Resolución Ministerial necesita la firma del Ministro y en muchos casos del Viceministro del ramo.

${ }^{6}$ El Decreto Supremo es la máxima institución pública aprobada por el poder ejecutivo, por lo que precisa la firma del Presidente de la República y de todos los ministros.

7 Proyecto de Manejo Forestal Sostenible, dependiente del gobierno boliviano, con financiamiento de USAID.

${ }^{8}$ El Sena, Santos Mercado, Villa Nueva, Bolpebra, Filadelfia y Bella Flor.

9 PANFOR, Proyecto de Manejo Forestal Sostenible de Pando, se encuentra bajo el paraguas del proyecto BOLFOR y es igualmente financiado por fondos de EEUU y depende de la Prefectura del departamento de Pando.

10 Según Eggertsson (1990), los costos de transacción se derivan de una o más de las siguientes actividades: de la generación de arreglos contractuales, de la supervisión de las contrapartes en el contrato para verificar que este se cumpla, de hacer que el contrato se cumpla, así como las penalidades que se derivan del incumplimiento de la relación contractual y de la protección de los derechos de propiedad frente a terceros (citado en Escobal 2000:7).

${ }^{11} \mathrm{La}$ CIRABO es junto a la CIPOAP (Central Indígena de Pueblos Originarios de la Amazonía de Pando) la principal organización social que representa los intereses indígenas en la región.

${ }^{12}$ La definición de territorio incluye para muchos actores sociales, especialmente para los pueblos indígenas y originarios no sólo la capa superficial destinada a las actividades agropecuarias, sino también los demás recursos disponibles que les permite desarrollar su existencia (de Vries 1998:12).

${ }^{13}$ Como ya se trató de explicar anteriormente, el concepto de "Territorio Indígena" hace alusión a dos elementos fundamentales que hasta la fecha no han podido ser aplicados en una TCO: a) la autonomía política y administrativa del pueblo indígena sobre su espacio ocupado y como ya se mencionó anteriormente b) la exclusión de la explotación de los recursos 
del subsuelo a terceras personas (de Vries 1998:12).

${ }^{14}$ Las demandas de TCO de Chacobo/ Pacahuara y Cavineño no se encuentran en su totalidad dentro del área de estudios. La demanda TCO Araona, titulada por decreto supremo, se encuentra fuera del área de estudio.

15 La TCO Multiétnico II está compuesta por tres etnias: La Tacana, Cavineña y Esse-ejja.

${ }^{16}$ Una estrada es una senda que conecta en un circuito a los árboles de goma y que es utilizada por los siringueros durante el proceso de recolección de la siringa. La Ley del 12 de diciembre de 1895, en su artículo 5, establecía que una estrada estaba compuesta por 150 árboles de goma. Stoian (2000) menciona que una estrada se compone de 80 a 200 árboles de goma. Pacheco (1992) considera entre 120 a 150 árboles. No existe ninguna relación exacta de cuántas hectáreas componían una estrada gomera, puesto que esta relación se encuentra muy influenciada por la densidad de árboles según cada lugar.

17 Imprescriptible es una característica especial de las "propiedades comunales", donde sus derechos adquiridos no caducan, posibilitando traspasar sus bienes de generación en generación de a cuerdo a sus tradiciones y costumbres.

18 Reglamento de la Ley Forestal, 1996: art. 79-I.

19 El habilito es un sistema de pago por adelantado con el objetivo de financiar todo tipo de actividades de aprovechamiento forestal, principalmente la extracción de PFNMs. La variación más simple consiste en que el zafrero o recolector recibe dinero por adelantado del barraquero para trasladarse al bosque, recolectar y entregar el producto al precio acordado con anterioridad (Bojanic 2001:87).

${ }^{20}$ Una de las primeras normas que obtuvo gran impacto en la región fue la aprobación del Decreto Supremo 25532, que convertía a las barracas en concesiones de PFNMs (05.10.99).

\section{REFERENCIAS}

Antelo, E. 2000. Políticas de estabilización y de reformas estructurales en Bolivia a partir de 1985. Serie Reformas Económicas No. 62. Gobierno de Países Bajos. pp. 5-44.

Birle, P. 1996. Editorial En: Birle, P. (ed.) Bolivien - Traumland der Reformen. Lateinamerika Analysen-Daten-Dokumentation Hamburg 13 (1996) 31. pp. 9-14.

Bojanic, A. 2001. Balance is beautiful: Assessing sustainable development in the rain forests of the Bolivian Amazon. PROMAB Scientific Series 4. 255 Pp.

CDF (Centro de Desarrollo Forestal Regional Nor-oeste). 1994. Registro de empresas forestales (Sin Publicar). 
CIRABO (Central Indígena de la Región Amazónica de Bolivia). 2000. Observaciones generales de la CIRABO al proceso de saneamiento del Territorio Indígena Esse Ejja, Tacana y Cavineño. En: INRA Archivo de Saneamiento TCO Multiétnico II. pp. 705-718. (Sin Publicar).

Contreras, A y Vargas, M.T. 2001. Las dimensiones sociales, ambientales y económicas de las reformas en la Política Forestal de Bolivia. Forest Trends. CIFOR. 51 Pp.

Crespo, F. 2000. Incidencia de las reformas estructurales sobre la agricultura boliviana. Serie Desarrollo Productivo No. 98. Red de Desarrollo Agropecuario de las Naciones Unidas. Santiago de Chile. 55 Pp.

de Vries, A. 1998. Territorios Indígenas en las Tierras Bajas de Bolivia. Un Análisis de su estado a 1998. CPTI/CIDOB-SNV. El País. Santa Cruz, Bolivia. 78 Pp.

DHV. 1993a. Sistemas de Recolección de Castaña en la Amazonía Boliviana. Estudios Agro-Ecológicos, Forestales y Socio-Económicos en la Región de la Castaña de la Amazonía Boliviana, Volumen C. DHV, La Paz.

DHV. 1993b. Tenencia de la Tierra en la Región Castañera de la Amazonía Boliviana. Estudios Agro-Ecológicos, Forestales y Socio-Económicos en la Región de la Castaña de la Amazonía Boliviana, Volumen E. DHV, La Paz.

Eggertsson, T. 1990. Economic Institutions and Behaviour, Cambridge. pp. 5-30

Escobar, J. 2000. Costos de transacción en la agricultura peruana: una primera aproximación a su medición e impacto. GRADE. Documento de Trabajo, 30. Lima, Perú. pp. 1-10.

Gordillo, G. y Boening, F. 2000. El acceso a la tierra en América Latina en la década de los noventa. Grupo Chorlavi. II Conferencia electrónica "Reformas agrarias y mercados de tierras" http:www.chorlavi.cl/ tierra/acceso.html. (consulta en mayo 2001).

Gottwald, C. 2003. Redistribution of forest resources in the Northern Bolivian Amazon -Perceptions and reactions in (independent) rural communities. (por publicar).

Hentschel, G. 2002. Die Veränderung institutionaller Rahmenbedingungen für die Waldnutzung durch Campesino-Siedler im bolivianischen Amazonasgebiet. Diplomarbeit. Universität Freiburg. Freiburg, Alemania. (no publicado).

INE (Instituto Nacional de Estadística). 2002. Censo Nacional de Población y Vivienda 2001. Distribución de la población por municipios. La Paz Bolivia.

INRA (Instituto Nacional de Reforma Agraria). 1957-2001. Registros de expedientes sobre propiedades agrícolas para el departamento de Pando, la Provincia Vaca Diez y el Municipio de Iximas. La Paz. www.inra.gov.bo/PortalINRA/DesktopModules/ (consulta en Enero 2003). 
INRA (Instituto Nacional de Reforma Agraria). 2002a. Informe de Resultados Polígono 03 (Bolpebra). Unidad de Saneamiento 0142/2002. Pando, Bolivia. (Sin Publicar).

INRA (Instituto Nacional de Reforma Agraria) 2002b. Informe de Resultados Polígono 10 (Rapirrán). Unidad de Saneamiento 0396/2002. Pando, Bolivia. (Sin Publicar).

Llanque, O. y Zonta, A. 2002. Participación de los Actores en la Actividad Forestal. VIII Congreso Nacional Forestal y IV Asamblea Nacional de Ingenieros Forestales PROMAB/IPHAE. (por publicar).

Loayza, M., Santa Cruz, J. y Pereira, R. (s/a): Bolivia. Unidad de Análisis de Políticas Económicas y Sociales (UDAPE). pp. 115-130.

Maldonado, R. 2002. Natural resource management in a Tropical protected area - Conflict between users and protection in the "Reserva Nacional de Vida Silvestre Amazónica Manuripi” (RNVSAM), Bolivia. Diplomarbeit. Universität Freiburg. Freiburg, Alemania. (no publicado).

Orduna, V. 21.07.2000. Empresarios piden la mitad del departamento en concesiones forestales: Pando empieza donde termina la Ley. Tierra a Debate. www.ftierra.org. (consulta en abril 2000).

Pacheco, P. 1992. Integración económica y fragmentación social - El itinerario de las barracas en la Amazonía boliviana -. La Paz, CEDLA. 295 Pp.

Pacheco P. 2000. Avances y desafíos en la descentralización de la gestión de los recursos forestales en Bolivia. CIFOR/BOLFOR. Santa Cruz, Bolivia.

Real, B. 2002. Legal reforms in Bolivia in the 1990S: Challenges and opportunities for Decentralisation, Indigenous rights and forest management. Thesis presented to the graduate School of the University of Florida for the degree of Master of Arts. 118 Pp.

Richter, R. y Furubotn, E. 1996. Neue Institutionenökonomik. Eine Einführung und kritische Würdigung. Übersetzt von Monika Streissler. Tübingen. $285 \mathrm{Pp}$.

Ruiz, S. 1996. Plan de Ordenamiento Territorial para la Unidad Agroforestal del PLUS (AF) al norte de los municipios de Santa Rosa y San Carlos. Prefectura del departamento de Santa Cruz/ PRODISA/Consorcio IP/ CES/KWC. Santa Cruz, Bolivia. 87 Pp.

Salm y Maconi (eds.) 1992. Reserva Nacional Amazónica Manuripi-Heath. Programa de Reestructuración (Fase II). LIDEMA, CORDEPANDO PL480. La Paz, Bolivia. pp. 147-195.

Stahl, J. 2002a. Rationalities in Cavineño Livelihood Strategies. A Case Study from the Bolivian Amazon. Magisterarbeit. Institut für Völkerkunde. Albert-Ludwigs-Universität, Freiburg. (No publicado).

Stoian, D. 2000. Variations and dynamics of extractive economies: the rural-urban nexus of non-timber forest use in the Bolivian Amazon. Dissertation presented at Freiburg University, Germany. 
SIF (Superintendencia Forestal). 1997. Proceso de conversión al régimen de Concesiones: Departamento de Pando. (Informe Técnico no publicado). SIF (Superintendencia Forestal). 1998-2001. Estadistas de Instrumentos aprobados en propiedades privadas para las gestiones 1998-2001. Cobija, Bolivia. (Informes Técnicos no publicado).

SIF (Superintendencia Forestal). 2002. Informe Anual de la Superintendencia Forestal Gestión 2001: Indicadores de cumplimiento: Santa Cruz, Bolivia. Julio 2002.

Torrez, C. 1930. Las maravillosas tierras del Acre - En la floresta amazónica de Bolivia - Colegio Don Bosco, La Paz, Bolivia. pp. 246-300 


\section{Capítulo 3}

\section{La nueva administración de tierras y bosques en el norte amazónico boliviano}

Sergio Ruiz

\section{INTRODUCCIÓN}

En el marco de la política boliviana de desarrollo sostenible aplicada a partir de mediados de los años 1990, la Ley Forestal y Ley INRA constituyen instrumentos fundamentales para modernizar el manejo de los recursos naturales. La Ley Forestal de julio de 1996 sustituyó al Decreto Ley Forestal de 1974, mientras que la Ley INRA de octubre de 1996 sustituyó la Ley de Reforma Agraria de 1956.

Los cambios están concentrados a eliminar graves errores del pasado, como la ausencia estatal en el control y recaudación de ingresos por el uso de los recursos naturales, la duplicidad de funciones en el otorgamiento de derechos de propiedad y los altos niveles de corrupción al interior de las instancias públicas. Al mismo tiempo, con el proceso de saneamiento de la tierra, la Ley INRA propone regular y perfeccionar el derecho de propiedad sobre la tierra.

La reforma de 1996 abre espacios para que los usuarios tradicionales del bosque compartan con las grandes empresas forestales el manejo comercial de los bosques, a través de las figuras legales como las Asociación Social del Lugar (ASLs), Tierras Comunitarias de Origen (TCOs) y Propiedades Comunales, estas últimas en el caso del área de estudio pueden superan las 500 hectáreas por familia (Ruiz, Capítulo 2). 
No obstante, ante la débil experiencia aplicando leyes nacionales en el norte amazónico boliviano, queda la incertidumbre sobre la implementación de los contenidos de las nuevas leyes, debido a que su entorno normativo estuvo históricamente caracterizado por la presencia casi exclusiva de fuertes arreglos institucionales privados, entre los cuales sobresalen los derechos tradicionales expresados en el "sistema de las barracas"1 y el "sistema de habilito"2 que se encargaron de estructurar las relaciones sociales y económicas en el uso de los recursos naturales.

El área de estudio incluye el norte amazónico boliviano, compuesto por el departamento de Pando, la provincia Vaca Diez del departamento del Beni y la parte norte del municipio de Ixiamas, ubicado en la provincia Iturralde del departamento de La Paz. ${ }^{3} \mathrm{Al}$ mismo tiempo, en el análisis sobre escenarios futuros, la presente investigación se enfoca en el municipio de Bolpebra, ubicado al noroeste del departamento de Pando, donde el proceso de saneamiento de la propiedad agraria se encuentra más avanzado.

En el norte amazónico boliviano habitan al rededor de 170,000 personas, cuya actividad económica está fuertemente influenciada por el uso y la industrialización de los productos forestales, sobresaliendo la extracción de castaña (Bertholletia excelsa), palmito (Euterpe precatoria) y la explotación de especies maderables. Desde 1992 Bolivia se ha convertido en el principal exportador de castaña procesada a nivel mundial, actividad que provee fuentes de trabajo a más de 18,000 personas de áreas rurales y urbanas de la región (Stoain 2000:284).

Este capítulo analiza la base de datos sobre tenencia de la tierra del Instituto Nacional de Reforma Agraria, ${ }^{4}$ compuesta por 2,717 expedientes registrados. Esta información cubre los años 1957-2001. En esta se provee información sobre nombre del titular del predio, nombre del predio, estado del trámite en que se encuentra, fecha de titulación, clase de propiedad, instancia encargada del registro, superficie en hectáreas del predio registrado e información adicional del predio. Para su interpretación y análisis se utilizó el programa de Microsoft Excel. Se complemento esta información con entrevistas a representantes de diferentes grupos de interés regional y con las observaciones directas de campo entre agosto de 2001 a junio del 2002.

El presente capítulo está dividido en cuatro partes: La primera examina las consecuencias directas de la aplicación de la Ley INRA, la segunda parte analiza las consecuencias directas de la aplicación de la Ley Forestal sobre la asignación de los títulos de propiedad agrarios y derechos de uso forestal. La tercera parte interpreta las consecuencias colaterales, actuales y a futuro de la aprobación de las leyes en estudio. Y por último, la cuarta parte formula algunas conclusiones en base de este análisis. 


\section{TITULACIÓN DE TIERRAS CON LA LEY DE REFORMA AGRARIA Y LA LEY INRA}

Durante la Reforma Agraria de 1956, fueron distribuidas en el país 46.8 millones de hectáreas de tierras a 652,626 beneficiarios. El $47 \%$ de estas tierras quedaron en manos de campesinos y colonizadores, mientras que el $53 \%$ quedo en poder de medianos y grandes propietarios (Lavadenz 1997, citado en Urioste y Pacheco 1998). El impacto de la Reforma Agraria de 1956 en el norte amazónico boliviano fue prácticamente nulo (Salm y Marconi 1992). En los departamentos del Beni y Pando la reforma benefició a quienes antes de 1956 ya eran propietarios de grandes extensiones de tierra (Ormachea 1987). El Censo Agropecuario de 1984 muestra que 84 grandes empresas abarcaban más de un millón de hectáreas en la región, lo que hace suponer que varios barraqueros superaban las 50,000 hectáreas. Los campesinos con propiedades menores a 500 hectáreas ocupaban un área de 220,000 hectáreas (Ormachea 1987).

La Reforma Agraria no pudo ser implementada en favor de las comunidades rurales; la administración nacional era caótica y profundamente corrupta. Además, la región estaba regida por otro tipo de régimen institucional, contradictorio a los contenidos legales. Durante el apogeo del caucho gran parte del territorio regional estuvo bajo el control de grandes empresarios, quienes impedían la intervención estatal. Los títulos ejecutoriales o los contratos de aprovechamiento de madera dispuestos por ley no contaban con ningún valor real. De facto era "el patrón" quien ejercía su derecho sobre el terreno, gozando o no de aprobación pública.

El primer título entregado en el norte amazónico data de 1959. Hasta el inicio oficial del saneamiento de tierras en todo el área de estudio, el último título entregado por el INRA fue en junio del 2001. Durante estos años se entregaron 1,189 títulos ejecutoriales. Aproximadamente el 63\% de todos los títulos sobre la tierra fueron distribuidos en la década de 1990, especialmente durante el gobierno de Jaime Paz Zamora (19891993). La mayoría de ellos fueron distribuidos entre 1990-1992, es decir hasta la intervención del Consejo Nacional de Reforma Agraria (CNRA). ${ }^{5}$ Durante este periodo se calcula que el $10 \%$ de la superficie analizada fue oficialmente titulada (ver Gráfico 3.1 y Tabla 3.1).

\section{El registro de las barracas}

Los rangos de superficie estipulados por la Ley de Reforma Agraria de 1956 para la empresa agraria en la región tropical abarcan de 500 a 2,000 ha y de 2,500 a 50,000 ha en el caso de empresas ganaderas que tengan más de 10,000 cabezas de ganado (Ley de la Reforma Agraria, 1956: art. 17 y 21) 
Gráfico 3.1. Títulos otorgados en el norte amazónico por periodo

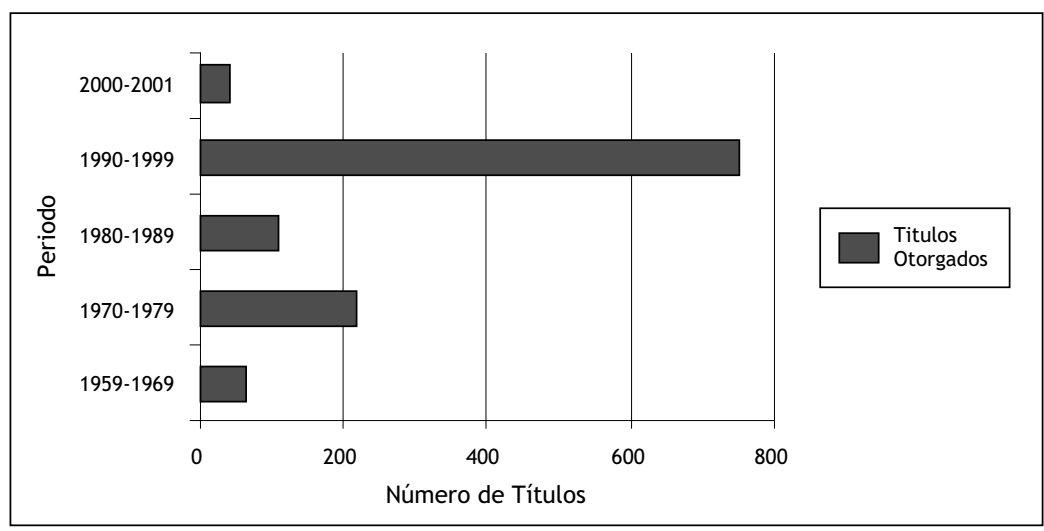

Tabla 3.1. Número de predios y superficie titulada en el departamento de Pando, en la provincia Vaca Diez y en el municipio de Ixiamas

\begin{tabular}{|c|c|c|}
\hline \multirow{2}{*}{$\begin{array}{l}\text { Clase de } \\
\text { Propiedad }\end{array}$} & \multicolumn{2}{|c|}{ Área total analizada } \\
\hline & No. Predios & Área (ha) \\
\hline Empresa & 60 & 577,783 \\
\hline Mediana propiedad & 319 & 183,818 \\
\hline Pequeña Propiedad & 774 & 86,916 \\
\hline Propiedad Comunal & 22 & 93,534 \\
\hline TCO & 3 & 410,182 \\
\hline Sin clase de propiedad & 13 & 31,847 \\
\hline$\overline{\text { Total }}$ & 1,191 & $1,384,080$ \\
\hline
\end{tabular}

Fuente: INRA Registro de expedientes sobre propiedades agrícolas 1957-2001

Estas extensiones han sido asumidas por la nueva Ley INRA hasta que el poder ejecutivo establezca nuevas disposiciones para cada zona (Ley INRA, 1996: Décima disposición final). Desde el punto de vista legal, las grandes superficies de las barracas solamente pueden ser categorizadas y obtener títulos como empresas agropecuarias.

La primera de estas empresa titulada en el departamento de Pando fue Conquista en el año 1968. Entre 1990 y 1992 se tituló aproximadamente el $65 \%$ del total de las barracas en la región. En Pando, en el año 1992 se titularon 18 de las 26 empresas. Hasta inicios de 2001, el 61\% de la superficie titulada en Pando estaba en manos de 26 empresarios, abarcando una superficie aproximada de 200,000 hectáreas. Si se relaciona esta superficie con los 3 millones de hectáreas estimadas bajo dominio barraquero a inicios del 2000 (Orduna 2000:1), se concluye que aproximadamente el 7\% de la superficie ocupada por las barracas tenían títulos de propiedad. 
Debido a la gran superficie que manejaban estos establecimientos productivos, se estima que ninguna de las barracas tituladas aprovechó la superficie total ocupada. Dentro de los registros analizados, un tercio de los empresarios obtuvieron títulos ejecutoriales en superficies mayores a las 5,000 hectáreas. La mayoría de los barraqueros recibieron títulos ejecutoriales en base a sus colocaciones o centros gomeros, ${ }^{6}$ que en promedio no superaban las 2,500 hectáreas. Para acceder a mayor cantidad de tierra titulada, los barraqueros acostumbraban a tramitar varios títulos ejecutoriales en base a sus centros gomeros, que para efectos legales se asignaban bajo diferentes nombres a miembros o parientes de su misma familia.

Con la aprobación del nuevo régimen agrario se redujo drásticamente la titulación de propiedades empresariales. De los 58 predios medidos en los polígonos 3 y 10 del departamento de Pando, tres predios corresponden a la categoría "empresa mediana ganadera"; un predio de 309 hectáreas a la categoría "empresa mediana agrícola" y un predio de 21,352 hectáreas a la categoría "empresa ganadera".

A falta del reconocimiento público de sus derechos y a consecuencia de los conflictos sociales emergentes en la región, en los últimos cinco años muchas de las barracas comenzaron a desaparecer. Por ejemplo, de las barracas originalmente tituladas se han transformado en comunidades rurales: Conquista (3,100 ha), Exaltación (2,409 ha), Corpus (2,177 ha), El Chive (39,487 ha) Campeones (3,321 ha), Canadacito (3,169 ha), etc. ${ }^{7}$

\section{El registro de tierras comunales}

Según los datos analizados, la primera Propiedad Comunal en el norte amazónico boliviano data de 1960 (Comunidad Campesina Libertad). La segunda comunidad campesina en la región titulada por el CNRA fue en 1974. Hasta el año de intervención del CNRA, este organismo había entregado 12 títulos comunitarios que abarcaban una superficie aproximada de 62,000 hectáreas, donde el $70 \%$ de la superficie correspondía a la comunidad Alto Ivon $(43,300$ hectáreas). Con la implementación del saneamiento de tierras, el proceso de distribución de tierras comunitarias se aceleró fuertemente (ver Gráfico 3.2).

La actual gestión del INRA se ha limitado a otorgar derechos de propiedad sobre la tierra a pequeñas propiedades (25), comunidades campesinas (10) y Tierras Comunitarias de Origen (3). ${ }^{8}$ La superficie titulada por el INRA como Propiedad Comunal abarca 441,346 hectáreas. Esta nueva política originó que el 32\% de las áreas tituladas desde 1960 correspondan a propiedades comunales. La superficie de las tres TCOs titulados representa cerca del 30\% de la superficie titulada hasta el 2001. 
Gráfico 3.2. Superficie titulada en Pando, Vaca Diez e Ixiamas según Instituto y Clase de Propiedad

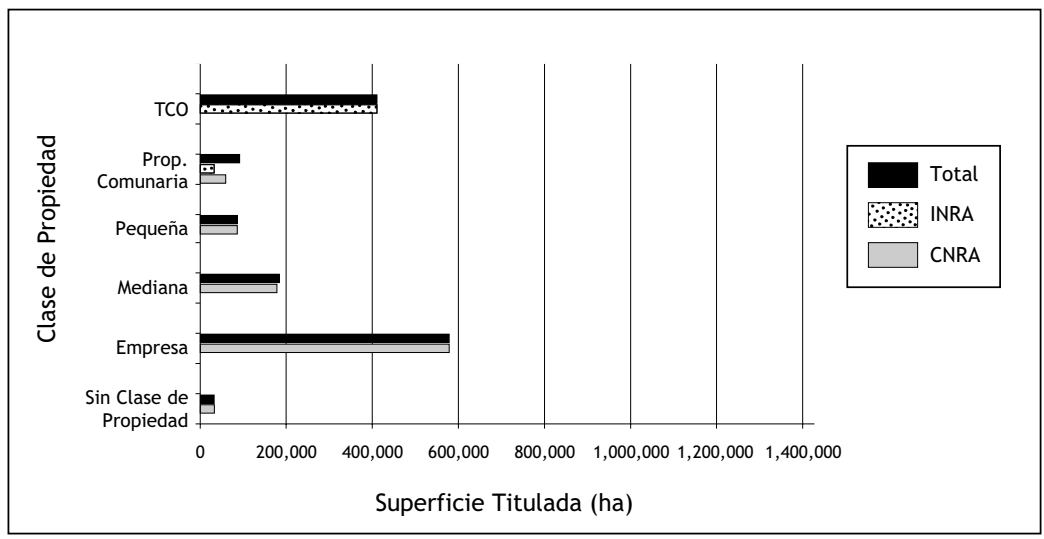

Fuente: INRA Archivo de registros de propiedades agrícolas de 1957-2001

Según proyecciones analizadas hasta el año 2004 en el caso de las comunidades campesinas, la Ley INRA multiplicará por ocho la superficie titulada en los 40 años de vigencia de la Reforma Agraria. Estas proyecciones incluyen los datos de cuatro de los 13 polígonos de saneamiento más desarrollados en el departamento de Pando.

La categoría menos privilegiada desde el punto de vista de superficie es la Pequeña Propiedad que abarca 86,916 ha, correspondientes a 774 predios titulados. La mayoría de los predios distribuidos bajo esta clasificación fueron otorgados por el CNRA. De los 25 títulos otorgados como Pequeña Propiedad y que abarcan 1,560 hectáreas, el $80 \%$ corresponde a la subcategoría "pequeña propiedad agraria" y el $20 \%$ restante pertenece a la subcategoría "pequeña propiedad ganadera".

Analizando el caso concreto del municipio de Bolpebra, se concluye que la reforma ha mejorado sustancialmente el acceso de las comunidades rurales a tierras. Hasta la fecha, en el municipio de Bolpedra el INRA ha titulado una comunidad campesina (San Pedro de Bolpebra) y una TCO (Yaminahua-Machineri), que en conjunto abarcan 27,766 hectáreas. En la actualidad se encuentran en proceso de trámite 39 predios saneados, 8 de los cuales corresponden a "comunidades campesinas", 17 a "pequeñas propiedades agrarias", 12 a "pequeñas propiedades ganaderas" y 2 a "medianas propiedades ganaderas". Si se llegan a consolidar todos estos trámites, el $52 \%$ del municipio estaría bajo derechos de propiedad comunal, el $3 \%$ de la superficie municipal pertenecería a propietarios individuales y el $45 \%$ quedaría como área fiscal (Gráfico 3.3). 
Gráfico 3.3. Escenarios a futuro de la distribución de los derechos agrarios en el municipio de Bolpebra

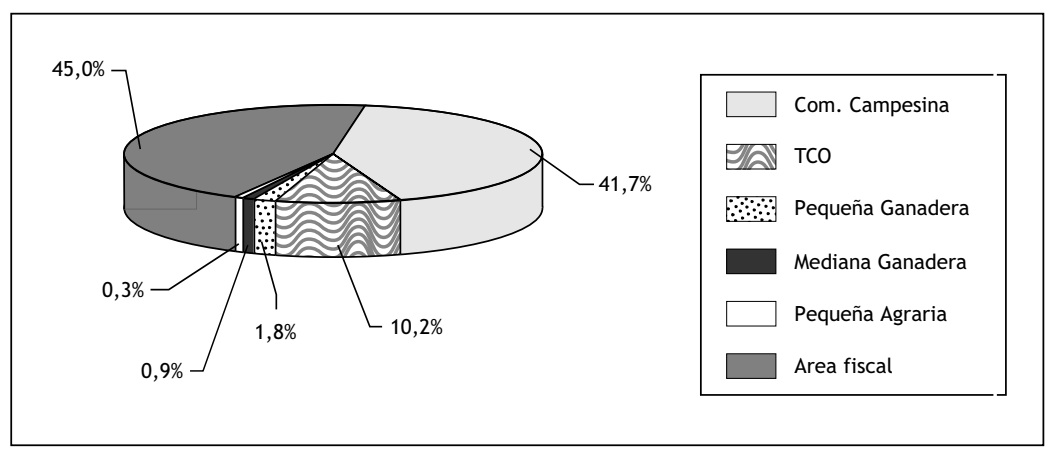

Fuente: INRA 2002: Informe de Resultados Polígono 3 (Bolpebra)

\section{LA ASIGNACIÓN DE ÁREAS FORESTALES BAJO CONCESIÓN}

\section{Reducción de concesiones forestales}

En la actualidad son las empresas forestales las que realizan principalmente el aprovechamiento de madera de los bosques en el norte de Bolivia, a través de concesiones forestales, aunque la Ley Forestal no margina a usuarios individuales o comunales a través de permisos de aprovechamiento sobre sus propiedades agrarias.

Con la aprobación del Plan Soberanía (1993), ${ }^{9}$ el gobierno boliviano permitió el establecimiento de empresas forestales en la región, ignorando incluso la vigencia del decreto de la Pausa Ecológica, que prohibía nuevos contratos de corte por un periodo de 5 años (1990-1995). En 1994 se calcula la existencia de 2,139,579 hectáreas bajo manejo forestal, 1,923,896 de ellas fueron otorgadas a 19 contratos de aprovechamiento a largo plazo (20 años) y 215,683 hectáreas bajo la modalidad de contratos de aprovechamiento único. Esta superficie forestal se redujo a la fecha en un $45 \%$, en dos diferentes periodos: La primera reducción, es el producto directo de la implementación de la nueva Ley Forestal, que convirtió los contratos de corte a largo plazo en 19 concesiones forestales, sobre una superficie de 1,533,967 hectáreas. Esta reducción significa el $60 \%$ del total de la superficie analizada entre los años 1994 y 2003. Las empresas que gozaban de áreas bajo aprovechamiento único desaparecieron, mientras que todas las empresas con contratos de aprovechamiento a largo plazo optaron en convertirse a concesiones forestales. Algunas mantuvieron sus superficies originales (Empresa Sagusa), otras decidieron aumentar (Empresa Cimagro) y otras por reducir (Empresa Mineros Pando y Empresa San Martín, SIF 1997). 
La segunda reducción que significa el restante $40 \%$, resulta de la presión social que ejercen actualmente otros grupos de interés hacia las áreas forestales y está en relación directa con el saneamiento de las tierras. Este proceso casi concluido en el municipio de Bolpedra, reveló la superposición de derechos de propiedad agraria con las cuatro concesiones forestales del municipio. Hasta inicios del año 2002, cerca del $65 \%$ de la superficie del municipio había sido distribuida a 4 concesiones forestales. Luego del saneamiento se redujo el área de aprovechamiento forestal de las empresas Dajer (95\% con superposición), Don Víctor (50\% con superposición) e Imapa (29\% con superposición) (INRA 2002). El $40 \%$ de la superficie bajo concesión en 1997 en el municipio fue transferido a otros usuarios. Por las mismas razones la empresa Aguilar S.A. ha renunciado a la totalidad de su concesión (34,900 hectáreas) (SIF 2002:6).

\section{Aumento de aprovechamiento en propiedades privadas}

Contrario a lo que ocurre con la reducción del área de las concesiones forestales, el aprovechamiento del bosque en propiedades privadas se incrementó paulatinamente en los últimos cuatro años. La reforma ha aumentado las expectativas de los usuarios del bosque sobre el aprovechamiento forestal dentro de sus predios. La SIF respondió a estas expectativas, cediendo permisos de aprovechamiento forestal en propiedades privadas, incluso sin que estos cuenten con títulos sobre sus tierras. La SIF actuó de esta manera porque: a) esperaba aumentar el control sobre el manejo forestal en la región; b) también esperaba aumentar el ingreso por pago de las patentes forestales; y, c) con esta medida se esperaba fomentar el manejo sostenible de los bosques de la región.

Tabla 3.2. Instrumentos de gestión forestal aprobados en Pando bajo la figura de propiedades privadas

\begin{tabular}{|c|c|c|c|c|c|}
\hline \multirow[b]{2}{*}{ Año } & \multicolumn{2}{|c|}{ Pando } & \multicolumn{2}{|c|}{ Bolivia } & \multirow[b]{2}{*}{ Observaciones } \\
\hline & $\begin{array}{l}\text { Inst. } \\
\text { Aprob. }\end{array}$ & $\begin{array}{c}\text { Área } \\
\%\end{array}$ & $\begin{array}{l}\text { Inst. } \\
\text { Aprob. }\end{array}$ & $\begin{array}{c}\text { Área } \\
\%\end{array}$ & \\
\hline 1998 & 12 & $\begin{array}{r}2,229 \\
2.7 \%\end{array}$ & 21 & 80,938 & $\begin{array}{l}\text { Los datos de Pando sólo incluyen los } \\
\text { PMF menores a } 200 \text { ha. }\end{array}$ \\
\hline 1999 & 50 & $\begin{array}{r}9,154 \\
8.6 \%\end{array}$ & 143 & 106,348 & $\begin{array}{l}\text { Los datos de Pando sólo incluyen los } \\
\text { PMF menores a } 200 \text { ha. }\end{array}$ \\
\hline 2000 & 34 & $\begin{array}{l}6,800 \\
17.0 \%\end{array}$ & 150 & 39,879 & $\begin{array}{l}\text { Los datos de Pando sólo incluyen los } \\
\text { PMF menores a } 200 \text { ha. }\end{array}$ \\
\hline 2001 & 47 & $\begin{array}{r}18,557 \\
16.9 \%\end{array}$ & 130 & 109,913 & $\begin{array}{l}\text { Los datos de Pando incluyen los PMF } \\
\text { menores a } 200 \text { ha y los Planes Operativos } \\
\text { Anuales Forestales mayores a } 200 \text { ha. }{ }^{10}\end{array}$ \\
\hline
\end{tabular}

Fuente: SIF- Cobija: Estadísticas de Instrumentos aprobados en propiedades privadas (1998-2001); SIF 2002: Informe Anual de la gestión 2001 
La Tabla 3.2 muestra la evolución de superficie de aprovechamiento forestal en propiedades privadas. En el año 2001 aumentó 8 veces en relación al año 1998. Los aumentos son significativos en cuanto a la cantidad de hectáreas bajo manejo forestal y a los porcentajes que dichas superficies representan a nivel nacional. Hasta el año 2001 el porcentaje de hectáreas manejadas como propiedades privadas se ha estabilizado en un $17 \%$ del total nacional. Se estima que con los Planes de Manejo Forestal (PMFs) aprobados en Riberalta este porcentaje puede llegar a un $25 \%$ del promedio nacional. Desde 1998, el $32 \%$ de todos los instrumentos de gestión forestal (especialmente PMF) aprobados a nivel nacional fueron realizados en Pando. Este dato es importante sobretodo si se consideran las fuertes limitantes técnicas (13 funcionarios) y financieras de la SIF en este departamento.

\section{CONSECUENCIAS DE LA NUEVA ADMINISTRACIÓN DE RECURSOS FORESTALES}

\section{Ámbito administrativo}

Las leyes analizadas forman parte del paquete de políticas de descentralización boliviana, en la transferencia de poderes y responsabilidades para la gestión de los recursos naturales. El proceso de descentralización boliviano, a través de la aprobación de las leyes de Participación Popular y Descentralización Administrativa, no dieron a instancias locales ninguna nueva función explícita relacionada con el manejo de los recursos naturales (Pacheco 2002), pero sirvieron de plataforma para ejecutar las reformas en el manejo de los recursos naturales. Aquí, la Ley Forestal incorpora de mejor manera que la Ley INRA los niveles de administración local, al reconocer el papel de los gobiernos municipales en la gestión del bosque. Específicamente, a nivel local se establece el modelo de las Asociaciones Sociales del Lugar (ASLs) y la recaudación de fondos destinados a ejecutar acciones de fiscalización y control de los recursos forestales. Para este efecto las municipalidades reciben el $25 \%$ del total de las patentes forestales ubicadas en su municipio.

Esta interacción entre la Ley de Participación Popular y la Ley Forestal se puede denominar como "sinergia institucional", donde el producto de las normas en sinergismo es mucho mayor que el resultado de cada una de ellas por separado. Otro ejemplo de sinergia institucional es el reconocimiento en la Ley de Participación Popular de los asentamientos rurales como Organizaciones Territoriales de Base (OTB). Esta denominación le dio estatus legal a un gran número de asentamientos rurales de la región como comunidades campesinas e indígenas, que permitió posteriormente la implementación de la Ley INRA y sus propuestas de distribución de tierras. Sin la base institucionalizada por la Ley de Participación Popular, titular las comunidades campesinas no hubiera sido 
posible. A ello puede añadirse también la figura del "aprovechamiento forestal en propiedades privadas", permitida por la Ley Forestal, en los nuevos asentamientos con estatus de comunidad campesina. Todo este paquete normativo dirigido a las comunidades rurales garantiza y acelera la ejecución de los objetivos planteados por la reforma.

Algunos de los efectos negativos de la implementación de la Ley INRA en la región, son por ejemplo la reducción del pago de la patente forestal. Los más afectados son los gobiernos municipales, que debido al reducido número de habitantes por municipio, perciben bajos ingresos de la coparticipación tributaria. ${ }^{11}$ En muchos de los casos el dinero de las patentes forestales constituye el único ingreso que permite a los municipios realizar inversiones en infraestructura socioeconómica o contratar personal especializado. Los municipios de Bolpebra, Ingavi, Nueva Esperanza y Santos Mercado, en el año 1999 recibieron más dinero por concepto de pago de las patentes forestales que por concepto de la coparticipación tributaria (Entrevistas a varios Técnicos de las Unidades Forestales Municipales). En el caso de Bolpebra, en el mismo año, las patentes forestales representaron hasta un $60 \%$ del total de los ingresos estatales que percibió el municipio. Si se añade la reducción por el pago de la patente forestal establecido por Decreto Supremo 27024, ${ }^{12}$ a partir de la gestión 2003, Bolpebra tendrá que renunciar a una buena parte de sus ingresos municipales.

Otro aspecto que disminuirá los ingresos municipales en el futuro una vez que los gobiernos municipales cuenten con un sistema de catastro rural, es la disposición que favorece a las propiedades comunales, el solar campesino y a la pequeña empresa a no pagar impuestos sobre la tierra. ${ }^{13} \mathrm{En}$ el caso del Municipio de Bolpebra únicamente se encuentran dos propiedades sujetas al pago de impuestos agrarios.

El hecho de entregar grandes superficies de tierra a título de propiedad comunal, puede también significar en el futuro la pérdida de la hegemonía estatal sobre la asignación, control y fiscalización de los recursos forestales, en caso que estos sean mal manejados. Al mismo tiempo esto significa el aumento de las exigencias de capacidad técnica y financiera de las organizaciones públicas con presencia local, como la SIF, el INRA y los gobiernos municipales. A falta de un control y asesoramiento estatal, serán las organizaciones no gubernamentales (ONGs) quienes sigan ganando espacios y responsabilidades.

\section{Ámbito social}

La administración descentralizada de los recursos forestales ha creado nuevas oportunidades para los usuarios locales del bosque (indígenas, colonos, campesinos y pequeños extractores de madera) (Pacheco 2002:4). 
En el norte amazónico boliviano se confirma que el acceso al bosque por parte de los campesinos e indígenas ha contribuido a fortalecer las raíces de los habitantes de las áreas rurales hacia sus territorios tradicionales. Así se contribuye también a disminuir la presión de la población rural hacia las grandes ciudades. Este logro es significativo para la región, si se considera que ciudades como Cobija y Riberalta, debido al flujo migratorio campo-cuidad contemplan altas tasas de crecimiento poblacional muy por encima de la media nacional (Llanque, Capítulo 9).

La descentralización en Bolivia ha debilitado la posición de concesionarios, hacendados y propietarios ausentistas (Pacheco 2000). En el caso del área de estudio esta afirmación tiene mayor importancia si se considera que hasta hace unos 10 años, los barraqueros y empresarios forestales ejercían sus derechos en base a la imposición de sus propias reglas de juego. El debilitamiento paulatino del "imperio de las barracas" ha originado que las fuerzas de poder se desplacen a favor de otros grupos sociales. La complejidad en las relaciones de poder no permiten llegar a conclusiones más específicas, sin embargo no debe descartarse el hecho de que las condiciones de negociación han mejorado significativamente en favor de los indígenas y campesinos.

Por otro lado, la actual redistribución de los recursos forestales está dejando de lado a un importante grupo de usuarios tradicionales, "los barraqueros". Especialmente los pequeños y medianos son los que cumplen tareas fundamentales dentro de las actividades extractivas regionales y muchos de ellos subsisten bajo las mismas características socioeconómicas que las comunidades rurales (dependencia del bosque para subsistir y difícil acceso a infraestructura socioeconómica). Este sector carece actualmente de seguridad jurídica, que resulta en la pérdida considerable de superficies boscosas.

Una causa indirecta de los cambios institucionales ha sido acentuar las diferencias entre intereses opuestos, que conllevan al origen de conflictos sociales. El conflicto social más agudo de los últimos años en el norte amazónico lo protagonizan los barraqueros contra las comunidades rurales de indígenas y campesinos. No sería justo atribuir la presencia de estos conflictos a la reforma. Sin embargo, la reforma ha servido como una válvula de escape que refleja las relaciones sociales existentes desde el momento mismo de la colonización del norte amazónico.

\section{Ámbito económico}

Los derechos de propiedad en teoría, contribuyen a estimular las inversiones y posibilitan el crecimiento económico. En el caso de los hogares rurales pobres, la propiedad es de particular importancia, principalmente 
para tener acceso a fuentes de financiamiento. Sin propiedad adecuada no es posible hipotecar la tierra, aunque sean personas productivas y estén en capacidad de involucrarse en actividades económicamente rentables (Bardham et al. 1998). No obstante la Ley INRA protege a las comunidades rurales y no les permite entrar en el mercado de tierras. El argumento utilizado es que bajo las actuales circunstancias de inequidad social y polarización con otros grupos de poder económicamente más fuertes el libre comercio de tierras aumentaría esta desigualdad (Urioste y Pacheco 1998:10).

Se prevé, que la mayoría de la superficie otorgada con título de propiedad en la región se otorgará bajo la categoría de "propiedad comunal", lo que podría provocar en primera instancia un estancamiento del mercado formal de tierras. Al limitarse las transferencias de compra y venta se estaría afectando también la creación de flujos económicos dentro de la región. En este sentido, el contar con título de propiedad pero no ser sujeto directo de crédito u otro tipo de transferencia no cumple los requisitos básicos para impulsar la economía regional.

Una situación similar que induce al estancamiento de la economía regional, se origina porque los miembros comunales no pueden excluir a otros miembros de disfrutar los beneficios de su propio esfuerzo. Debido a estas externalidades las familias rurales no se encontrarán lo suficientemente incentivadas para utilizar sus recursos de forma eficiente o para invertir. El impedir que los recursos mal manejados sean transferidos a usuarios de bosques más competitivos podría provocar también efectos negativos en la conservación de los recursos naturales.

Respecto a las inversiones ejecutadas en la región, la extracción de PFNMs se ha caracterizado por tener bajos niveles de inversión dentro de las barracas, pero alcanzan importantes niveles dentro de la industria de la castaña, donde se verifican inversiones de capital de alrededor de los US\$12 millones en 1998 (Bojanic 2001:62). Estas cifras pueden disminuir a falta de acceso al crédito por parte de las comunidades rurales, o por la pérdida considerable de tierras de los "empresarios forestales", cuyas barracas constituían la principal fuente de abastecimiento de materia prima para sus beneficiadoras. La consecuencia inmediata para la economía regional sería la reducción de fuentes de trabajo directo de la industria de la castaña que fueron estimadas para el año 1998 en 22,000 personas (Bojanic 2001:62).

Un factor positivo es que la redistribución de recursos forestales contribuirá a que los hogares rurales se incorporen con mejores condiciones al mercado regional de productos forestales. Por una parte mejorarán sus ingresos económicos, específicamente con la venta de madera 
y castaña, y por otra influirán en la oferta y demanda de los mismos, obligando así a los empresarios a pagar precios más justos por los productos recibidos.

\section{Ámbito ambiental}

A pesar que la nueva reforma se enmarca en la política del Estado boliviano de desarrollo sostenible, el contenido de la Ley Forestal, no profundiza verdaderamente en la conservación de los bosques. La formulación de la Ley se concentra en establecer las pautas para un manejo comercial de los bosques, ateniéndose a las disposiciones sobre conservación de los bosques estipuladas en el capítulo quinto de la Ley del Medio Ambiente. Principalmente se critica la ausencia de fuertes sanciones o incentivos para que los usuarios forestales se enmarquen en un sistema de manejo sostenible. También se critica que los mecanismos de control y fiscalización se atienen a la capacidad de "débiles" organizaciones gubernamentales, sin mayor participación y responsabilidad de los actores sociales.

En el norte amazónico se observa ya que la gran mayoría de los grupos de interés entrevistados (representantes de ONGs, de instancias gubernamentales o usuarios directos del bosque) no asumen tareas relacionadas con la conservación de los bosques. Si bien el grave problema del norte amazónico no es la deforestación, ${ }^{14}$ el manejo de los recursos naturales está lejos de considerarse como sostenible, siendo dos las actividades que amenazan este sistema: por un lado, las actividades de caza y pesca de la fauna silvestre y por el otro la tala ilegal de la madera.

La primera actividad está íntimamente relacionada con el periodo de zafra de la castaña, pero también tiene que ver con la dependencia que han creado los habitantes de la región con el bosque para asegurar su alimentación, sobretodo en comunidades menos vinculadas con los centros de abastecimiento (Antezana et al. 2001:37). Por ejemplo, durante la zafra de castaña, anualmente se desplazan al bosque aproximadamente 8,000 personas, entre zafreros, contratistas, transportistas, cargadores, etc. (Bojanic 2001, Stoian 2000). Entre los meses de diciembre a marzo, la mayoría de estas personas dependen de los animales silvestres como fuente de proteína para su alimentación, por ser una alternativa barata de alimentación. Las especies más amenazadas son los animales de mayor porte como son los primates (Cebus spp, Alouatta spp.) y los ungulados (Mazama spp, Tayassu spp y Tapirus spp).

Respecto a la tala ilegal de la madera, esta acelera la pérdida de las características biológicas de los bosques. En la provincia Vaca Diez por 
ejemplo, esta actividad se practicaba desde los años 1980 bajo la categoría de aprovechamiento único. El maderero compraba los árboles de su interés en las parcelas de las comunidades rurales o solicitaba al CDF permisos para cortar árboles de bosques fiscales (Beekma et al. 1996:37). En la actualidad la venta de árboles sigue siendo una importante fuente de ingresos para los hogares de las áreas rurales. Aunque muy pocos admiten la venta de madera a terceras personas sin PMF aprobado, en las entrevistas efectuadas a siete diferentes unidades productivas, ${ }^{15}$ todos los titulares declararon vender por lo menos una vez madera con fines comerciales. Además, en todos los establecimientos se ha declarado que especies como la mara (Swietenia macrophylla) y el cedro (Cedrela odorata) son difíciles de encontrar comenzando la sobreexplotación de otras especies como el tumi (Ambaruna cearensis), mara macho (Cedrela catenaeformis), cuta (Astronium fraxinifolium), ibauba (Mezilauus itauba) y tabijo (Tabebuia sp).

Ambas actividades se ven favorecidas por la debilidad de los acuerdos institucionales privados, y a corto plazo se prevé que estas normas sociales no serán discutidas ni mejoradas en el afán de proteger la sobreexplotación de los recursos naturales, sobretodo dentro de las propiedades comunales.

\section{CONCLUSIONES}

En resumen, hay dos procesos en evolución en el norte amazónico. Mientras la presión al acceso de los bosques disminuye a través de la consolidación de los derechos forestales, aumentan al mismo tiempo las expectativas de propiedad sobre la tierra de los usuarios del bosque amazónico. Por lo tanto dada la importancia y el protagonismo de la Ley INRA en la región, cualquier acción política, técnica o científica dirigida a evaluar el acceso, distribución y manejo de los bosques debe involucrar necesariamente el análisis de ambos regímenes. La estrecha vinculación legal entre la Ley INRA y Ley Forestal en la distribución de derechos de propiedad desaparece al formularnos la pregunta, si las nuevas regulaciones cuentan con los mecanismos necesarios para evitar la degradación de los recursos y fomentar la conservación de los bosques, en caso que las actividades agropecuarias demuestren mayor rentabilidad que las actividades forestales actuales.

Si bien, la aplicación de la reforma mejorará considerablemente la seguridad jurídica de los usuarios del bosque amazónico, no garantiza la reducción de conflictos sociales, el crecimiento económico regional, ni se compromete con la sostenibilidad de los bosques. Bajo estas circunstancias no debe extrañar que en el futuro los acuerdos institucionales privados sigan ganando espacio en regular las interrelaciones entre individuos en el manejo de los recursos forestales. 
Contrario a lo que podría ocurrir en otras regiones de Bolivia, y en contraposición a la idea de muchos otros autores que argumentan la discriminación de los campesinos e indígenas al acceso de los recursos naturales, en el norte de Bolivia la redistribución de recursos naturales está favoreciendo a los grupos de campesinos e indígenas de la región. Esto se puede observar claramente en el caso del municipio de Bolpebra, donde el $52 \%$ del municipio quedará bajo derechos de propiedad comunal, otorgados a nueve comunidades campesinas y una TCO. Este nuevo escenario provocó la reducción del $60 \%$ de la superficie originalmente distribuida a tres concesiones forestales.

No debe subestimarse la reducción de los ingresos municipales por concepto del pago de las patentes forestales o de los impuestos a la propiedad agraria. Los regímenes agrario y forestal fueron elaborados para mejorar el control sobre el uso de los recursos naturales por parte de las organizaciones públicas y por ende para fortalecer el proceso de descentralización administrativo. Uno de los principales problemas de la aplicación de la reforma en la región sigue siendo la escasa participación de los gobiernos municipales, quienes al momento carecen de medios técnicos y financieros para cumplir sus funciones. Los fondos que reciben por la participación popular no son suficientes. Sin fuentes de financiamiento adicionales dirigidas al sector del manejo y conservación de los recursos naturales el impacto de la reforma podría ser muy cuestionado.

En teoría, la nueva administración de los recursos forestales contribuye a la conservación de los recursos naturales (Diaz 1999). En el caso del proceso de degradación de los recursos forestales del norte amazónico boliviano, no sólo la otorgación de títulos ejecutoriales sobre la tierra servirá para mejorar esta situación. Las políticas nacionales deben orientarse básicamente a reducir los altos índices de pobreza ${ }^{16}$ de las poblaciones rurales; a generar fuentes de trabajo alternativas al comercio de la castaña y madera y a reconocer la existencia de acuerdos institucionales privados que determinan el manejo de los bosques. Por otro lado, se espera que las normas estatales aprobadas contribuyan a fortalecer los hasta ahora débiles acuerdos institucionales privados en favor de la conservación de los recursos forestales.

\section{NOTAS}

${ }^{1}$ Existe un sinnúmero de definiciones sobre el término Barraca. En el marco del presente documento se entiende la barraca como la unidad económica productiva central del "régimen barraquero", y ha sido reconocida bajo normas de derecho tradicional como espacio destinado al aprovechamiento de los recursos forestales, principalmente de goma y castaña. 
${ }^{2}$ El habilito es un sistema de pago por adelantado con el objeto de financiar todo tipo de actividades de aprovechamiento forestal, principalmente la extracción de productos forestales no maderables. La variación más simple consiste en que el zafrero o recolector recibe dinero por adelantado del barraquero para trasladarse al bosque, recolectar y entregar el producto al precio acordado con anterioridad (Bojanic 2001:87).

${ }^{3}$ Por la disponibilidad de información y la dificultad que representa distinguir los predios al interior del municipio de Ixiamas que pertenecen a la región del norte amazónico, el análisis de la presente investigación incorpora a toda la circunscripción del municipio, a pesar de que los límites geográficos consideran únicamente la parte norte del mismo dentro de la región norte amazónica boliviana.

${ }^{4}$ La base de datos que contiene los expedientes del antiguo Consejo Nacional de Reforma Agraria (CNRA), fue oficialmente publicada en la página Web del INRA en enero de 2003.

${ }^{5}$ El CNRA y el INC fueron intervenidos el 24 de noviembre de 1992 (Hernáiz y Pacheco 2001:21).

6 Una colocación o centro gomero se considera como sub-unidad de producción al interior de una barraca.

${ }^{7}$ www.inra.gov.bo/PortalINRA/DesktopModules

${ }^{8}$ A las dos TCOs ubicadas en la zona de estudio, se adiciona la TCO Araona ubicada en el municipio de Ixiamas.

${ }^{9}$ Este plan cedío grandes superficies forestales a empresas nacionales a lo largo de los límites internacionales con los países de Brasil y Perú. El objetivo principal fue resguardar el patrimonio de los recursos naturales ante el aprovechamiento furtivo efectuado por habitantes extranjeros. Aproximadamente un $20 \%$ de la superficie corresponde a espacios de compensación a empresas forestales que cedieron sus espacios de aprovechamiento en los bosques de producción Chimanes.

${ }^{10}$ En el año 2001 se aprobaron 34 Planes Operativos Anuales (POA), a cuenta de la elaboración del PMF en superficies mayores a las 200 ha. Esta política fue aprobada en abril del 2000 , en razón que los usuarios del bosque fraccionaban sus predios buscando únicamente las manchas boscosas, a fin de adecuarse a la modalidad de "propiedades privadas menores de 200 ha", desvirtuando el espíritu del manejo forestal sostenible (SIF, 2000: Resolución 44/2000).

${ }^{11}$ Las recaudaciones anuales del Estado, son distribuidas a los 314 municipios del país teniendo en cuenta el total de habitantes por Municipio.

${ }_{12}$ El decreto aprobado el 6 de mayo del 2003 establece que el pago de la patente forestal se calcule sobre la base única de la superficie total productiva de manejo anual, más el costo de la Tarifa de Regulación Forestal (TRF) que llega a US\$4 ha/año. Según Llanque et al. (2003) con esta nueva norma las empresas forestales reciben una subvención del 75\% para el pago de sus derechos de uso del bosque. 
${ }^{13} \mathrm{El}$ argumento utilizado para liberar del pago de impuestos a las clases de tierras mencionadas, es la condición de extrema pobreza de las poblaciones rurales (Urioste y Pacheco 1998:22).

${ }^{14}$ Según informe de DHV (1993) el norte amazónico boliviano presenta una superficie desboscada total de 211,600 ha, es decir aproximadamente el 2.5\% del área total (DHV 1993 citado en Beekema et al. 1996:54). Según datos del Plan de Uso de Suelo de Pando (1996), este departamento cuenta con una cobertura boscosa del 94\%. Entre 1985 y 1990, la tasa de deforestación anual de Pando fue de 4,789 ha/año, concentrándose en la provincia Nicolás Suárez. Esta cifra se encuentra muy por debajo de las tasas de deforestación anual registradas en Bolivia (168,012 ha) o Santa Cruz (203,400 ha) para los últimos siete años (Camacho et al. 2001: Sección III y IV).

15 Las siete unidades productivas que conforman los tres estudios de caso en el marco del estudio de doctorado son: barraca, comunidad campesina, comunidad indígena, ASL, concesión forestal, habitantes brasileros y propietario privado.

${ }^{16}$ La región se clasifica como la segunda más pobre de Bolivia, después de Potosí, con un nivel de pobreza que supera el 70\% de la población asentada en Pando. Por ejemplo, cuatro de sus cinco provincias registran una pobreza mayor al 90\% (INE 2002).

\section{REFERENCIAS}

Antezana, M. et al. 2001. Seguridad Alimentaria en Pando: Aprovechamiento de los recursos naturales en la alimentación de los pobladores de Pando. PIEB/Universidad Amazónica de Pando/CIPA. La Paz, Bolivia. pp. 37-55

Bardham, P. et al. 1998. Wealth Inequality, Wealth Constraints and Economic Performance. University of Massachusetts, Amherst.

Beekma, J. et al. 1996. Base ambiental para el desarrollo del departamento de Pando y la provincia Vaca Diez. Servicio Holandés de Cooperación al Desarrollo. pp. 36-54

Bojanic, A. 2001. Balance is beautiful: Assessing sustainable development in the rain forests of the Bolivian Amazon. PROMAB Scientific Series 4. 255 Pp.

Camacho, M. et al. 2001. Tasa de deforestación del departamento de Santa Cruz, Bolivia (1993-2000).BOLFOR/Superintendencia Forestal. Santa Cruz, Bolivia.

Diaz, D. 1999. Landrechte und Waldnutzung im semiaride Chaco Argentiniens. Dissertation. Forstwissenschaftliche Fakultät der Albert-Ludwigs-Univerität Freiburg. $258 \mathrm{Pp}$.

Hernáiz, I. y Pacheco, D. 2001. La Ley INRA en el espejo de la Historia. Propuestas de modificación. Fundación TIERRA. La Paz, Bolivia. 116 Pp.

INE (Instituto Nacional de Estadística). 2002. Censo Nacional de Población y Vivienda 2001. Distribución de la población por municipios. La Paz, Bolivia. 
INRA (Instituto Nacional de Reforma Agraria). 1957-2001. Registros de expedientes sobre propiedades agrícolas para el departamento de Pando, la Provincia Vaca Diez y el Municipio de Iximas. La Paz. www.inra.gov.bo/ PortalINRA/DesktopModules/ (consulta en Enero 2003).

INRA (Instituto Nacional de Reforma Agraria). 2002. Informe de Resultados Polígono 03 (Bolpebra). Unidad de Saneamiento 0142/2002. Pando. (Sin Publicar).

INRA (Instituto Nacional de Reforma Agraria). 2002. Informe de Resultados Polígono 10 (Rapirrán). Unidad de Saneamiento 0396/2002. Pando. (Sin Publicar).

Llanque, 0. et al. 2003. Patente forestal boliviana: Crisis crónica de financiamiento. II Reunión anual sobre investigación forestal. Del 9 al 11 de agosto de 2003. Cochabamba, Bolivia.

Orduna, V. 2000. Empresarios piden la mitad del departamento en concesiones forestales: Pando empieza donde termina la Ley. Tierra a Debate. www.ftierra.org. (consulta en abril 2000).

Ormachea, 1987. Beni y Pando: Latifundio y Minifundio en el Norte Boliviano. Centro de Estudios para el Desarrollo Laboral y Agrario (CEDLA). La Paz, Bolivia. pp. 25-77.

Pacheco P. 2000. Avances y desafíos en la descentralización de la gestión de los recursos forestales en Bolivia. CIFOR/BOLFOR. Santa Cruz, Bolivia.

Pacheco P. 2002. Contribuye la descentralización a mejorar la gestión forestal?. Las lecciones aprendidas del caso boliviano. CIFOR/BOLFOR/USAID. Bogor, Indonesia. $10 \mathrm{Pp}$.

Salm y Maconi (ed). 1992. Reserva Nacional Amazónica Manuripi-Heath. Programa de Reestructuración (Fase II). LIDEMA, CORDEPANDO PL-480. La Paz, Bolivia. pp. 147-195.

Stoian, D. (2000): Shifts in forest product extration: The Post-rubber era in the Bolivian Amazon. International Tree Crops Journal, 2000, Vol. 10, pp. 277-297

SIF (Superintendencia Forestal). 1997. Proceso de conversión al régimen de Concesiones: Departamento de Pando. (Informe Técnico no publicado).

SIF (Superintendencia Forestal). 1998-2001. Estadistas de Instrumentos aprobados en propiedades privadas para las gestiones 1998-2001. Cobija, Bolivia. (Informes Técnicos no publicado).

SIF (Superintendencia Forestal). 2002. Informe Anual de la Superintendencia Forestal Gestión 2001: Indicadores de cumplimiento: Santa Cruz, Bolivia. Julio 2002.

Urioste, M. y Pacheco, D. 1998. Bolivia: Mercado de tierras en un nuevo contexto (Ley INRA). Fundación Tierra. http://www.ftierra.org/ docs_trabajo.htm. (consulta en abril 2001). 


\title{
Capítulo 4
}

\section{Participación política de comunidades forestales en el norte amazónico boliviano}

\author{
Carmen Gottwald
}

\section{INTRODUCCIÓN}

Uno de los principales temas en el debate actual sobre desarrollo es la relación que existe entre el uso local de los recursos y su potencial papel en el alivio de la pobreza. La falta de capacidad para atender adecuadamente esta relación explica parcialmente el fracaso de los esfuerzos por mejorar el nivel de vida de las comunidades rurales. Muchos países latinoamericanos han seguido procesos democráticos y de descentralización en las últimas dos décadas. Estos procesos han conllevado cambios en la legislación que afectan la tenencia de tierra y el uso de los recursos forestales, afectando directamente a las poblaciones rurales dependientes de los bosques.

Este capítulo analiza cómo es percibido el proceso de cambio y la descentralización legislativa por habitantes de áreas rurales en el norte amazónico boliviano. El capítulo examina cómo los habitantes de áreas rurales se reorganizan para atender sus intereses, como resultado de este proceso político de transformación. Este capítulo registra la percepción del cambio en reglas informales y organización social en dos comunidades rurales en el norte amazónico boliviano, cómo las percepciones de los cambios legales y sus implicaciones difieren entre las dos comunidades. Las reglas informales así como la organización social juegan un papel importante en el uso local del bosque en comunidades rurales en esta región. 
La población rural del norte amazónico boliviano vive en unas 500 comunidades o como trabajadores en barracas ${ }^{1}$ (Stoian 2000: xii). Este estudio escogió dos comunidades: San Juan kilómetro 27 y Trinidadcito. En ambos la extracción de PFNMs juega un papel importante (Stoian y Henkemans 2000). En San Juan km 27 la agricultura tiene una importancia moderada, igual que la extracción de castaña. En Trinidadcito las familias cosechan un promedio anual de 104 cajas de castaña. Ambas comunidades tiene una diferencia histórica marcada en el uso de la tierra.

Para este capítulo, se consultó la literatura para obtener información sobre la historia de la región, y los cambios legales de la última década. Para seleccionar las comunidades se entrevistó a expertos bolivianos y se consultó las bases de datos preparadas por Stoian y Henkemans (2000) y por CIPCA Norte (2001). El trabajo de campo se realizó entre octubre del 2001 y junio del 2002. Se utilizó cuestionarios estandardizados y entrevistas semi- estructuradas. Adicionalmente se participó en reuniones comunales.

La siguiente sección proporciona información sobre la región y la nueva legislación que afecta a las comunidades de la región en el uso de los recursos forestales. Siguen los resultados del trabajo de campo, una discusión de los resultados y conclusiones.

\section{INFORMACIÓN DE FONDO}

La economía en comunidades rurales en el norte amazónico boliviano se basa principalmente en la extracción agrícola para el autoconsumo y en la extracción de castaña para la exportación. La crianza de ganado y extracción de oro juegan un papel secundario en la economía regional, mientras que la extracción de madera juega un papel cada vez más importante (Bojanic 2001). Hoy muchas comunidades recolectan castaña (Bertholletia excelsa) como su principal actividad económica. Los pobladores recolectan castaña en sus territorios comunales, o participan en la recolección, contratados por los dueños de las barracas. La mayoría los dueños no tiene título oficial sobre los bosques que explotan.

El auge en la recolección de los PFNMs se inició a finales del siglo XIX. La explotación de los recursos forestales era supervisada por los patrones, quienes controlaban grandes áreas de bosque. Aunque el sistema de patrones ha cambiado en la actualidad, las huellas del viejo sistema feudal se mantiene debido a las estructuras previamente mencionadas y a las relaciones sociales. La figura de comunidades campesinas como una manera de apropiación espacial coincide con la crisis del sistema extractivista tradicional. La élite económica controló la producción del caucho (Hevea brasiliensis) por medio de un control absoluto de la tierra, de la producción, 
del trabajo, de los mercados, y del suministro interno. Esta organización empezó a desintegrarse con la caída de los precios del caucho a inicios del siglo XX, terminando durante la década de 1940. Los minifundistas se instalaron en áreas de bosque no reclamadas en barracas abandonadas (Assies 1997: 44).

La Reforma Agraria de 1953 otorgó a los pobladores de comunidades forestales el acceso a un área forestal con dos estradas de caucho por familia. Sin embargo, muy pocos lograron obtener el título legal para sus tierras (DHV 1993e: 81). Tradicionalmente, las comunidades se establecían por ríos (Assies 1997: 45). En el presente, las comunidades independientes se establecen principalmente a lado de caminos (Stoian 2000: 188). Este proceso se ha llevado a cabo por varias décadas y ha aumentado a finales de la década de 1980 como resultado de las mejoras en los caminos.

\section{La nueva legislación que afecta las economías forestales en el norte amazónico boliviano}

La Reforma Agraria de 1953, propuso la abolición de los latifundios y las relaciones feudales entre patrones y campesinos. La ley propuso una redistribución de la tierra. Sin embargo, en la actualidad, una distribución equitativa de la tierra, agua y bosques no ha sido posible (Urioste y Pacheco, sin fecha). En la actualidad al igual que en la década de 1990, el caos y la corrupción gobernaron la administración y la distribución de la tierra en Bolivia. Dos agencias, el Consejo Nacional de Reforma Agraria y el Instituto Nacional de la Colonización tienen a su cargo la entrega de títulos de propiedad en áreas rurales. El 18 de octubre de 1996 se firmó una nueva Ley de Servicio Nacional de Reforma Agraria $\left(\mathrm{N}^{\circ} 1715\right)$, conocida como Ley INRA. Esta ley fue promulgada para resolverse la distribución inadecuada de la tierra en el país y tiene vigencia hasta el 2006. La ley demanda un proceso completo de saneamiento, o de todas las actividades técnicas y judiciales necesarias para la regulación y consolidación de derechos de propiedad. La ley también demanda una redistribución de la tierra.

La ley distingue seis tipos de propiedad agraria. Reconoce la tierra en posesión de comunidades campesinas y comunidades indígenas. Este último como Tierras Comunitarias de Origen (TCOs). Los derechos que campesinos e indígenas tienen sobre sus tierras son muy limitados. No se permite vender, alquilar o hipotecar estas tierras. Urioste y Pacheco (sin fecha) creen que estas restricciones no llevarán necesariamente a una asignación más transparente de la tierra, debido a que dependen en gran parte de factores económicos, poderes políticos y corrupción. A dos años de terminar el proceso de saneamiento, este se encuentra muy retrasado. 
La nueva Ley Forestal 1700, aprobada en julio de 1996, establece que el bosque de Bolivia pertenece al Estado, donde no existe título de propiedad privada. Bajo la nueva ley, las concesiones forestales son ofrecidas al sector privado por un proceso de subasta pública. La nueva Ley Forestal establece concesiones para comunidades locales e indígenas. Además define la figura legal de Agrupación Social de Lugar (ASL) reconociendo sus derechos a la explotación de áreas boscosas bajo concesión. Los grupos locales pueden organizarse llegando a ser reconocidos como ASLs y obtener derechos de concesión forestal. Los grupos indígenas pueden hacer lo mismo dentro de sus TCOs. La Ley Forestal especifica que el $20 \%$ de la tierra del área forestal dentro de un municipio se puede convertir en reserva forestal municipal. Estas reservas pueden ser dadas en concesión a las ASLs. La nueva Ley Forestal sugiere un alto compromiso en el manejo forestal sostenible y desarrollo. Se reconoce como usuarios del bosque a los grupos locales importantes, y no sólo a las empresas madereras. En la práctica, sin embargo, el lento avance en el proceso de saneamiento es un obstáculo para la implementación de la Ley Forestal. Sin un proceso terminado sobre la propiedad de tierras forestales, los municipios no pueden entregar tierras forestales en concesión a las ASLs. Los grupos locales, al igual que las empresas forestales, tienen que preparar Planes de Manejo Forestal (PMFs), antes de aprovechar la madera. De hecho, actualmente se vende mucha madera para la cual no existe ningún plan de manejo. Generalmente, las comunidades venden madera ilegalmente o dependen de planes de manejo preparados por alguna ONG o empresa forestal. En el último caso, la empresa gana la primera opción de comprar la madera (Hentschel, Capítulo 5).

La Ley de Participación Popular (LPP), aprobada en abril de 1994, introduce descentralización a nivel municipal. Con la Ley de Descentralización Administrativa, aprobado en julio de 1995, las estructuras administrativas se complementaron para esta descentralización a nivel departamental. La Ley de Participación Popular ha permitido la municipalización del país, delegándose autoridad y responsabilidades importantes a los gobiernos municipales. Este cambio en la autoridad y responsabilidades fue acompañado de una redistribución de los fondos públicos hacia los municipios. Los municipios reciben un porcentaje del presupuesto nacional en proporción a sus habitantes, también reciben un porcentaje de los impuestos recaudados por el aprovechamiento de los recursos naturales en su territorio.

La LPP institucionalizó la participación de los ciudadanos en la toma de decisiones en la administración municipal. La LPP reconoce el carácter organizativo de las poblaciones rurales, y su papel en la administración municipal. Reconoce a las Organizaciones Territoriales de Base (OTBs). La OTB es la unidad territorial más pequeña en la jerarquía nacional del 
gobierno. Una OTB en la mayoría de los casos representa una comunidad rural. Según la LPP, ciudadanos locales tienen la oportunidad de influir en el proceso de toma de decisiones respecto a la asignación de los recursos financieros del municipio y control sobre la implementación de las decisiones. Los representantes de todas las OTBs dentro de un municipio eligen a los miembros del Comité de Vigilancia. Cada municipio propone un Plan de Desarrollo Municipal (PDM) a cinco años, y un Plan Operativo Anual (POA). Cada OTB tiene la oportunidad de hacer propuestas y demandar la realización de ciertos proyectos dentro de un proceso participativo. El municipio tiene que incluir estos pedidos en su plan operacional y priorizar la distribución del presupuesto. El Comité de Vigilancia supervisa la realización del plan y la ejecución del presupuesto.

\section{Las comunidades de investigación}

La comunidad de San Juan km 27 es una comunidad agro-extractiva (Stoian 2000) con un área comunal de 3,400 ha, ubicada en la provincia Vaca Diez del departamento del Beni. Localizada cerca del centro urbano de Riberalta y en el camino de Riberalta a Cachuela Esperanza, la comunidad contaba con 30 familias durante el periodo de investigación. La tierra comunal se divide en lotes forestales individuales que no sólo se utilizan para la extracción de PFNMs, sino también para otros usos forestales y agrícolas. Los primeros colonizadores llegaron a la comunidad a inicios de los años 1970.

Trinidadcito es una comunidad extractiva de la provincia de Madre de Dios, departamento de Pando, con un área por definir de 6,000 a 8,500 ha. Se encuentra lejos de cualquier centro urbano, y en la temporada lluviosa sólo accesible después de viajar uno a varios días por barco, en la temporada seca se puede ingresar con moto. La comunidad de 60 familias extrae PFNMs en bosques de propiedad comunal. Los chacos agrícolas se trabajan individualmente. Trinidadcito fue el centro de una barraca hasta 1972 cuando se independiza como comunidad.

\section{RESULTADOS}

\section{El conocimiento de las leyes}

Para que las comunidades rurales se vean beneficiadas de las nuevas oportunidades creadas por el Estado, es necesario que los pobladores sean informados. No podemos suponer, por ejemplo, que el contenido de las nuevas leyes son transmitidas fácilmente a los pobladores. Esto especialmente en ciertas áreas remotas, donde el Estado no tiene presencia y los pobladores no tienen acceso a la información fácilmente. Esto puede implicar que nuevas obligaciones legales no sean aceptadas, 
porque no son conocidas o porque no concuerdan con las reglas o condiciones locales.

Para identificar cómo los pobladores de San Juan km 27 y Trinidadcita estaban informados sobre la nueva legislación, se pidió a los entrevistados mencionar una o más leyes de las cuales habían escuchado. Cerca del $50 \%$ de los entrevistados no pudo mencionar ninguna. Trinidadcito tuvo un porcentaje más alto de entrevistados informados que San Juan km 27 (Figura 4.1). Los entrevistados que indicaron no saber sobre las leyes eran en su mayoría mujeres, mientras que los hombres estaban mejor informados.

Figura 4.1. Conocimiento de las leyes en dos comunidades en el norte amazónico de Bolivia

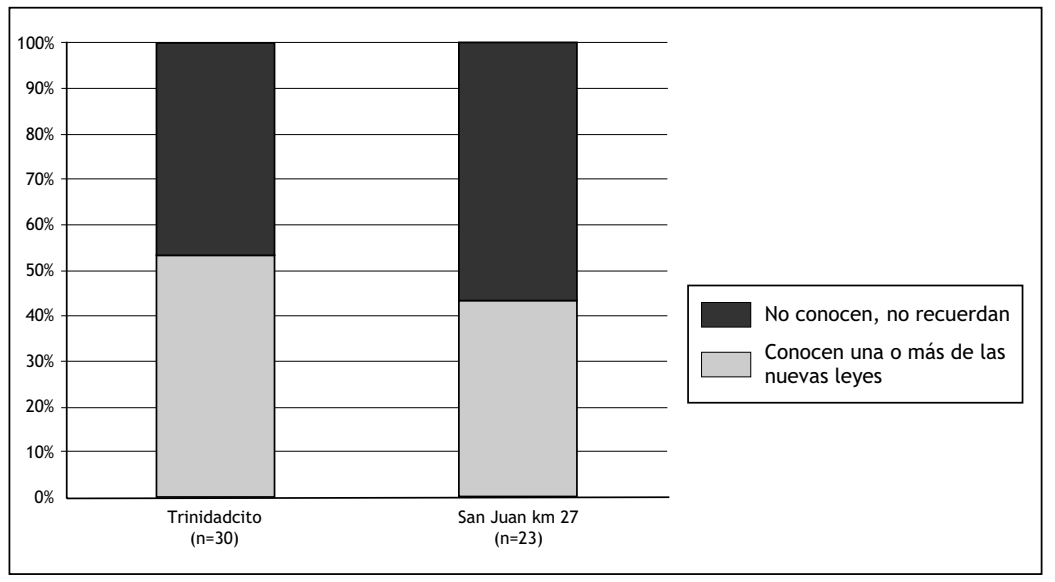

\section{La percepción de las leyes}

Se pidió a los entrevistados que podían mencionar una o más leyes evaluarlas. No todos fueron capaces de proporcionar una evaluación. La ley más mencionada fue la Ley INRA. En ambas comunidades, todas las evaluaciones directas de la Ley INRA eran positivas (Tabla 4.1). La Ley de Participación Popular se caracterizó como ineficaz porque los políticos no la tuvieron en cuenta en el momento de tomar decisiones. Un entrevistado valoró la Ley de Participación Popular positivamente, porque trajo dinero a la comunidad.

Otras leyes se mencionaron muy raramente durante las entrevistas. Los entrevistados tuvieron la percepción de que la Ley de Municipio causó desacuerdos. La ley de Reforma Educativa fue mencionada, pero recibió 
Tabla 4.1. Evaluación de la Ley INRA

Trinidadcito San Juan Km 27

La Ley INRA es buena por que demarca

7 3

los linderos de la comunidad, y asegura los derechos de propiedad

La ley INRA es buena por que no se puede vender la tierra

una evaluación mixta. Dos entrevistados respondieron positivamente sobre la Ley Contra la Violencia Intra Familiar 1674, porque creó una base legal para actuar contra cualquier persona que utiliza la violencia contra niños, mujeres u hombres. Sólo un entrevistado de San Juan $\mathrm{km} 27$ y uno de Trinidadcito mencionaron la Ley Forestal, pero no hicieron comentarios.

Se preguntó si habían experimentado algún cambio dentro de la comunidad o sus vidas como resultado de las nuevas leyes (Tabla 4.2). Si un entrevistado mencionaba una nueva ley, se le pedía mencionar los cambios asociados con esa ley particular. Si el entrevistado no mencionaba ninguna ley, se le preguntaba si había notado cambios en la comunidad durante los últimos años.

Tabla 4.2. Cambios experimentados como resultado de las nuevas leyes

San Juan km 27 Trinidadcito

\begin{tabular}{lrr}
\hline Cambio & $39 \%$ & $63 \%$ \\
No cambios & $9 \%$ & $17 \%$ \\
No expresó su opinión & $52 \%$ & $20 \%$
\end{tabular}

Los entrevistados que no expresaron ninguna opinión (52\% en San Juan km 27 y $20 \%$ en Trinidadcito) eran en su mayoría pobladores que previamente no habían mencionado ninguna ley. En San Juan km 27 los entrevistados atribuyeron cambios exclusivamente como resultado de la Ley INRA, mientras que en Trinidadcito, los entrevistados mencionaron cambios como resultado de la Ley de Participación Popular. Según los entrevistados en San Juan km 27, como resultado del saneamiento las fronteras de la comunidad son ahora claras y los miembros de la comunidad pueden estar seguros del tamaño del territorio comunal. Esto es importante porque San Juan $\mathrm{km} 27$ está situada en altura, las tierras en la comunidad tienen productividad más baja que en otras comunidades de la región y son más apropiadas para el uso forestal. Terminado el trabajo de campo para el saneamiento, la comunidad decidió distribuir la tierra a recién llegados. En medio año, el número de habitantes aumentó en un $50 \%$. Muchos entrevistados consideraron las fronteras de la comunidad como seguras, resultado positivo del saneamiento y de la Ley INRA. Al mismo tiempo, sin embargo, los 
entrevistados se quejaron que ellos no habían experimentado las mejoras personales con respecto al uso de los recursos y la generación del beneficio. La distinción entre la comunidad y el bienestar propio no era un tema en las respuestas de los entrevistados de Trinidadcito. Esto se explica porque Trinidadcito maneja su tierra comunal como un bien común. Algunas mejoras se hicieron en la comunidad como resultado de disponibilidad de recursos por el proceso de descentralización (Ley de Participación Popular y la Ley de Municipalidades), pero también por relaciones personales con personas que son miembros del parlamento nacional y entidades representativas del distrito. Los entrevistados mencionaron que había mejorado la calidad de vida en la comunidad como resultado de la adquisición de un generador eléctrico, radio, teléfono, televisión pública y un edificio escolar nuevo. Además, la comunidad obtuvo un barco comunal para la posta de salud, extendiendo así sus servicios en otras comunidades, y un barco comunal adicional utilizado para transportar y poder vender sus productos agrícolas.

\section{Las percepciones de la representación política}

La cultura política se define como: La preferencia de las personas a una determinada forma para tomar decisiones sobre cómo debe ser gobernada una nación. Es una visión de cómo la gente debe hacer política para el bienestar de un grupo y cómo los responsables deben hacer su trabajo (Anónimo 2001). Se estudió la cultura política de ambas comunidades, preguntando cómo los pobladores perciben que sus intereses personales son considerados en la comunidad a nivel político. Las respuestas no reflejaron qué debe hacer la política, pero sí quiénes, en su opinión, están (o no) haciendo la política para ellos en el presente. Siguiendo los principios de la antropología cognoscitiva, el autor trató de utilizar técnicas de entrevistas y procesos analíticos que resaltan categorías locales de los entrevistados en lugar de imponer un sistema cultural del entrevistador (compara Colby 1996: 211).

En Trinidadcito casi la mitad, y en San Juan km 27 casi la tercera parte de los entrevistados tiene la percepción que nadie representa sus intereses a nivel político. Respuestas como "Políticos, todos mienten" o "Yo lucho por mis intereses" fueron dadas comúnmente a esta pregunta. El segundo grupo de respuestas más comunes, era que un partido específico representaba los intereses de la comunidad en la política. Esta respuesta era más común en Trinidadcito. En esta comunidad, un diputado y un político del distrito, ambos pertenecientes a un partido político, ayudaron a asegurar los derechos de pesca en un lago cercano (fuente de ingresos importante al igual que la castaña) y otros beneficios para la comunidad. Según un entrevistado estos políticos “...compran nuestros votos y nosotros obtenemos lo que queremos". Los habitantes de San Juan km 27 no cuentan con tal apoyo político. 
Figura 4.2. Representación de los interéses políticos (San Juan km 27 y Trinidadcito)

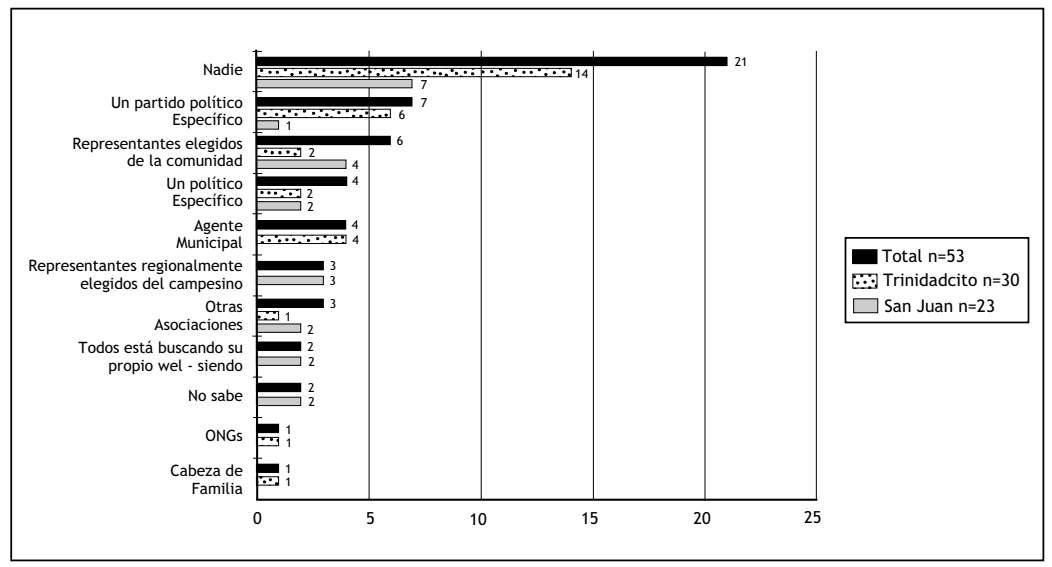

La tercera respuesta más común fue que representantes elegidos de la comunidad representaron los intereses de los pobladores. Los miembros elegidos de la comunidad gozan de legitimidad considerable, especialmente en San Juan km 27 donde la OTB opera como el sindicato de trabajo. Es obligatorio ser miembro del sindicato para todos los adultos de la comunidad, y todos deben participar en las reuniones comunales. En estas reuniones se eligen a los representantes de la comunidad. Los representantes locales de la comunidad fueron mencionados también en Trinidadcito, pero aquí el papel de los miembros de la OTB no se considera tan importante. Los habitantes de Trinidadcito sienten que el agente municipal, quien representa al alcalde del municipio en la comunidad, representa mejor sus intereses. San Juan km 27 no tiene un agente municipal que resida en la comunidad. En ambas comunidades, diferentes políticos fueron identificados como influyentes. En estos casos, los políticos identificados tuvieron alguna relación especial de parentesco o una relación de trabajo con el entrevistado.

\section{La participación en las elecciones}

En Bolivia, es obligatorio por la ley votar en las elecciones municipales y generales. En la elección de representantes comunales cada adulto de la comunidad puede votar, mientras que en la elección municipal participan aquellos que tienen documento de identidad reconocido por el Estado. La participación en elecciones en Trinidadcito es relativamente alta (Tabla 4.3) y puede ser explicada en parte por las buenas relaciones que tiene la comunidad con sus representantes. Muchos políticos, con conexiones en las comunidades, compran los votos de los miembros de la comunidad a 
Tabla 4.3. Nivel de participación en las últimas elecciones

San Juan km 27 Trinidadcito

\begin{tabular}{lll}
\hline Elección de representantes comunales & $47.83 \%$ & $55.33 \%$ \\
Elecciones Municipales & $52.17 \%$ & $70.00 \%$ \\
\hline
\end{tabular}

cambio de proporcionarles documentos de identidad. En el censo de 2001 conducido por CIPCA Norte en 77 comunidades de la región se puede observar que el $44.8 \%$ de la población no es registrada en ningún registro civil, 56.2\% de la población rural no tiene certificado de nacimiento (requisito para obtener el documento de identidad) y el $82.3 \%$ no posee tal identificación. Hay una variación pequeña entre hombres y mujeres en estas cifras.

Se les preguntó a los entrevistados, que votaron en las últimas elecciones, qué criterios utilizaron para decidir por qué candidato votar. En San Juan $\mathrm{km} 27$ una respuesta frecuente fue "voté en blanco, sin hacer una cruz". De esta manera se cumple con el deber ciudadano, sin hacer realmente una selección. En Trinidadcito los criterios para decidir por quién votar fue influenciada fuertemente por candidatos que ofrecían pagos en efectivo a la comunidad si ellos ganaban. Alguna presión parece coincidir con esta práctica, un entrevistado que inicialmente no quería ceder a estas presiones terminó cediendo porque como él indicó personalmente: "nadie quiere tener problemas durante mucho tiempo". Es también una práctica común que partidos manden camiones para llevar a los pobladores a los lugares de votación, o repartan comida y camisetas para que voten por ellos.

\section{Las personas con cargo de oficina}

La posición del líder comunal ya existía desde antes de ser promulgada la Ley de Participación Popular. Sin embargo, las responsabilidades de los líderes comunales han aumentado con esta ley. En San Juan km 27 el $60.87 \%$, y en Trinidadcito el $56.67 \%$ de los entrevistados con cargo fueron elegidos previamente como líder comunal. En general, sólo dos entrevistados en Trinidadcito se habían ofrecido como candidatos. En la mayoría de los casos, otras personas ponen a candidatos para cualquiera de las posiciones en las elecciones de la comunidad. Las razones para aceptar el cargo no son el interés personal ni compromiso político (ver Tabla 4.4).

Sólo dos entrevistados de 31 con cargo de oficina hicieron comentarios positivos sobre su cargo. Un entrevistado comentó: “... siempre tuve la suerte a ser elegido para diferentes oficinas. Yo lo quiero porque uno aprende, puede acumular experiencia y tiene la oportunidad de visitar talleres en Riberalta". El otro dijo que recientemente había empezado a ver los aspectos positivos de esta tarea. 
Tabla 4.4. Comentarios sobre por qué aceptan los cargos públicos comunales

\begin{tabular}{|l|}
\hline Comentarios \\
\hline Si no aceptas, se molestan \\
\hline $\begin{array}{l}\text { Nunca quise, pero cuando me nombraban tenía que aceptar. Si no } \\
\text { aceptas te tratan a la defensiva. Les tienes que complacer. }\end{array}$ \\
\hline $\begin{array}{l}\text { No me gusto la idea, porque no entendí la tarea. Nadie más quiso } \\
\text { hacerlo. }\end{array}$ \\
\hline Ellos querían que yo sea el responsable \\
\hline $\begin{array}{l}\text { Recibí el cargo por recomendación. Primero no lo quise hacer, pero } \\
\text { mi esposo me dijo que tenía que defender los intereses. }\end{array}$ \\
\hline
\end{tabular}

En San Juan km 27, cada miembro adulto de la comunidad debe pagar una contribución mensual al tesoro de la comunidad. Parte de estos fondos va a la Federación Regional de Campesinos, y otra parte es utilizada por la comunidad y para viáticos de los representantes elegidos. Esta contribución es actualmente muy baja, limitando a los representantes cumplir satisfactoriamente su cargo. Por ejemplo, como parte del proceso de saneamiento, cada comunidad tuvo la oportunidad de controlar y verificar sus archivos en la oficina del INRA en Riberalta. Los representantes de San Juan $\mathrm{km} 27$ no pudieron ir debido a la falta de dinero. Los representantes elegidos propusieron incrementar la contribución, pero la mayoría de los pobladores no estuvo de acuerdo con la iniciativa. Los pobladores temían por un mal uso de su dinero y porque no tenían la capacidad económica para afrontarlo.

\section{DISCUSIÓN}

La descentralización en Bolivia respondió a tendencias centrífugas dentro de las capitales departamentales del país, y las tendencias federalistas relacionadas (Grindle 2000: 118, Sánchez de Lozada, 2001 com.per.). El principal mecanismo, para contrarrestar estas tendencias, utilizado por el estado boliviano ha sido promulgar una nueva legislación que redistribuya los poderes y recursos a diferentes niveles del gobierno y a la sociedad civil. Los pobladores en las regiones remotas que anteriormente no eran tomados en cuenta, ahora participan como ciudadanos con derechos y obligaciones. Como consecuencia de estos cambios los pobladores de regiones remotas ahora se encuentran con un conjunto de reglas y mecanismos implementados para los cuales no están acostumbrados.

Para que una nueva legislación sea efectiva, las personas que se benefician de ella, primero deben ser informadas de su existencia, de tal manera que sean capaces de entender su contenido. No deberán tener sólo una 
comprensión vaga de la ley. La medida en la que ciudadanos se conforman con la nueva legislación, y pueden beneficiarse personal o comunitariamente, depende directamente de qué tan enterados estén. Individuos que no son bien informados y que cuentan con información inexacta, se beneficiarán de la nueva legislación sólo por casualidad. Lazarte (2000) en un estudio conducido en nueve departamentos bolivianos mostró los bajos niveles de información o información errónea sobre las organizaciones del Estado en un $86 \%$ de los entrevistados.

Los resultados del estudio muestran que el conocimiento entre pequeñas comunidades respecto a la legislación sobre recursos naturales u organizaciones del Estado es muy bajo. Los entrevistados que tuvieron algún conocimiento sobre las nuevas leyes generalmente las valoran según el impacto directo que tuvieron en su vida dentro de la comunidad. En el caso de San Juan km 27, la Ley INRA fue la ley más conocida. En el caso de Trinidadcito, la Ley INRA así como la Ley de Participación Popular eran conocidas. La Ley Forestal apenas fue mencionada, aunque ambas comunidades dependen de los recursos forestales para su sustento. Posiblemente, su implementación no ha llegado al nivel de la comunidad, o no afecta prácticas actuales de extracción.

Este hecho sugiere la necesidad de más estudios para evaluar las causas y los peligros de este desarrollo respecto a las metas trazadas con la Ley Forestal y las reformas legislativas en general. Se debe considerar que muchas de las comunidades en el norte amazónico boliviano son bastante jóvenes, y sus habitantes en muchos casos viven en relaciones de dependencia con un patrón. Esta situación apenas ha cambiado en muchos lugares (Pacheco, $2001 \mathrm{com}$. pers.). Esta situación contrasta con estándares de la participación efectiva de ciudadanos que requiere: “... una forma de conciencia política que es a la vez crítico de las desigualdades e injusticias existentes $y$, al mismo tiempo, conciente de las promesas de la acción colectiva a lograr la reforma progresiva” (Souza 2001: 165).

Contrario a las percepciones de los entrevistados que los intereses personales se representan pobremente a nivel político, la participación de miembros de la comunidad en elecciones es relativamente alta. Sin embargo, muchas personas participan formalmente en elecciones, pero votan en blanco. Por esta razón, la participación no dice mucho sobre la actividad política verdadera ni la convicción personal. En Trinidadcito, el voto colectivo de la población para un candidato que soborna ha sido una estrategia exitosa para aumentar el desarrollo de la comunidad. Como resultado, por ejemplo, actualmente los pobladores pueden utilizar un barco para llevar sus productos a mercados en un centro urbano. Esto confirma que: "por lo menos la corrupción se ha descentralizado y el dinero llega donde nada llegaba antes - aunque no siempre acaba por donde debe” (Sánchez de Lozada, 2001 
com. pers.). Se tiene evidencia que el efecto de la descentralización se siente en muchos asentamientos rurales, pero en forma muy diferente a la que se pensó cuando la respectiva legislación se decretó. Un fenómeno común es que las estructuras anteriores de poder político y la propiedad se quedan básicamente iguales, pero adoptan una nueva apariencia.

El proceso de saneamiento ciertamente parece requerir un nivel más alto de organización dentro de las comunidades. Esto, sin embargo, no ha tenido como resultado la creación de nuevas posiciones de liderazgo, sino ha generado un aumento de tareas y su complejidad para los líderes locales. El trabajo que realiza la mayoría de estos líderes no es remunerado, y sólo se reconocen los viáticos. Los resultados del estudio demuestran que no podemos asumir que los líderes de las comunidades aceptan su cargo a causa de compromisos personales, aunque esto sea verdad en algunos casos. Básicamente, los representantes de las comunidades deben ser considerados como personas que cumplen un deber esperado por la comunidad. Semejantes condiciones existen por ejemplo en los Andes bolivianos donde cada miembro de la comunidad tiene que cumplir los deberes comunales de liderazgo (Ticona et al. 1995: 82). Estas condiciones aisladamente no pueden asegurar una representación efectiva de la comunidad, aunque cumplen con los estándares de la democracia.

Existe evidencia que una élite política existe o puede evolucionar en las dos comunidades estudiadas. Un grupo selecto de miembros de la comunidad tiene más conocimiento de cómo funciona el mundo exterior, y esta desigualdad de información puede fomentar una élite política. Esto implica un peligro, que los intereses comunales no se representen y los intereses individuales dominen, sin el conocimiento de la comunidad. Aunque los pobladores eligen a sus representantes, no existe suficiente conocimiento compartido y el intercambio de información entre los representantes y la población en general es inadecuado.

El hecho que cada miembro de la comunidad de San Juan km 27 debe aceptar las tareas representativas de la comunidad, se puede percibir como un contrapeso al peligro de que un grupo se aproveche de los cambios políticos. Al mismo tiempo, las deficiencias de información llegan a ser aparentes cuando ciertos individuos toman responsabilidades pero no pueden utilizar el potencial completo de sus posiciones. En Trinidadcito, la representación del interés de la comunidad es ligada a unos pocos individuos. Los miembros de la comunidad tienen sólo influencia indirecta en las actividades de sus representantes. Actualmente, los representantes parecen seguir una estrategia exitosa que favorece a toda la comunidad. Por lo tanto la legitimidad de representantes en Trinidadcito es alta y el efecto de deficiencias en el intercambio de información con la comunidad es relativamente bajo en comparación con San Juan km 27. 


\section{CONCLUSIONES}

El éxito para la descentralización, desde un punto de vista de la gobernabilidad democrática más efectiva y significativa, o desde un punto de vista del desarrollo económico, depende de la generación de respuestas adecuadas de los ciudadanos y de sus representantes a las oportunidades que estas iniciativas ofrecen (Agrawal 1998: 8). Este conjunto de respuestas se puede resumir como participación. Mientras muchos consideran la participación como positiva, hay quienes discuten los riesgos de que actores localmente dominantes socaven el gobierno local, democrático y verdadero, al reforzar su propia posición. Los cambios legislativos en Bolivia que tuvieron el objetivo de descentralización y distribución de los recursos naturales han mostrado efectos diferentes en las áreas rurales. En el norte amazónico boliviano hay un avance notable en el área de derechos legales. Como resultado, los derechos regionales anteriormente controlados por el Estado han sido reemplazados por la presencia de los derechos formales.

Sin embargo, el progreso es lento. Los recolectores forestales independientes que viven en áreas rurales fueron informados sobre la Ley INRA, y valoraron su impacto como positivo. Los entrevistados mencionaron la Ley de Descentralización en menor grado. Esto sugiere que esa implementación y democratización efectiva de procesos de descentralización y devolución requieren mejoras en la transferencia de información del nuevo cambio legal hacia los niveles de base. Esto contribuye al conocimiento de nuevas oportunidades, responsabilidades y derechos, también, una condición (pero no la única) para evitar que una élite local controle el proceso de descentralización, ya que tendrá el control exclusivo de la información.

Adicionalmente al flujo de información, es necesario que el Estado mejore algunos servicios básicos, para evitar que actores externos controlen el proceso de descentralización y distribución. Los políticos que intentan ingresar al municipio o posiciones políticas más altas, contemplan ayudar a los pobladores de áreas rurales para obtener documentación, pero sólo para ganar votos. Aunque este proceso contribuya a la conversión de no-ciudadanos a ciudadanos verdaderos, no sucederá donde no hay ganancia política. Cuando el porcentaje de la población rural es baja en el municipio de Riberalta, donde San Juan km 27 está ubicada, pocos políticos se preocupan en ayudar a personas rurales a obtener, por ejemplo, documentos de identificación a cambio de votos. Esto puede llevar también al descuido político cuando se trata de mejoras más importantes para la población rural: infraestructura, uso del bosque, agricultura o agroforestería. Trinidadcito se encuentra en un municipio rural. Por lo 
tanto, cada voto es de importancia estratégica relativamente más alta para los políticos. Esto ha tenido una influencia positiva en las oportunidades para adquirir apoyo en los proyectos de la comunidad.

Ambas comunidades se encuentran bajo el mismo sistema legal. Sin embargo, las circunstancias y diferencias a nivel comunal traen como consecuencia una asignación de los recursos diferente. Tienen en común que la mayoría de sus habitantes cree que nadie representa sus intereses a nivel político. Esto explica por qué los habitantes de las dos comunidades todavía no se sienten parte de un Estado donde ellos pueden ejercer sus derechos a la representación o participación democrática. Estos pobladores ven al Estado como un agente externo. Los que ven sus intereses representados, nombran a personas con quien tienen un contacto personal, o a personas que muestran su presencia física en la comunidad. Este resultado muestra que la percepción del Estado incluye sólo instituciones del Estado, las organizaciones y los cargos políticos a nivel administrativo más alto. Los habitantes de comunidades rurales en el norte amazónico boliviano no se consideran como parte de los actores en el medio político. Esto contrasta con la influencia de campesinos y representantes indígenas a nivel regional y nacional. La sociedad civil en el norte amazónico boliviano muestra las mayores diferencias relacionadas a su interacción e impacto. Mientras que algunos grupos organizados con un mandato rural negocian en temas políticos, la mayoría de los habitantes rurales todavía no son parte de una sociedad civil. La participación política en las áreas rurales en el norte amazónico boliviano, como se describe aquí, aumenta, pero de manera lenta.

\section{NOTA}

${ }^{1}$ Coincidimos con la definición de Ruiz, (Capítulo 2): La barraca es la unidad económica productiva central del "régimen barraquero", y ha sido reconocida bajo normas de derecho tradicional como espacio destinado al aprovechamiento de los recursos forestales, principalmente goma y castaña.

\section{REFERENCIAS}

Agrawal, A. 1998. Decentralization and Development. Departamento de Ciencias Sociales Universidad de Yale, New Haven.

Anonymus. Sin fecha. Final Report on the Workshop: Decentralization and Social Policies in Latin America. www.idrc.ca/socdev/pub/documents/ quito-e.html.

Assies, W. 1997. Going Nuts for the Rainforest. Non-Timber Forest Products, Forest Conservation and Sustainability in Amazonia. Thela Publishers Amsterdam. 
Bojanic, A. 2001. Balance is beautiful: Assessing sustainable development in the rain forests of the Bolivian Amazon. PROMAB Serie Científica 4. 255 Pp.

CIPCA Norte 2001. Porcentajes de personas que tienen documentos de identidad - comunidades del norte amazónico. Documento no publicado del Centro de Investigación y Promoción del Campesinado, Riberalta.

Colby, B. 1996. Cognitive Anthropology. En: Levison, D. y Ember, M. (eds.) Encyclopedia of Cultural Anthropology 1., New York, pp. 209-214.

DHV 1993. Tenencia de la Tierra en la Región Castañera de la Amazonía Boliviana. Proyecto de Desarrollo Agropecuario, Banco Mundial/Gobierno de Holanda, Bolivia.

Flores, G. 1999. La Ley INRA de Bolivia: ¿una segunda reforma agraria? www.fao.org/WAICENT/FAOINFO/SUSTDEV/SPdirect/LTan0033.htm.

Grindle, M.S. 2000. Audacious Reforms. Institutional Invention and Democracy in Latin America. Johns Hopkins University Press, Baltimore.

Lazarte R.J. 2000. Entre dos mundos. La cultura política y democrática en Bolivia. Plural / microcosmos, La Paz.

Ribot, J.C. 2002. Democratic Decentralization of Natural Resources. Institutionalizing Popular Participation. World Resources Institute, Washington D.C.

Souza, C. 2001. Participatory Budgeting in Brazilian Cities: Limits and Possibilities in Building Democratic Institutions. Environment \& Urbanisation, Vol. 13, No. 1.

Stoian, D. 2000. Variations and dynamics of extractive economies: the rural-urban nexus of non-timber forest use in the Bolivian Amazon. Tesis de doctorado Universidad de Freiburg Alemania.

Stoian, D. y Henkemans, A. 2000. Between extractivism and peasant agriculture: Differentiation of rural settlements in the Bolivian Amazon. International Tree Crops Journal, Vol.10. pp. 299-319.

Ticonas, E., Rojas, G. y Albó X. 1995. Votos y Whipalas. Campesinos y pueblos originarios en democracia. Fundación Milenio, CIPCA, Cuadernos de Investigación 43, La Paz.

Thévoz, L. Decentralization in Bolivia: A model under Construction. www1.worldbank.org/wbiep/decentralization/ciesin/bolivdecentr.pdf.

Urioste F. de C., Miguel y Diego Pacheco, sin fecha. Bolivia: mercado de tierras en un nuevo contexto (Ley INRA). Fundación Tierra. www.cepes.org.pe/coalition/Paises/Bolivia/Cas_Bol/Document/ Mcdo\%20de\%20tierras\%20nuevo20contexto.htm 


\title{
Capítulo 5
}

\section{El uso del bosque comunitario bajo el nuevo régimen forestal}

\author{
Gunther Hentschel
}

\section{INTRODUCCIÓN}

La región del norte amazónico boliviano es considerada una de las regiones boscosas más ricas del mundo. En el pasado, el aprovechamiento comercial de la madera en esta región se reducía a un sistema de concesiones forestales de corto plazo, otorgadas bajo mecanismos poco transparentes, de los cuales sólo unas pocas empresas madereras obtenían beneficios. Los derechos de uso de las comunidades rurales no fueron respetados por las empresas madereras y el Estado. La reforma estatal llevada a cabo a mediados de los años 1990 intentaba cumplir con las condiciones necesarias para hacer posible una mayor participación de la población rural en los procesos políticos y permitirles el acceso al uso del bosque. Con este trasfondo, la redistribución de tierras y bosque establecida en la Ley Forestal y Ley INRA ${ }^{1}$ proveen oportunidades de desarrollo para las comunidades rurales del norte amazónico boliviano (Ruiz, Capítulo 2).

El objetivo de este capítulo es la identificación de cuáles son los acuerdos adecuados para mejorar la actual situación social y económica de las poblaciones rurales, a través de un aprovechamiento sostenible de los recursos naturales. Este capítulo analizará especialmente el proceso de 
adaptación de una comunidad campesina en el norte amazónico boliviano con relación a los cambios recientes del marco legal del país. Se busca identificar los problemas que se presentan en comunidades campesinas respecto a un escenario a futuro del manejo de bosques comunitarios.

Para fines del presente trabajo se entiende "instituciones" como las normas y reglas que son aceptadas dentro de la sociedad y que por consiguiente coordinan las interacciones sociales entre sus individuos (North 1992:3, Knight 1997:3). Este capítulo se centra en cómo las instituciones al interior de la comunidad estudiada, y las distintas organizaciones externas involucradas, influyen en el proceso de implementación de la Ley Forestal y Ley INRA en la comunidad campesina de Santa María. Se estiman los costos de transacción para medir los obstáculos que tienen las comunidades en cumplir con los artículos de la Ley Forestal. Los costos de transacción que considera el presente capítulo son los gastos que tiene la comunidad para adaptar los lineamientos estatales de la nueva Ley Forestal de Bolivia.

La investigación se elaboró en la comunidad de Santa María, localizada a $20 \mathrm{~km}$ de la ciudad de Riberalta, donde se colectó datos primarios durante los meses de abril y agosto del 2002. Otras fuentes importantes de información fueron las organizaciones regionales que coordinan sus actividades con la comunidad, específicamente en cuanto a la aplicación de la Ley Forestal. Se realizó entrevistas semi-estructuradas, discusiones informales, visitas de seguimiento y observaciones participativas. Los expertos entrevistados se eligieron bajo el criterio de obtener información detallada sobre el proceso de implementación de la Ley Forestal en la comunidad de Santa María. Otros puntos adicionales de apoyo para la investigación fueron las fuentes secundarias, especialmente los textos de la Ley Forestal y Ley INRA y sus respectivos reglamentos. Para una triangulación de los datos obtenidos se realizó de forma complementaria entrevistas informales con expertos, se comparó el material con los resultados de las observaciones cualitativas (sobretodo del bosque de la comunidad y de las reuniones comunitarias), y se incluyeron fuentes secundarias adicionales.

Este capítulo está divido en cinco partes, incluyendo la introducción. La segunda parte discuté la forestería comunitaria bajo el nuevo régimen forestal de Bolivia. La tercera parte analiza en detalle los desafíos de los planes de manejo forestal comunal, que son un requisito para poder aprovechar la madera y otros recursos forestales de territorios comunales. La cuarta sección calcula los costos de transacción que conlleva la elaboración de un plan de manejo forestal comunal, y la última sección discute las implicaciones del análisis presentado aquí formulando recomendaciones. 


\section{LA FORESTERÍA COMUNITARIA BAJO EL NUEVO RÉGIMEN FORESTAL}

La economía en el norte amazónico boliviano se basa en la extracción de castaña (Bertholletia excelsa), en esta actividad participa activamente la población rural y urbana (Bojanic 2001, Stoian 2000). Según encuestas realizadas a ocho familias de la comunidad Santa María, el trabajo en la época de zafra como recolector y la venta de la castaña extraída dentro de la propia comunidad constituyen las principales fuente de ingreso familiar (Tabla 5.1). Otra fuente importante de ingreso es la venta de productos agrícolas, siendo para la comunidad Santa María de especial importancia debido a su cercanía con el mercado de Riberalta. No debe extrañar que la venta de madera se constituya en el rubro menos productivo de la economía familiar (aproximadamente el 5\%), sobretodo en comunidades que gozan de infraestructura de caminos. En lugares como Santa María las especies maderables valiosas han sido casi eliminadas.

Tabla 5.1. Ingreso promedio de ocho familias de la comunidad (US\$/año)

\begin{tabular}{cccccc}
\hline $\begin{array}{l}\text { Venta de } \\
\text { Castaña }\end{array}$ & $\begin{array}{l}\text { Venta de } \\
\text { productos } \\
\text { agrícolas }\end{array}$ & $\begin{array}{l}\text { Venta de } \\
\text { madera }\end{array}$ & $\begin{array}{l}\text { Trabajo } \\
\text { como } \\
\text { recolector }\end{array}$ & $\begin{array}{l}\text { Otros } \\
\text { ingresos }\end{array}$ & Total \\
\hline 514 & 428 & 86 & 520 & 170 & 1,718 \\
\hline
\end{tabular}

La nueva Ley Forestal al igual que la Ley INRA (véase Ruiz, Capítulo 2 y 3 y Gottwald, Capítulo 4 para su explicación detallada) han tenido como objetivo permitir la explotación de madera a más sectores sociales del país. La nueva reforma propone dos sistemas que permiten a las comunidades campesinas acceder de forma legal a los recursos del bosque. Por un lado, la comunidad puede formar una Asociación Social del Lugar (ASL) para obtener una concesión forestal en los bosques de las tierras fiscales municipales. Esta opción ha perdido importancia en el área de estudio debido a que el Decreto Supremo 25848 otorga a las comunidades campesinas en el norte amazónico boliviano un área mínima equivalente a 500 ha multiplicada por el número de familias de la comunidad. En conjunto, esta área puede convertirse en una extensión significativa para realizar el manejo forestal comercial. Por otro lado, varios de los entrevistados concuerdan en que los espacios en concesión podrían estar distantes de las áreas ocupadas por los campesinos, y su uso comercial demandaría altos costos de transporte y organización. Por ello, las comunidades campesinas se han inclinado por el segundo sistema, es decir la "Autorización de aprovechamiento en tierras de propiedad privada y en Tierras Comunitarias de Origen (TCO)". Esto implica que la comunidad obtiene un título ejecutorial sobre la tierra como propiedad comunal. Para acceder a esta clase de derechos las comunidades 
deben cumplir con tres requisitos: 1) Tener el reconocimiento como Organización Territorial de Base (OTB), ${ }^{3}$ 2) Tener una titulación saneada según la ley, y este debe ser reconocido por las instancias relevantes, y 3) Preparar un Plan de Manejo Forestal (PMF) como prueba del uso sostenible del bosque.

El reconocimiento como Organización Territorial de Base está definido en la Ley de Participación Popular. La tenencia comunal es regulada en la Ley INRA, y el requisito del PMF es resultado de la Ley Forestal.

De acuerdo con las declaraciones de los miembros de la comunidad, el principal costo para cumplir con los requisitos legales es compilar los documentos personales de los miembros de la comunidad. Eso no es cosa sencilla, ya que gran parte de la población en la región no cuenta con una identificación personal (Gottwald, Capítulo 4). Otro punto es demostrar la organización comunal, es decir, contar con un líder elegido democráticamente y un sistema de varios cargos regulados por la comunidad que se ocupen de los temas importantes de sus miembros: por ejemplo secretario general, secretario de hacienda, casa de la mujer, secretario de tierra y territorio, secretario de educación y salud, etc. El reconocimiento de la comunidad de Santa María como OTB fue un proceso lento y relativamente sin problemas.

Debido al retraso en el proceso de saneamiento de tierras (Gottwald, Capítulo 4), la comunidad Santa María aún no cumple con el requisito de tener título ejecutorial sobre la tierra. Según la Ley INRA, el derecho de posesión de la comunidad debe ser reconocido por el estado boliviano como propiedad comunal. La comunidad Santa María tiene actualmente 87 familias y 6,800 hectáreas ocupadas. Sin embargo bajo el Decreto Supremo 25848, la comunidad espera obtener un área de 100,495 hectáreas. Este interés, sin embargo, no parece ser difundido entre todos los miembros de la comunidad, ya que algunos de los entrevistados no conocen los motivos de esta pretensión.

Los argumentos de los dirigentes y comunitarios convencidos fueron: asegurar tierras para las futuras generaciones, lograr el desarrollo empresarial de la comunidad en base al manejo de sus recursos forestales, obtener un mayor derecho para poseer la tierra en comparación con los empresarios regionales y finalmente, porque la ley no les prohibe acceder a tanta tierra. La estrategia de la comunidad es demostrar ante las autoridades que cumple con el requisito de la función económico-social del bosque para la comunidad. El tener esta función le da a la comunidad el derecho de reclamar un área tan grande como territorio comunal. Por esta razón, la comunidad quiere presentar un PMF para un área de 50,000 hectáreas. 
El PMF también es un requisito para obtener una Autorización de Aprovechamiento, o para cualquier clase de uso comercial de la madera. Hasta la conclusión del estudio de campo, se discutía la aprobación de un PMF para la explotación de la castaña. Esta norma fue aprobada a finales del 2002. La Figura 5.1 muestra los pasos que una comunidad como Santa María debe cumplir para poder beneficiarse comercialmente de la madera en su territorio.

Figura 5.1. Pasos formales para las comunidades campesinas hacia un uso legal de madera

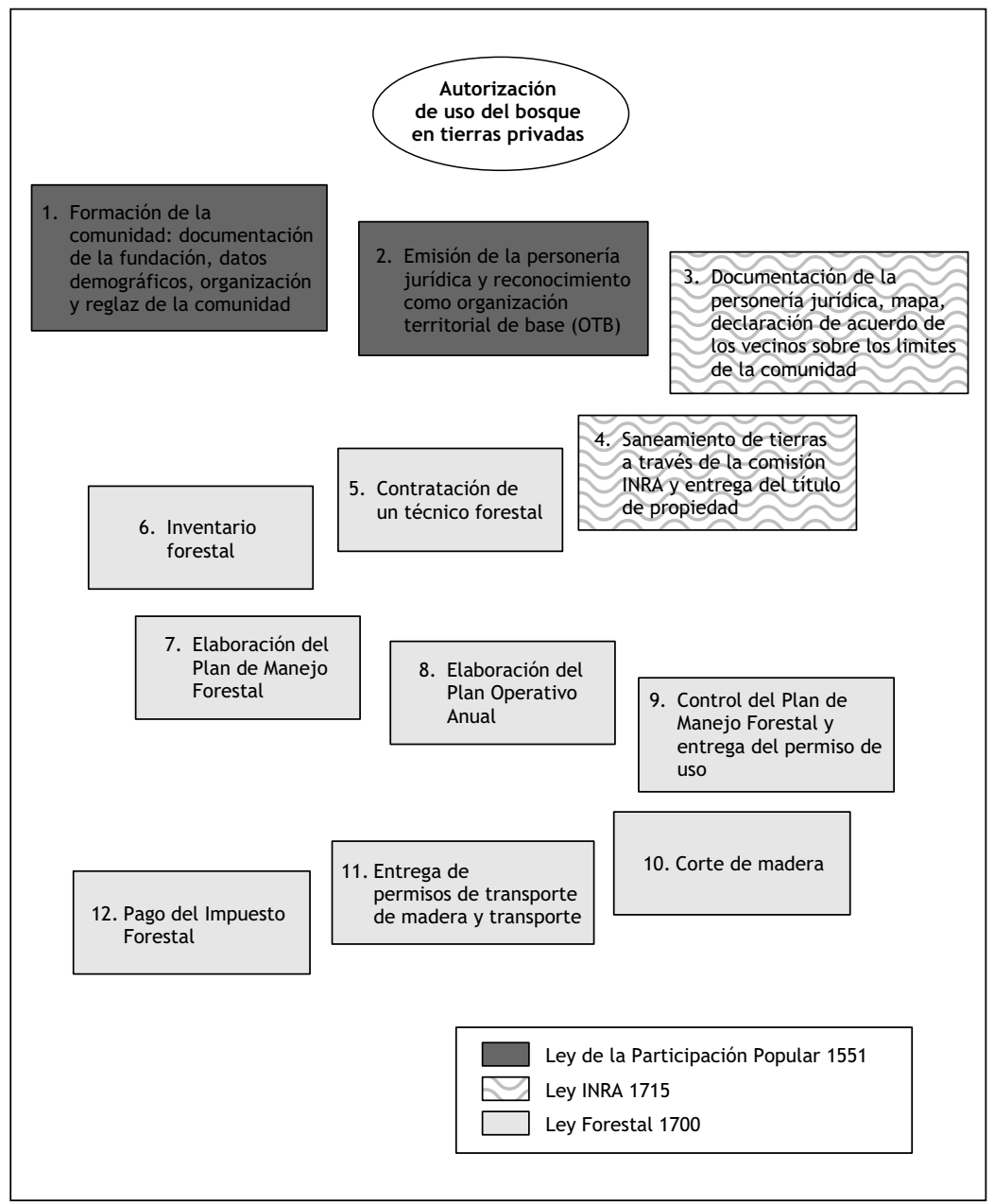




\section{DESAFÍOS DE LOS PLANES DE MANEJO FORESTAL COMUNALES}

Durante la investigación de campo, la comunidad de Santa María estaba preparando un PMF maderable sobre un área de 300 hectáreas como un primer requisito antes de la elaboración y aprobación del mismo plan sobre las 50,000 hectáreas. En el proceso de aplicación legal, el trabajo de la comunidad se concentró en la obtención de información y en la preparación de documentos. En este contexto, el trabajo conjunto de la comunidad con organizaciones no gubernamentales (ONGs) es básico para una implementación de las normas formales. Las ONGs participan directa e indirectamente en este proceso a través del refuerzo organizacional en las comunidades y la educación adicional de colonos individuales. Su relevancia en el proceso de implementación de la Ley Forestal se refleja en un total de 46 visitas de miembros de la comunidad a estas organizaciones, las cuales se llevaron a cabo en el marco de la elaboración del PMF de las 300 hectáreas. La Tabla 5.2 muestra información sobre las organizaciones potencialmente envueltas en los planes de manejo en el área de la ciudad de Riberalta y sus funciones.

La cooperación de la comunidad en estudio con las organizaciones regionales es fundamental para la aplicación de los lineamientos estipulados por las leyes de la reforma. Debido a la capacidad limitada de las organizaciones

Tabla 5.2. Organizaciones y sus funciones generales respecto a los PMFs para las comunidades campesinas.

\begin{tabular}{|c|c|c|c|c|}
\hline $\begin{array}{l}\text { Organización } \\
\text { (número de } \\
\text { visitas) }\end{array}$ & Información & Ejecución & Financiamiento & $\begin{array}{l}\text { Calificación } \\
\text { en la } \\
\text { organización }\end{array}$ \\
\hline $\begin{array}{l}\text { Superintendencia } \\
\text { forestal (3) }\end{array}$ & $\begin{array}{l}\text { Pasos formales } \\
\text { y técnicos }\end{array}$ & $\begin{array}{l}\text { Controly } \\
\text { recepción }\end{array}$ & - & $\begin{array}{l}\text { deficiente/ } \\
\text { regular }\end{array}$ \\
\hline $\begin{array}{l}\text { Unidad Forestal } \\
\text { Municipal (7) }\end{array}$ & $\begin{array}{l}\text { Pasos formales } \\
\text { y técnicos }\end{array}$ & - & - & deficiente \\
\hline IPHAE (5) & $\begin{array}{l}\text { Pasos formales } \\
\text { y técnicos } \\
\text { Asistencia }\end{array}$ & $\begin{array}{l}\text { Ejecución } \\
\text { técnica } \\
\text { Asistencia }\end{array}$ & Ejecución gratis & regular/buena \\
\hline CIPCA (5) & Pasos formales & - & - & buena/muy buena \\
\hline $\begin{array}{l}\text { Federación de } \\
\text { Campesinos (7) }\end{array}$ & $\begin{array}{l}\text { Pasos formales } \\
\text { Mediación entre } \\
\text { la comunidad y } \\
\text { las organizaciones }\end{array}$ & - & - & regular / buena \\
\hline $\begin{array}{l}\text { Empresas } \\
\text { madereras (19) }\end{array}$ & $\begin{array}{l}\text { Pasos formales } \\
\text { y técnicos }\end{array}$ & $\begin{array}{l}\text { Ejecución } \\
\text { técnica }\end{array}$ & $\begin{array}{l}\text { Créditos para } \\
\text { la financiación } \\
\text { de la ejecución } \\
\text { o para la } \\
\text { ejecución propia }\end{array}$ & buena \\
\hline
\end{tabular}


Tabla 5.3. Criterios de comunidades para ser elegible a asistencia técnica para formular Planes de Manejo Forestal

\begin{tabular}{|l|}
\hline Criterios \\
\hline 1 Tamaño de la comunidad \\
2 Distancia entre la comunidad y las organizaciones \\
3 Grado de organización de la comunidad \\
4 Determinación de la comunidad para mantener la cooperación \\
5 Disposición de los miembros de la comunidad a negociar \\
6 Potencial de uso del bosque para la comunidad \\
\hline
\end{tabular}

regionales, estas seleccionan a sus comunidades en base a la ponderación de los criterios que se presentan en la Tabla 5.3.

La comunidad de Santa María calificó de la siguiente manera según estos criterios:

Criterios 1 - 3. Santa María tiene 87 familias y está ubicada a una distancia de $20 \mathrm{~km}$ de la ciudad de Riberalta. Otro punto a favor de la comunidad, según las declaraciones de los expertos entrevistados, es el grado de desarrollo en la organización comunal. La comunidad se encuentra por encima del promedio observado en otras comunidades del norte amazónico. Este hecho se explica porque Santa María, como otras comunidades campesinas en la región, era organizada a través del sindicato agrario. Este sindicato comunal tenía una directiva que fue adaptada por la nueva estructura de la OTB. Sin embargo, la organización comunal también tiene sus propios desafíos (véase Gottwald, Capítulo 4). Un puesto en el sindicato es considerado por la mayoría de los comunitarios entrevistados como poco atractivo puesto que conlleva descuidar las labores forestales y agrícolas y por lo tanto renunciar a importantes ingresos económicos. El acceso a una mejor educación y conocimiento personal es considerado como una ventaja fundamental de esta actividad ad honorem. Por otro lado, ex-representantes de la comunidad Santa María han logrado ocupar importantes puestos en las asociaciones campesinas de la región, cuya sede es Riberalta.

Criterio 4. Los puntos débiles, según las declaraciones de los comunitarios se mantienen debido a los conflictos internos de intereses y a la falta de transparencia y comunicación entre las actividades del consejo comunal y la base. Los miembros de la comunidad comparten el interés de una ejecución rápida del proceso de saneamiento. Por el contrario, las opiniones de los comunitarios son divergentes en cuanto al uso del bosque de acuerdo al plan de manejo. De acuerdo a los resultados del trabajo de campo, fueron necesarias de tres a cuatro asambleas generales para aprobar la implementación de la Ley Forestal. Un argumento importante 
en contra de los planes de manejo es el temor a una mala distribución de los beneficios obtenidos. Algunos comunitarios se pronunciaron durante la votación fundamentalmente en contra de la implementación del plan de manejo, ellos prefieren usar su madera en la forma tradicional sin prestar atención a las restricciones estatales o de la comunidad.

Criterio 5. La disposición para negociar de la comunidad se muestra a través de un contacto activo entre la comunidad y las organizaciones, el cual es llevado a cabo en primer plano por el consejo comunal. Sobretodo las ONGs son consultadas por lo menos dos veces por semana. De acuerdo con las organizaciones, la comunidad dispone de miembros dinámicos e instruidos.

Criterio 6. La importancia de la explotación de madera en la comunidad Santa María debe ser observada en forma particular. Tradicionalmente se realizaba de manera individual en parcelas privadas. Actualmente juega un papel secundario en la comunidad, ya que las maderas más valiosas (mara, Swietenia macrophylla y cedro, Cedrela odorata) ya han sido extraídas de todas las áreas boscosas de la región. Además, el uso individual de madera ya no es posible debido a los lineamientos de la Ley Forestal y las restricciones impuestas por la directiva de la comunidad. En una reunión comunal durante las investigaciones de campo, un comunitario fue denunciado por sus vecinos por talar sin dar aviso a la directiva. La silvicultura comunitaria a través de un PMF legal es considerada por la mayoría de los entrevistados como una buena alternativa a futuro, aunque muy pocos comunitarios son capaces de relacionar los beneficios económicos concretos que significa contar con un plan de manejo. El pago de la madera por metros cúbicos es visto por los comunitarios como una ventaja fundamental de los planes de manejo que requiere la nueva Ley Forestal, en comparación con el pago por troza hasta principios de los años 1990.

De acuerdo con los resultados de las entrevistas, la estructura de comercialización de madera ha cambiado significativamente. En el pasado los compradores de madera en troza eran principalmente personas individuales y pequeños talleres de carpintería. En la actualidad debido a la Ley Forestal, esta clientela practicamente ha desaparecido al no poder obtener los documentos necesarios para transportar la madera por los puntos de control. Para el uso futuro de la madera por parte de la comunidad, se ha visto conveniente realizar un contrato con la mayor empresa que a la vez financia el Plan de Manejo Forestal.

\section{COSTOS DE TRANSACCIÓN PARA ELABORAR EL PMF COMUNAL}

La iniciativa para elaborar el PMF comunal fue tomada por los dirigentes de la comunidad, en base a dos argumentos principales: a) justificar los derechos de propiedad sobre la tierra, a través del cumplimiento de la 
función económica-social durante el proceso de saneamiento de la tierra y b) desarrollar el interés de los comunarios para convertir la comunidad en una empresa maderera independiente. No todos los habitantes de la comunidad conocen estos motivos. La mayoría de los miembros de la comunidad fueron informados sobre los planes de manejo forestal a través del contacto con las ONGs. Mientras que las autoridades del sindicato apoyan la introducción del plan de manejo, una gran parte de los comunitarios son neutrales en cuanto a las metas que se persiguen. Las decisiones se toman bajo un sistema democrático, lo cual ayuda a resolver problemas de consenso entre los dirigentes y comunarios, evitando que esto se convierta en un conflicto.

Según los expertos entrevistados el costo del inventario forestal que incluye la elaboración del Plan de Manejo Forestal es aproximadamente de US\$5 a US\$8 por hectárea. Estos costos normalmente los asume la empresa maderera contratada e incluye el trabajo de un técnico forestal especializado.

Dentro del contexto de la búsqueda de organizaciones contraparte se identifican dos escenarios de costos de transacción. En general pocos eventos pueden ser exclusivamente asignados a la preparación del PMF y por lo tanto incluidos directamente en el cálculo de los costos de transacción. Por esto, por ejemplo el número de visitas de ONGs (ver Tabla 5.4) es relativamente bajo en comparación con otras organizaciones, pero según las observaciones participativas su número es más alto. La identificación del punto inicial de transacción (en el sentido de una negociación específica) fue difícil de separar de la búsqueda general de información. Un problema adicional es la duración de conversaciones informativas sobre el Plan de Manejo Forestal en las organizaciones, el cual no puede estimarse de forma confiable, porque datan de hace más de un año. Por esta razón no son incluidas dentro de los costos de transacción.

Debido a las circunstancias mencionadas, los costos de transacción para la introducción de los planes de manejo en la comunidad están subestimados. Sin embargo, en el caso analizado, la relación de los costos de transacción de la etapa de iniciación $(70 \%)$ y realización $(30 \%)$ es cercana a la realidad. Los costos de transacción son asumidos por las personas directamente involucradas. Los costos de gasolina son financiados parcialmente por las ONGs, pero por lo general son directamente pagados por los miembros activos de la comunidad. El representante de la comunidad participa en casi todas las visitas a las organizaciones y le corresponde por lo tanto la mayor parte de los costos de transacción. Debido a que la comunidad sólo dispone de US\$140 por año como efectivo en la caja comunal, la elaboración del PMF ha dependido directamente del interés y disposición 
de invertir ingresos personales por parte de los miembros activos de la comunidad.

Con el trabajo de campo se obtuvo costos de transacción relacionados con la elaboración de un PMF en un área de 300 hectáreas variando entre US\$173 y US\$400, es decir entre US\$0.6 y US\$1.3 por hectárea. Los costos se basan en los costos de oportunidad que generan el tiempo invertido en las reuniones de la comunidad, los viajes para buscar las organizaciones, así como los costos de gasolina (sobretodo para obtener información, ver Tabla 5.4).

Aunque las sumas totales calculadas son relativamente bajas, se debe considerar que los costos de transacción calculados representan un valor mínimo, pues por un lado no fueron calculados en forma completa, y por otro lado porque la distancia a la ciudad es un factor dominante en la formula matemática del cálculo. Las conexiones de transporte de Santa María hacia Riberalta representan una característica poco común compartida por el resto de comunidades rurales en la región. En el caso del plan sobre las 300 hectáreas, los costos de transacción varían entre el 10 y $20 \%$ de los costos de inventario. En el caso específico de la comunidad Santa María para un plan de 50,000 hectáreas, el porcentaje de costos de transacción en relación a los costos totales será más bajo debido a dos factores: no existe una relación directa con el área y ya se cuenta con la información.

Tabla 5.4. Costos de transacción del PMF en Santa María sobre 300 hectáreas

\begin{tabular}{|c|c|c|}
\hline \multicolumn{3}{|c|}{ Fase inicial de transacción. Obtención de información } \\
\hline \multicolumn{3}{|c|}{$\begin{array}{l}\text { Escenario A: US\$69 Costos de oportunidad + US\$85 Costos de gasolina }=\text { US\$154 } \\
\text { Escenario B: US\$15 Costos de oportunidad + US\$13 Costos de gasolina }=\text { US\$28 }\end{array}$} \\
\hline \multicolumn{3}{|c|}{ Fase inicial de transacción. Negociación. Resolución de conflictos y decisión US\$124 } \\
\hline \multicolumn{3}{|c|}{ Transacción de ejecución. Búsqueda de un copartícipe } \\
\hline \multicolumn{3}{|c|}{$\begin{array}{l}\text { Escenario A: US\$21 Costos de oportunidad + US\$28 Costos de gasolina = US\$49 } \\
\text { Escenario B: US\$5 Costos de oportunidad + US\$4 Costos de gasolina = US\$9 }\end{array}$} \\
\hline \multicolumn{3}{|c|}{ Transacción de ejecución. Firma del contrato } \\
\hline \multicolumn{3}{|c|}{$\begin{array}{l}\text { Escenario A: US\$17 Costos de oportunidad + US\$22 Costos de gasolina = US\$39 } \\
\text { Escenario B: US\$4 Costos de oportunidad + US\$3 Costos de gasolina = US\$7 }\end{array}$} \\
\hline \multicolumn{3}{|c|}{ Transacción de ejecución. Adaptación del plan de manejo } \\
\hline \multicolumn{3}{|c|}{$\begin{array}{l}\text { Escenario A: US\$15 Costos de oportunidad + US\$19 Costos de gasolina = US\$34 } \\
\text { Escenario B: US\$3 Costos de oportunidad + US\$3 Costos de gasolina = US\$6 }\end{array}$} \\
\hline Total & Escenario A: US\$400 & Escenario B: US\$174 \\
\hline
\end{tabular}




\section{DISCUSIÓN Y CONCLUSIONES}

La introducción del PMF en la comunidad Santa María representa un proceso complicado en varios aspectos. El primer paso para obtener información básica ha sido percibido por los comunitarios como uno de los mayores obstáculos. Los reglamentos que norman su elaboración son considerados por los entrevistados como amplios y complicados. Aunque la comunidad estudiada presentaba ventajas comparativas en organización e información disponible al promedio de comunidades rurales en la región, fue necesario desarrollar un proceso intenso de búsqueda de contactos y cooperación técnica con organizaciones locales. Especialmente con aquellas organizaciones que poseen información y experiencia sobre los contenidos y aplicación de la reforma. La comunidad en estudio es una de las más favorecidas de la región en cuanto al acceso a información y capacitaciones. Para las comunidades que no tienen este nivel de formación y un buen contacto con las organizaciones, el proceso será más complicado e inseguro en cuanto a efectos internos en la comunidad.

Dentro de la comunidad, el proceso de elaboración del PMF estuvo fuertemente dirigido por unos pocos comunitarios interesados. Para obtener un PMF es necesario que dentro de la comunidad exista un grupo de personas interesado en formular metas y coordinar la gestión del PMF. La consecuencia lógica es que este grupo activo logre tener una fuerte ventaja informativa en comparación a los demás miembros de la comunidad. Esta debilidad en el acceso a la información podría favorecer el aprovechamiento individual y no los intereses colectivos. La motivación principal del grupo activo no son los ingresos económicos obtenidos por el aprovechamiento comunal de los recursos forestales sino el acceso a la información, el posicionamiento personal en organizaciones (P.ej. Federación de Campesinos, Cooperativa Campesina, etc.) y la posibilidad de participar en programas de capacitación a través de la cooperativa y organizaciones privadas. En el caso analizado, la motivación del grupo activo actualmente no tiene influencias negativas en los intereses de la comunidad. Generalizando, se debe considerar la posibilidad que el grupo activo dentro de una comunidad intente compensar sus esfuerzos en la gestión del PMF con un mayor porcentaje de beneficios obtenidos de la venta de los recursos maderables. Actualmente faltan reglamentaciones que definan la distribución de las ganancias obtenidas por el uso comunal del bosque. Estas reglamentaciones son necesarias para evitar conflictos y prevenir riesgos.

Como es lógico, la formulación del PMF implica costos de transacción. Los costos de transacción ligados a los planes de manejo no son percibidos en este caso como un obstáculo, sino como una inversión personal de los miembros activos durante el proceso. Aunque los costos de transacción 
no son muy altos, la comunidad no dispone de los recursos suficientes para una posterior compensación económica. Los costos de transacción pueden tener un efecto limitante para la ejecución de los planes de manejo, sobretodo en aquellas comunidades rurales que cuentan con escasa infraestructura de transporte. Los efectos del seguimiento y control de las normas para cumplir con el PMF a largo plazo han sido hasta ahora poco considerados. La comunidad investigada no está preparada para la exitosa implementación del PMF por varias razones:

Primero, no existen modelos definidos que traten la temática de la distribución equitativa de las ganancias, o de cómo las comunidades manejarán sus bosques comunales de forma empresarial. Para lograr el éxito y entrar en un ámbito empresarial faltan conocimientos y experiencias sobre lo que representaría implementar esta idea. La distribución de las ganancias y la distribución de responsabilidades en el manejo empresarial aparecen como futuros problemas centrales.

Segundo, no existe un procedimiento apropiado para solucionar posibles diferencias de interés en torno al manejo forestal. Actualmente los comunarios que no comparten la posición generalizada son controlados por el resto de la comunidad, sin poder afirmarse que esta situación sea estable. En este contexto no se garantiza que los nuevos líderes comunales den seguimiento a las estrategias actuales de la comunidad en torno al PMF, después de ser aprobado. Para los miembros de la comunidad el bosque representa su mayor capital. Sin embargo el PMF genera condiciones desfavorables para realizar inversiones, sea en forma particular o colectiva. Esto porque el PMF exige el seguimiento estricto de los lineamientos normativos durante 20 años - por ejemplo el área de aprovechamiento está definida y limitada para cada año. Desde el punto de vista empresarial, la comunidad tiene poca libertad de decisión sobre el capital bosque una vez aprobado el PMF. La fase de campo demostró que los comunarios apenas están conscientes de esta consecuencia.

Tercero, la comunidad no está capacitada para financiar la preparación e implementación del PMF. Para ello está obligada a cooperar con las empresas madereras, quienes contribuyen en el proceso con la preparación del plan y aseguran la compra de la madera por un plazo de 20 años. Conflictos potenciales entre la cooperación actual de la comunidad con la empresa forestal son los siguientes: Intereses divergentes entre los comunarios respecto al manejo forestal a futuro y definición de precios tanto por parte de la comunidad como por parte de la empresa forestal. Esta realidad hace cuestionable el impacto positivo de la Ley Forestal, en cuanto a su contribución para mejorar los ingresos "de facto" de las comunidades rurales y de su participación a largo plazo en el manejo comercial del bosque. 
Para una implementación exitosa de la Ley Forestal por parte de las comunidades campesinas surgen, las siguientes recomendaciones:

1. Crear fuentes de financiamiento independientes, para la preparación e implementación de un PMF por parte de la comunidad, para disminuir así la dependencia de las empresas madereras.

2. Desarrollar una guía con los pasos necesarios para la elaboración y posterior aprobación de los PMFs, reduciéndose así los costos de transacción.

3. Desarrollar una lista de los requisitos a cumplir por parte de las comunidades para la elaboración del plan de manejo.

4. Desarrollar modelos de organización como empresa comunal forestal (quién se encargará de las negociaciones, quién será el responsable de dirigir los trabajos necesarios y contratar a terceros, etc.) y también el desarrollo de una acta adecuada (para controlar el liderazgo de las negociaciones, control de las haciendas de la empresa comunal forestal, pagar a los miembros activos de la comunidad por su trabajo en la silvicultura comunal, tomar decisiones estratégicas, distribuir ganancias, etc.); tomando en cuenta el evitar poner en peligro los intereses colectivos y la aceptación del uso del bosque de acuerdo a la Ley Forestal.

\section{NOTAS}

${ }^{1}$ Ley del Instituto Nacional de Reforma Agraria.

2 Debido a la caída del precio de la castaña en el mercado internacional, el gobierno nacional institucionalizó un proyecto social dirigido a todos los recolectores de castaña durante la zafra de la gestión 2001-2002.

${ }^{3}$ Mostrando la fundación, los datos demográficos (mínimo 10 miembros), la organización/el sindicato de la comunidad, según la Ley de la Participación Popular 1551, la misma puede ser reconocida como OTB por el municipio y obtener la "Personería Jurídica" como derecho judicial.

\section{REFERENCIAS}

Bojanic, A. 2001. Balance is beautiful: Assesing sustainable development in the rain forests of the Bolivian Amazon - Utrecht, PROMAB Scientific Series 4.

BOLFOR - Superintendencia Forestal. 1997. Directriz sobre Concesiones para Agrupaciones Sociales del Lugar (Resolución Ministerial No. 133/97) - BOLFOR, Sta.Cruz.

Knight, J. 1997. Institutionen und gesellschaftlicher Konflikt - Tübingen, Mohr.

North, D.C. 1992. Institutionen, institutioneller Wandel und Wirtschaftsleistung - Tübingen, Mohr. 
Stoian, D. 2000. Variations and dynamics of extractive economies: the rural-urban nexus of non-timber forest use in the Bolivian Amazon disertación en el Instituto de Política Forestal, grupo Mercado y Marketing, Albert-Ludwigs-Universitaet de Freiburg, Alemania. 


\title{
Capítulo 6
}

\section{El nuevo régimen legal y los derechos sobre tierras y bosques indígenas}

\author{
Andrea Garzón
}

\section{INTRODUCCIÓN}

El presente estudio analiza los derechos de propiedad comunal actuales en las comunidades Puerto Yaminahua y San Miguel de Machineri que han surgido como consecuencia de la nueva legislación de los años 1990. El nuevo régimen legal en Bolivia reconoce varios tipos de derechos de propiedad sobre áreas boscosas, y asigna estos derechos a actores 0 grupos claramente definidos (ver Ruiz, Capítulo 2). Reconoce, entre otros, derechos comunitarios para comunidades indígenas, llamadas Tierras Comunitarias de Origen (TCO), y comunidades campesinas. En un régimen de propiedad común, el grupo administrador o dueños son los únicos con derecho para usar y tomar decisiones sobre un recurso. Este régimen, al igual que el régimen de propiedad privada, excluye de estos privilegios a los no-dueños. Propiedades comunes suelen ser inalienables, intransferibles fuera de la comunidad e indivisibles. Sin embargo, los dueños pueden usar uno u otro recurso bajo régimen común de manera individual (Devlin y Grafton 1998, Bromley 1991). Schlager y Ostrom (1992) identifican los siguientes tipos de derechos que en su conjunto caracterizan los derechos de propiedad común:

1. Acceso: El derecho para ingresar a un área física y disfrutar de beneficios no-sustractivos. 
2. Extracción: El derecho de obtener unidades o productos del recurso dentro de un sistema de recursos.

3. Manejo: El derecho de regular patrones de uso interno y transformar el recurso dando valor agregado.

4. Exclusión: El derecho de determinar quién tendrá derechos de acceso o de extracción, y cómo pueden ser transferidos estos derechos.

5. Alienación: El derecho de vender o arrendar derechos de manejo y de exclusión.

Los regímenes de propiedad común han sido criticados de ineficientes y de ser responsables de la sobreexplotación de los recursos (Hardin 1968). La propiedad común promueve la sobreexplotación como consecuencia de un fenómeno de "libre acceso". Solamente bajo un régimen de regulación fuerte puede este fenómeno ser detenido. Cuando los beneficios del recurso en propiedad común tienen un valor económico relativamente bajo, la inversión para crear y mantener este régimen puede no justificar estos beneficios. Cuando tampoco existe la oportunidad de dividir este recurso y así convertirle en propiedad privada, entonces existe la posibilidad real de sobreexplotación.

Este capítulo analiza los derechos de propiedad sobre tierras y bosques en el caso específico de la TCO Yaminahua-Machineri para evaluar la efectividad del nuevo sistema legal boliviano, y para estimar su impacto sobre grupos similares en el país.

El estudio tiene dos fuentes primarias de información: 1) información obtenida a través de entrevistas a informantes clave y a los habitantes de las dos comunidades, y 2) fuentes escritas sobre el proceso de consolidación y el manejo de la TCO: tales como reglas, cartas, contratos y el periódico local. Los informantes claves son aquellos individuos que representan a las organizaciones que participaron en la creación de la TCO o que están relacionadas con el manejo de los recursos naturales de la TCO. Estos incluyen: Instituto Nacional de Reforma Agraria (INRA), Central Indígena de Pueblos Originarios de Pando (CIPOAP), Organización Yaminahua-Machineri (OYAMA), Unidad Departamental de Asuntos Indígenas y Pueblos Originarios (UDAIPO), Apoyo a los Pueblos Indígenas del departamento de Pando (API), Proyecto de Manejo Forestal Sostenible de Pando (PANFOR). Entre las fuentes escritas, las leyes bolivianas, como la constitución, la Ley Forestal y la Ley INRA, fueron indispensables para entender el desarrollo de los derechos indígenas estatales y la creación del territorio indígena. Documentación referente a la creación de la TCO Yaminahua-Machineri fue obtenida de la oficina regional INRA-Pando. PANFOR proporcionó información sobre los recursos naturales de la TCO y su proyecto de forestería comunal. Ejemplares del periódico local "Expresión Amazónica" fueron revisados desde el 15 de enero del 2001 hasta el 10 de enero del 2002. 
La siguiente sección describe el área de estudio, seguido por una sección que explica el proceso formal del reconocimiento de derechos de propiedad sobre tierras y recursos naturales para pueblos indígenas en Bolivia, en parte desde una perspectiva histórica. A continuación el capítulo presenta una discusión sobre el largo y complejo proceso de gestión y aprobación de la TCO Yaminahua-Machineri. La penúltima sección compara brevemente los derechos de propiedad que tienen los mismos grupos en los países vecinos, Brasil y Perú, para después concluir con una sección de discusión y conclusión.

\section{ÁREA DE ESTUDIO}

Las dos comunidades indígenas en estudio, Puerto Yaminahua y San Miguel de Machineri, están situadas en el departamento de Pando en el extremo norte de la región amazónica boliviana. Pando es el departamento más joven de Bolivia y, con sólo 57,000 habitantes, tiene la tasa más alta de inmigración del país (25\% entre 1987 y 1992) (INE 2000). Pando surgió en la época del caucho (1938) que atrajo a inmigrantes bolivianos y brasileños, a los cuales se les responsabiliza por la desaparición de los pobladores originarios de la región (Saavedra 2001). Actualmente, inmigrantes, primordialmente de las tierras altas de Bolivia, llegan a Pando buscando mejores oportunidades laborales. Muchos de ellos llegan a la capital Cobija, ciudad fronteriza con Brasil (Llanque, Capítulo 9).

Las dos comunidades indígenas pertenecen al municipio de Bolpebra en la provincia Nicolás Suárez. Bolpebra limita en el este con la provincia peruana de Madre de Dios y en el norte con el Estado brasileño de Acre. El acceso más eficaz desde Cobija a las comunidades indígenas San Miguel de Machineri - Puerto Yaminahua se realiza por la carretera brasileña que une Assis Brasil (localizada frente a Bolpebra), con Cobija. San Miguel de Machineri y Puerto Yaminahua se encuentran a una o dos horas de navegación en bote de Assis Brasil, respectivamente. Además es posible llegar a las comunidades navegando el río Acre, que también fluye a través de Cobija.

Puerto Yaminahua es la única comunidad Yaminahua ${ }^{1}$ en Bolivia, mientras que existen varias comunidades Yaminahua en la provincia peruana de Madre de Dios y en el Estado brasileño de Acre. Los Yaminahua son uno de al menos diez grupos étnicos clasificados dentro de la familia lingüística Panoe. Aunque no existen límites claros que diferencien a los grupos étnicos Panoe se estima que aproximadamente 400 indígenas Yaminahua habitan en Perú, 500 en Brasil y 53 en Bolivia (Herbas 2000). Esta distribución es el resultado del "boom del caucho", que obligó a los Yaminahua a abandonar el territorio que habitaban anteriormente y que era rico en árboles de caucho, o a establecer relaciones de dependencia con siringeros o explotadores del caucho. 
La comunidad Yaminahua en territorio boliviano existe desde hace 60 años (Herbas 2000). En 1978 una pareja misionera se estableció en la comunidad por ocho años, iniciando el proceso de aculturación. Su trabajo misionario fue continuado por el Instituto Lingüístico de Verano y la Misión Evangélica Suiza (Zúñiga 1995), siendo estos últimos quienes proporcionaron los medios económicos para la adquisición legal de los primeros derechos de propiedad de la comunidad (INRA 2000a).

Los habitantes de San Miguel de Machineri pertenecen al grupo étnico Machineri $^{2}$ de la familia lingüística Arawak. Aunque este grupo es sólo conocido como Machineri en fuentes bibliográficas bolivianas, es más conocido como grupo étnico Piro en el Perú. Los Piro fueron ya contactados por misioneros en el siglo XVII y tienen, desde entonces, una larga historia de contacto con la iglesia católica (Knight 1999). Al igual que los Yaminahua, la forma de vida de los Machineri fue drásticamente afectada por el boom del caucho. Muchos fueron reclutados como fuerza de trabajo en los siringales $^{3}$ y servían, también, como intermediarios entre siringeros y grupos indígenas menos accesibles, como los Yaminahua (Bromley 1994). Actualmente, los Piro (los Machineri del Perú) viven en el departamento de Loreto, situado en el noreste de Perú (Knight 1999). En Brasil, en el Estado de Acre viven 459 Machineri (ACRE 2000). La comunidad San Miguel de Machineri fue establecida en 1985 en Bolivia bajo la administración de brasileños, quienes emplearon a algunas familias Machineri para la recolección de castaña (Díez y Murillo 1999).

\section{EL RECONOCIMIENTO LEGAL DE LOS DERECHOS DE PROPIEDAD INDÍGENA}

Las necesidades de los pueblos indígenas en el norte amazónico boliviano, en cuanto a derechos de propiedad, han sido verdaderamente reconocidas y formalizadas por el Estado en los últimos años. La primera Reforma Agraria $^{4}(1953)$ reconoció y atendió las necesidades de un gran número de campesinos de las tierras altas, quienes vivían en un ambiente de agricultura servil feudal. Sin embargo, el carácter agrario de esta reforma no coincidió con las necesidades y estilos de vida de los grupos indígenas de las tierras bajas. Primero, se concedía tierras sólo al comprobar su utilización agrícola y ganadera, lo cuál no es común bajo el sistema de agricultura de roce, tumba y quema practicado en las tierras bajas. Segundo, las tierras concedidas no excedían las 50 hectáreas por familia, tamaño insuficiente para mantener los estilos de vida tradicionales de los pueblos amazónicos. Tercero, los títulos entregados no concedían derechos de utilización de los recursos forestales (De Vries 1998). Finalmente, la reforma agraria negaba el derecho a propiedades agrarias a aquellos grupos que no sean sedentarios (Almaraz 1998). 
La década de 1990 es de gran importancia para el desarrollo de la legislación boliviana en miras a mejorar los intereses de los pueblos indígenas de las tierras bajas. Son varias las disposiciones legales que modifican la situación de los derechos de propiedad para los indígenas, como indica la Tabla 6.1.

Tabla 6.1. Dispositivos legales relacionados con el reconocimiento legal de los derechos de propiedad territorial de grupos indígenas en Bolivia

\begin{tabular}{ll}
\hline Decreto Supremo & Declara la necesidad nacional y social del reconocimiento, \\
(D.S.) 2905862 & asignación y tenencia de áreas territoriales en favor de \\
(1989) & grupos silvícolas y comunidades indígenas originarias del \\
& Oriente y la Amazonía boliviana para garantizar su \\
& supervivencia y pleno desarrollo socioeconómico y \\
& cultural.
\end{tabular}

\begin{tabular}{ll}
\hline D.S. 22609 (1990) & Reconoce el territorio indígena Sirionó. \\
\hline D.S. 22610 (1990) & $\begin{array}{l}\text { Reconoce el territorio indígena Parque Nacional } \\
\text { Isiboro-Sécure. }\end{array}$
\end{tabular}

D.S. 22611 (1990) Reconoce el territorio indígena Chimane y Multiétnico.

El Congreso Nacional Bolivia se comprometió a aplicar las normas y derechos Boliviano ratifica el básicos especificados en favor de los pueblos indígenas Convenio 169 (1991) y tribales de la Organización Internacional del Trabajo (OIT) Ordóñez (2000).

Ley de Participación Reconoce, promueve y consolida la participación Popular (1994) de comunidades indígenas en los procesos políticos, legales y económicos de Bolivia.

Ley INRA o Ley 1715 La Ley del Servicio Nacional de Reforma Agraria define (1996) los nuevos derechos territoriales para pueblos indígenas y los procesos necesarios para acceder a estos derechos.

Dentro de las leyes bolivianas recientemente establecidas se encuentran los aspectos básicos que definen los derechos de propiedad garantizados a los pueblos indígenas amazónicos:

1. La aceptación de una diversidad cultural y étnica. Al declararse una nación multiétnica y pluricultural (ver CPE 1994), Bolivia se compromete a la implementación de las leyes existentes, que garanticen esta diversidad y también a desarrollar políticas e instrumentos políticos con este fin.

2. El reconocimiento de la personería jurídica de pueblos y comunidades indígenas. La Ley de Participación Popular (LPP) reconoce el derecho de las comunidades y pueblos indígenas a personería jurídica (LPP, Párrafo II). Con la personería jurídica, el Estado boliviano reconoce que pueblos y comunidades indígenas tienen derechos colectivos, tales como el de propiedad. 
3. El derecho a tierras y territorios indígenas. De acuerdo al artículo 14 del Convenio 169 que exige reconocer el derecho a tierra y uso de la tierra de los indígenas, la última constitución boliviana (artículo 171) declara reconocer, respetar y proteger el derecho de los pueblos indígenas a sus tierras comunitarias de origen (TCO).

4. Acceso a los recursos naturales. La constitución, en concordancia con el Convenio 169, confiere a pueblos indígenas derechos diferenciados de acceso, extracción y manejo de sus tierras y recursos naturales (artículo 171).

5. Sistemas indígenas de autoridad (Derecho Consuetudinario). El Convenio 169 también incorpora en su artículo 8 el derecho de los pueblos y comunidades indígenas de gobernar sus vidas y sus relaciones, y en su artículo 9 el derecho de mantener sus instituciones privadas concernientes a la resolución de conflictos. La constitución boliviana otorga atributos jurisdiccionales a las autoridades internas de las comunidades indígenas (artículo 171).

En cuanto a los derechos de propiedad para comunidades indígenas, la primera reforma agraria boliviana inició la entrega de tierras con carácter inalienable. De esta manera se quería impedir que grandes terratenientes compren estas propiedades y asegurar que las comunidades indígenas mantengan sus tierras. Bajo la reforma legal de los años 1990, las propiedades diferenciadas bajo el concepto de TCO adquieren también este carácter sustancial. El artículo 41 de la Ley INRA declara su inalienabilidad, irreversibilidad, indivisibilidad e inembargabilidad.

Solamente la Ley Forestal 1700 de 1996 define los derechos sobre los recursos naturales en TCOs. Los pueblos indígenas tienen el derecho exclusivo de usar los recursos naturales dentro de su TCO (artículo 32). Las comunidades no requieren autorización para el uso tradicional y doméstico con propósitos no comerciales de sus recursos forestales. Para el uso comercial, sin embargo, las comunidades deben contar con planes de manejo forestal autorizados, igual que cualquier otro usuario (P.ej. Hentschel, Capítulo 5).

\section{CREACIÓN DE LA TCO YAMINAHUA-MACHINERI}

Los derechos de propiedad de las comunidades Puerto Yaminahua y San Miguel de Machineri (comúnmente llamadas TCO Yaminahua-Machineri) fueron formalizados en un período de cinco años. Este largo período, frecuentemente criticado, se debe a que el proceso de titulación no se desenvolvió en un marco organizacional e institucional preestablecido. Las organizaciones e instituciones necesarias tuvieron que desarrollarse durante el proceso. Se pueden reconocer dos etapas principales: 1) Primeros pasos para la formación de la TCO, 1996-1998, y 2) Saneamiento y titulación de la TCO, 1998-2001. 
La primera gestión se realizó en 1996 con la segunda marcha indígena Marcha por el Territorio, Derechos de Participación Popular y Desarrollo que resultó en la aprobación de la Ley INRA y la presentación de 16 demandas de territorios indígenas, incluyendo el territorio YaminahuaMachineri. Estas demandas siguieron un proceso burocrático que carecía aún de las organizaciones e instituciones requeridas. Durante este tiempo la comunidad Puerto Yaminahua ya contaba con títulos sobre 2,000 hectáreas, obtenidos con la ayuda financiera de la Misión Suiza. Basandose en estos títulos, los 161 habitantes de Puerto Yaminahua y 41 de San Miguel de Machineri, reclamaban títulos de TCO sobre 41,000 hectáreas. La demanda para los títulos de la TCO Yaminahua-Machineri, resultó en la inmovilización del área demandada por una resolución del INRA en junio de 1997. A partir de este momento no se podía entregar nuevos títulos dentro de las 41,000 hectáreas hasta la finalización del saneamiento. Con la obtención de la personería jurídica de las comunidades y la notificación de las Superintendencias Agraria y Forestal, el saneamiento debía continuar. Sin embargo, la falta de reglas claras para el saneamiento y medios, tanto financieros como humanos, retrasaron el proceso.

\section{Autogestiones de los actores indígenas}

Hasta el año 1998, la Central Indígena de la Región Amazónica Boliviana (CIRABO), con base en Riberalta, representaba los intereses de los cinco pueblos indígenas distribuidos en 32 comunidades del departamento de Pando, entre otros. En aspectos legales, CIRABO contaba con la colaboración del Centro de Estudios Jurídicos e Investigación Social (CEJIS). INRA era la organización que debía dirigir, coordinar y ejecutar las políticas establecidas por el Servicio Nacional de Reforma Agraria (SNRA) y clarificar los derechos sobre la propiedad agraria. Pero recién en 1997 llega a Pando el primer director departamental para iniciar y constituir una dirección departamental del INRA (Maia 2000).

El interés de administrar los recursos y procesos territoriales incentivó a un grupo de representantes indígenas pandinos a formar una organización indígena propia (Rodríguez, $2002 \mathrm{com}$. pers). Con el apoyo financiero de la prefectura, un grupo de trabajo realizó una consulta departamental para la creación de la Central Indígena de Pueblos Originarios de Pando (CIPOAP). En agosto de 1998, 29 de las 32 comunidades indígenas del departamento participaron en la primera asamblea de la CIPOAP en Cobija, donde se eligió a su primer representante. A pesar de la fuerte oposición de la CIRABO, en el 2000 la CIPOAP adquiere personería jurídica y reemplaza a la CIRABO en los trámites de las TCOs del departamento de Pando.

Las gestiones de los grupos organizados tuvieron apoyo del sector estatal. La política oficial de descentralización de 1998 establece que cada prefectura 
departamental debe crear una Unidad Departamental de Asuntos Indígenas y Pueblos Originarios (UDAIPO). Las UDAIPOs están encargadas de poner en práctica la corriente política indígena y de pueblos originarios: "Desarrollo con identidad" (Von Boeck et al. 2000). Desde su creación, UDAIPO-Pando se transformó en un vínculo entre organismos estatales y organizaciones indígenas. UDAIPO-Pando colaboró en el proceso de titulación de la TCO Yaminahua-Machineri y forma parte de las Comisiones Agrarias Departamentales (CAD), encargadas de supervisar y controlar el trabajo de reforma agraria a nivel departamental. UDAIPO creó la organización Apoyo a los Pueblos Indígenas del Departamento de Pando (API). Aunque, el objetivo de API es generar programas productivos para el desarrollo económico de las comunidades indígenas, también ha brindado asesoramiento a las comunidades. Junto con la CIPOAP y UDAIPO, la oficina departamental INRA-Pando se convierte en una organización capaz de llevar a cabo la reforma agraria. En 1998 INRA-Pando establece su primer equipo de trabajo, y en el 2000 el saneamiento de Pando comienza con la TCO Yaminahua-Machineri como su primer proyecto (Maia, 2002 com. pers.).

\section{Adaptación del INRA}

Simultánea a la evolución de organizaciones, las mismas directrices de la reforma agraria estaban pasando por un proceso de adaptación. El INRA, al no contar con los instrumentos técnicos y legales necesarios, no puede cumplir con los plazos para el saneamiento de las TCOs demandadas. Por esta razón, los plazos no fueron cumplidos y las regulaciones necesarias tuvieron que ser desarrolladas. Las primeras "Regulaciones de la Ley INRA", aprobadas en 1997, no eran adecuadas para la realidad boliviana porque se basaban en leyes argentinas (Maia, 2002 com. pers.). Las regulaciones fueron parcialmente modificadas en 1999 con lo cual INRAPando ya cuenta con normas adaptadas para su realidad que permiten iniciar el proceso de saneamiento. En este año también se contó con manuales y directrices de trabajo de campo y otros materiales (Contreras y Vargas 2002). Finalmente, en mayo del 2000 se aprueba el Reglamento de la Ley 1715 del Servicio Nacional de Reforma Agraria definitivo.

Estos procesos de formación organizativa y de instrumentos regulatorios retardaron la creación de la TCO Yaminahua-Machineri. En febrero de 1998, el director nacional del INRA firma la resolución de saneamiento de la TCO Yaminahua-Machineri. Un año más tarde el INRA solicita a la UDAIPO el "Reporte de Identificación de Necesidades Espaciales de los Indígenas Yaminahua y Machineri", elemento básico para la determinación de la superficie a ser otorgada. Por falta de recursos financieros, el saneamiento se realiza recién en el 2000 . Con la presión ejercida por la tercera marcha indígena: La Marcha por la Tierra, el Territorio y los Recursos Naturales, 
UDAIPO e INRA-Pando inician su trabajo con el financiamiento de la cooperación danesa, DANIDA.

\section{Resolución de demandas de terceros}

El saneamiento de TCOs requiere que se considere demandas de tierras de otros actores dentro del área considerada. Hubo dos conflictos dentro de la TCO Yaminahua-Machineri. La familia Farah, dueña de más de 60,000 hectáreas, rechazó la primera demarcación del INRA. Uno de los hijos se encargó de retirar los mojones y amenazó a las comunidades indígenas, las cuales respondieron con la amenaza de armarse. Finalmente, la familia Farah decidió acordar con la TCO, ya que el miembro familiar más activo tuvo problemas con la justicia brasileña, y que el mantenimiento de una propiedad tan extensa era muy costoso (Mopi, 2002 com. pers.).

El segundo conflicto era con concesiones forestales dentro del área de la TCO. Éste se resolvió con el informe de la UDAIPO. El informe debía establecer la superficie necesaria para que los indígenas demandantes pudieran vivir y desarrollarse según su cultura y características naturales. Debido a la reducción poblacional de un total de 202 a 162 indigenas de Yaminahua y Machineri, el informe determinó que el área a otorgarse debía ser sólo de 22,492 hectáreas. Sin embargo, tras negociaciones de los representantes indígenas apoyados por el CEJIS, el 28 de julio de 2001 el presidente encargado, Leopoldo Fernández, entrega títulos por 25,000 hectáreas de TCO a las comunidades Puerto Yaminahua y San Miguel de Machineri.

\section{Los recursos naturales en la TCO y su estado de propiedad interno}

Sistemas de recursos son áreas con la capacidad de producir unidades de recurso, mientras que unidades de recurso son las que individuos pueden extraer o apropiar de un sistema de recursos. Un sistema de recursos puede requerir o no de provisión para poder producir unidades de recurso, por ejemplo de trabajo de desmonte y cultivo o de regadío (Ostrom 1990).

Dentro de la TCO se diferencian tres sistemas de recursos que producen diversos tipos de unidades de recurso (Mapa 6.1). El primer sistema de recursos es el bosque, el cuál cubre casi la totalidad de la TCO. Los bosques de la TCO no requieren de provisión para producir la gama de unidades de recursos aprovechados por las comunidades (castaña, caucho, frutos del bosque y caza). Todos los dueños de la TCO tienen derechos de propiedad en todo el bosque. La castaña es el único producto forestal extraído exclusivamente para la venta, por lo tanto es también la única actividad en el bosque en la que cada familia trabaja y obtiene beneficios 
Mapa 6.1. La TCO Yaminahua-Machineri

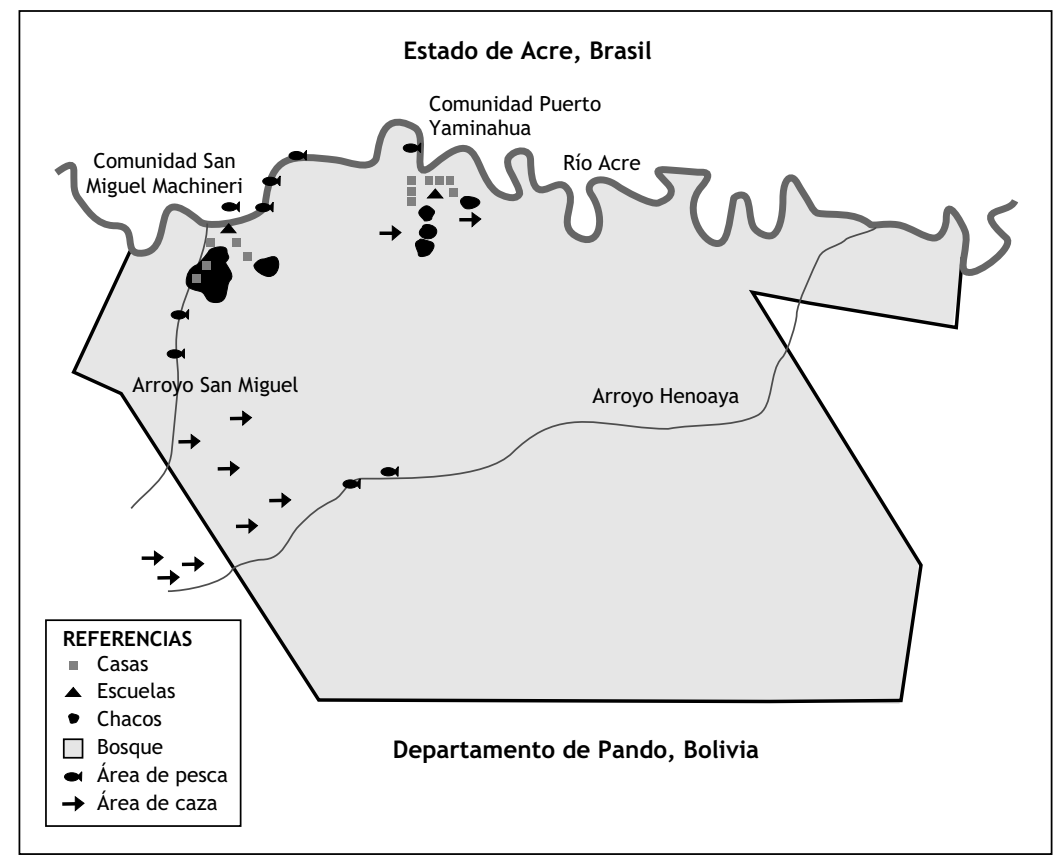

independientemente. La caza es realizada por los hombres de las comunidades en grupos, o acompañados por las mujeres. La recolección de frutos es realizada por cualquier miembro de la familia. La extracción de madera con fines comerciales está restringida hasta que la TCO cuente con el Plan de Manejo Forestal (PMF) de acuerdo a ley.

El segundo sistema de recursos en la TCO son las áreas de cultivo o chacos. Los chacos siguen siendo el único sistema de recursos que requiere de provisión, tales como el desmonte y cultivo, para generar unidades de recurso. Así los chacos son considerados propiedad de la familia que los cultiva por lo que tienen derechos de acceso, extracción y exclusión. Es labor de los hombres el desmonte y de las mujeres el cultivo y la recolección.

El tercer sistema de recursos son los ríos y riachuelos. Cualquier individuo tiene derecho al acceso y extracción (pesca) en el río Acre, que marca el límite norte de la TCO. Los riachuelos dentro de los límites de la TCO son restringidos a los habitantes de la TCO. La pesca es una actividad de grupo en la que puede participar cualquier miembro de la comunidad. 
Tabla 6.2. Sistema de recursos dentro de la TCO Yaminahua-Machineri y sus unidades de recurso, provisión, apropiación y utilización

\begin{tabular}{lllll}
\hline $\begin{array}{l}\text { Sistema de } \\
\text { recurso }\end{array}$ & $\begin{array}{l}\text { Unidades } \\
\text { de recurso }\end{array}$ & Provisión & Apropiación & Utilización \\
\hline Bosque & $\begin{array}{l}\text { Madera } \\
\text { Frutos Forestales } \\
\text { Castaña } \\
\text { Caza }\end{array}$ & $\begin{array}{l}\text { no necesario } \\
\text { no necesario } \\
\text { no necesario } \\
\text { no necesario }\end{array}$ & $\begin{array}{l}\text { restringido } \\
\text { común } \\
\text { común }\end{array}$ & $\begin{array}{l}\text { restringido } \\
\text { común } \\
\text { comerconsumo } \\
\text { autoconsumo } \\
\text { y comercio }\end{array}$ \\
\hline Chaco & Cosecha & privado & privado & $\begin{array}{l}\text { autoconsumo } \\
\text { y comercio }\end{array}$ \\
\hline $\begin{array}{l}\text { Ríos y } \\
\text { riachuelos }\end{array}$ & Peces & no necesario & común & $\begin{array}{l}\text { autoconsumo } \\
\text { y comercio }\end{array}$ \\
\hline
\end{tabular}

\section{DERECHOS DE PROPIEDAD DE LOS YAMINAHUA Y MACHINERI EN BRASIL Y PERÚ}

Debido a que los dos grupos indígenas residen en Bolivia, Perú y Brasil encontramos tres diferentes sistemas legales que influyen en sus derechos de propiedad sobre tierras y bosques. Por esta razón, es útil hacer una breve comparación de los derechos de propiedad para estos grupos indígenas en los tres países.

\section{El desfase histórico de los territorios indígenas en los tres países}

La creación de los territorios indígenas se inició mucho antes en el Estado de Acre (Brasil) que en el vecino departamento de Pando (Bolivia). Mediante el trabajo del organismo estatal que atiende asuntos indígenas, la Fundação Nacional do Índio (FUNAI), Acre ha regularizado ${ }^{5}$ trece tierras indígenas ( $\mathrm{TI}$ ), y otras quince están en vías de ser regularizadas (ACRE 2000). A pesar de que el Estado brasileño es más extenso que el departamento de Pando, cabe recalcar que cuatro de los trece territorios han sido otorgados a comunidades Yaminahua localizadas cerca de la TCO Yaminahua-Machineri: TI Cabeceira do Rio Acre, TI Mamoadate (otorgados a comunidades Yaminahua y Machineri), TI Jaminawa/Arara do Rio Bagé y TI Jaminawa do Igarapé Preto.

Mientras que la TCO Yaminahua-Machineri fue demandada en 1996, la TI Mamoadate ya había sido identificada y limitada en 1977 por la FUNAl. La FUNAl, creada en 1967, comenzó a defender activamente los derechos de los indígenas de Acre en 1975. Así se logró que la TI Mamoadate fuera demarcada en 1985, una década antes de que el vecino territorio boliviano haya sido siquiera demandado. 
Muchas familias han abandonado Puerto Yaminahua para añadirse a las comunidades Yaminahua de la TI Mamoadate y la TI Cabeceira do Rio Acre. Algunos indígenas de Madre de Dios también han preferido asentarse con sus parientes brasileños (ACRE 2000). Esta situación esta probablemente relacionada a la capacidad brasileña de defender los derechos de los indígenas, junto con su capacidad para proporcionar mejor ayuda médica, económica y educativa.

\section{El nivel de protección que ofrecen los tres países}

En general, el carácter sustancial que los estados dan a las tierras de los pueblos indígenas puede ser considerado como el nivel de protección a estas culturas. Restringir el derecho de propiedad "alienación" es percibido como un avance a favor de los pueblos indígenas (ver OIT 2002). Por otro lado, esta restricción ha sido calificada de discriminatoria, indemocrática y económicamente improductiva (ver Thiesenhusen 1996). De manera similar a la Ley INRA, la constitución brasileña establece la inalienabilidad de los territorios indígenas (artículo 231: § 4). De manera contraria, la última constitución peruana (1993) y la Ley de Tierras peruana (1995) abolieron el carácter anterior de sus tierras indígenas (inalienables, imprescriptibles e inembargables). De este modo, el nuevo carácter de las tierras indígenas peruanas ha abierto sus posibilidades comerciales $y$ de desarrollo a nuevas estrategias económicas, pero a su vez, expone a los indígenas a perder sus tierras. La constitución peruana de 1993 también abolió la restricción de vender e hipotecar las tierras comunales indígenas, incrementando la autonomía comunal y estableciendo la disposición libre de las comunidades sobre sus tierras (Rioja 1999). La Ley de Tierras de 1995 (artículo 11) otorga a las comunidades el derecho de disponer sobre sus tierras con el consentimiento de sólo dos tercios de sus habitantes.

Mientras Perú ha desarrollado derechos de propiedad estatales menos protectores, Brasil ha tomado una posición más paternalista respecto a los indígenas amazónicos y sus tierras. El Estatuto do Índio, "regula la situación legal de los pueblos y comunidades indígenas para preservar su cultura e integración progresiva y armónica en la sociedad nacional" (artículo 1). El artículo 4 de esta legislación clasifica a los indígenas en isolados (aislados), en vías de integración e integrados. Los derechos civiles y políticos de los indígenas dependen de esta clasificación, que ha sido frecuentemente criticada. Sin embargo, los principios del Estatuto do Índio también pueden considerarse como la respuesta para prevenir engaños y maltratos a indígenas, y así impedir que éstos terminen en la extrema pobreza. Los indígenas clasificados como no integrados están sujetos al trato tutelar de la FUNAI (artículo 7). A los ciudadanos regulares no se les permite realizar transacciones con, o disturbar a, nativos no integrados sin la supervisión y el permiso del Estado brasileño. Los individuos pueden 
renunciar a este tratamiento tutelar probando tener plena conciencia sobre el significado del trato o transacción.

\section{DISCUSIÓN Y CONCLUSIONES}

El proceso agrario ha hecho posible que estas dos comunidades indígenas del norte amazónico boliviano cuenten con derechos de propiedad reconocidos por el Estado. Sin embargo, las reformas en las leyes bolivianas deberían no solo asegurar la propiedad de Yaminahua y Machineri sobre estas tierras, sino también la no degradación de este territorio rico en recursos naturales. La riqueza, sobretodo forestal, de la TCO no ha sido alterada debido a que ha recibido poca presión. Sin embargo están ocurriendo grandes cambios en la región y el interés en los recursos forestales de la TCO incrementa rápidamente. La sustentabilidad dependerá de seis condiciones fundamentales que caracterizan los derechos comunitarios exitosos y que previenen que un régimen de libre acceso gobierne la TCO Yaminahua-Machineri. Un análisis de las leyes, las normas internas y las organizaciones que gobiernan la TCO nos permite establecer el nivel de cumplimiento de estas condiciones estrechamente ligadas a la sustentabilidad del régimen de propiedad común de la TCO.

Condición 1 "Límites Claramente Definidos" (Ostrom 1990): Los límites geográficos de la TCO con el mundo externo están mejor definidos que los límites que definen qué individuos o familias tienen derechos para extraer recursos de la TCO. Esta falta de claridad se explica con la poca necesidad existente dentro de la TCO de excluir a los pocos habitantes de uno $u$ otro recurso. Los propietarios establecerían normas más rígidas cuando sus beneficios se sientan amenazados a causa de la apropiación de otro.

Condición 2 "Congruencia entre las Reglas de Apropiación, Provisión y Condiciones Locales" (Ostrom 1990): El derecho a extracción probablemente derive de la necesidad de asegurar los frutos de nuestro trabajo (Bromley 1991). Lo cual explica que sólo se restrinja el derecho de extracción dentro de los chacos que han requerido de trabajo para producir frutos.

Los Yaminahua y Machineri ponen especial énfasis en impedir que foráneos extraigan madera de la TCO. La tala de madera significa la destrucción del sistema del recurso bosque, y así poner en riesgo la subsistencia de otras unidades de recurso como la caza y los frutos del bosque. También el valor comercial, al parecer sobre estimado, de la madera incentiva a las comunidades a tener normas internas más estrictas en cuanto a la extracción de árboles. La apropiación de troncos de una persona significa 
una pérdida económica para los demás. Sin embargo, hasta la fase de campo de este estudio la TCO ha estado en un nivel de muy poca utilización haciendo que el organizarse y el desarrollo de normas traiga pocas ventajas.

Condición 3 "Decisiones con Acuerdo Colectivo" (Ostrom 1990): El número reducido de habitantes de la TCO permite que todos opinen. Sin embargo, las distancias y la falta de un sistema bien organizado que administre la TCO dificulta el cumplimiento de esta condición. Además, aunque la organización conjunta OYAMA asume ciertas responsabilidades, la mayoría de las decisiones son tomadas individualmente por cada una de las dos comunidades. Por esto, si el manejo de la TCO se vuelve más complejo en el futuro las comunidades necesitarán desarrollar un mecanismo más efectivo de toma de decisiones conjuntas.

Condición 4 "Monitoreo" (Ostrom 1990): El monitoreo completo de la TCO requeriría de instrumentos de teledetección sofisticados o de una gran cantidad de recursos humanos. La falta de esta capacidad de monitoreo es un problema común para todos los países amazónicos, que procuran proteger territorios indígenas, detener la tala ilegal, la extracción de plantas o animales en peligro de extinción y el narcotráfico. Éstas son amenazas a las que la TCO Yaminahua-Machineri se encuentra expuesta y que pueden agravarse en el futuro.

Condición 5 "Sanciones Graduales y Mecanismos de Resolución de Conflictos" (Ostrom 1990): Adicionalmente a las sanciones legales que significan el incumplimiento de las leyes, de acuerdo con los entrevistados, en las comunidades no existe un sistema interno de sanciones. Sin embargo, existen sanciones no reconocidas. Sabemos que los comunitarios tienen expectativas en cuanto al cumplimiento de las labores y reglas por parte de otros miembros de la comunidad y en comunidades pequeñas la decepción de la mayoría podría considerarse un tipo de sanción.

Condición 6 "Reconocimiento Mínimo del Derecho de Organizarse" (Ostrom 1990): El derecho consuetudinario estipulado en el Convenio 169 y adoptado por la constitución boliviana reconoce a las autoridades, administración y normas tradicionales indígenas.

Una buena organización local dentro de la TCO Yaminahua-Machineri podría prevenir un régimen de libre acceso, lo cual a su vez evitaría que los recursos naturales de la TCO sean degradados y que las comunidades indígenas terminen en la pobreza. Ostrom (1999) recomienda a las organizaciones gubernamentales y a las ONGs que contribuyan con esta organización local en propiedades comunales "proporcionando información precisa de los sistemas de recursos naturales, proporcionando 
espacios en los que los participantes puedan dedicarse al descubrimiento y a los procesos de resolución de conflictos, y proporcionando mecanismos que respalden el monitoreo local y los esfuerzos en cuanto a sanciones" (Traducción personal).

\section{NOTAS}

1 También llamados Jaminawa, Yamanahua, Xixinawa, Bashonawa y Marinawa.

2 También llamados Machinery, Matxineri, Maniteneri y Manchinei.

3 Siringales son las áreas con concentración de árboles de chiringa, que es otro nombre en la región para el jebe.

${ }^{4}$ Reforma agraria se refiere a la redistribución popular de propiedades grandes de terratenientes; un resultado de la época colonial.

${ }^{5}$ Los territorios indígenas brasileños son primero identificados, luego declarados, después registrados, y finalmente regularizados (ACRE 2000).

\section{REFERENCIAS}

ACRE - Governo do Estado do Acre. 2000. Zoneamentoecológico-econômico do Estado do Acre: recursos naturais e meio ambiente - documento final. Rio Branco. www.ac.gov.br.

Almaraz, A. 1998. Pueblos indígenas de la Amazonía, el Oriente y el Chaco. En: C.I. Degregori. COMUNIDADES: Tierra, Instituciones, Identidad. Lima. pp. 171-190.

Bromley, D.W. 1991. Environment and Economy: Property Rights and Public Policy. Cambridge y Oxford.

Contreras H.A. y Vargas R.M.T. 2002. Social, Environmental and Economic Dimensions of Forest Policy Reforms in Bolivia. Washington D.C. y Bogor.

CPE - Constitución Política del Estado. 1994. www.congreso.gov.bo.

De Vries, A. 1998. Territorios Indígenas en las Tierras Bajas de Bolivia. Un análisis de su estado a 1998. Santa Cruz.

Devlin, R.A. y Grafton, R.Q. 1998. Economic Rights and Environmental Wrongs. Property Rights for the Common Good. Cheltenham y Northampton.

Diez, A.A. y Murillo, D. 1999. Pueblos Indígenas de las tierras bajas: Características Principales.

Herbas, M. 2000. Diagnóstico Socioeconómico del Nor occidente de Pando TCO Yaminahua - Machineri Reserva de Vida Silvestre Tahuamanu. Cobija: Universidad Amazónica de Pando. Herencia.

INE - Instituto Nacional de Estadística. 2000. Migraciones de la Población Económicamente Activa. www.ine.gob.bo.

Knight, K. 1999. The Catholic Enclyclopedia, Volume XII. New York www.newadvent.org/cathen/12109b.htm.

Maia L., F. 2000. Informe de Pando. En: Instituto Nacional de Reforma Agraria. Memoria 1996-2000. Bolivia. pp. 89-93. 
Maia L.F. 2002, Abril. Entrevistas a informantes clave: INRA-Pando. Cobija. Mopi, H. 2002, Abril. Entrevistas a informantes clave: UDAIPO. Cobija.

Ordóñez C., J.E.R. 2000. Introducción: Análisis interdisciplinario del Convenio 169 de la OIT. In J. E. R. Ordóñez C. Análisis interdisciplinario del Convenio 169 de la OIT IX Jornadas Lascasianas. México pp. 1-6 www.bibliojuridica.org.

Ostrom, E. 1990. Governing the Commons. The Evolution of Institutions for Collective Action. Cambridge.

Rioja, G. 1999. Estudio de Prefactibilidad sobre Atención Integral a Comunidades Indígenas/Nativas. Documento sin publicar para el proyecto "Desarrollo Sostenible de Áreas Fronterizas Amazónicas Programa de Acción Integrado Peruano Boliviano" de la Organización de Estados Americanos (OEA). Cobija.

Rodríguez T.M. 2002, Marzo. Entrevistas a informantes clave: OYAMA. Cobija. Saavedra P.V.C. 2001. Pando: El Último Paraíso. Cobija.

Thiesenhusen, W.C. 1996. Trends in Land Tenure Issues in Latin America. Experiences and Recommendations for Development Cooperation. Latin America. www.gtz.de/orboden.

Von Boeck G., Ali W., Dury G., Sánchez P. y Rodríguez T. 2000. Propuesta de apoyo a los pueblos indígenas del departamento de Pando. Sin publicar. Cobija.

Zúñiga, Eliseo. 1995. La Gran Conquista. Cupertino. 


\title{
Capítulo 7
}

\section{Estratégias de medios de vida aplicadas por los indígenas Cavineños}

\author{
Johannes Stahl
}

\section{INTRODUCCIÓN}

Por más de 150 años la economía en el norte amazónico boliviano ha dependido de la extracción de recursos naturales como el oro, caucho, palmito, pieles de animales silvestres y más recientemente de la castaña (Bertholletia excelsa) y la madera. La época del auge de la explotación de los productos del bosque ha sido crucial para el desarrollo de la estructura socioeconómica actual de la región. Durante el primer boom del caucho, alrededor de 1880, miles de migrantes ingresaron a la región para trabajar como siringueros en las barracas emergentes. Durante los períodos de recesión económica que siguieron, los pobladores rurales abandonaron las barracas y salieron a fundar nuevas comunidades en el área rural.

Este desarrollo generó una élite regional que tenía fuertes derechos de propiedad informales sobre grandes áreas del bosque en la región, y la presencia de comunidades rurales, campesinas e indígenas, que tenían su propio territorio pero con un estatus normativo más débil.

Durante los años 1990, después de un período de intensa lucha política, Bolivia aprobó una serie de leyes que mejoraron la administración estatal y 
establecieron un concepto más apropiado sobre el uso sostenible de los recursos naturales del país. ${ }^{2}$ Respecto a las comunidades indígenas la nueva legislación buscó aumentar los derechos de propiedad y llamó a una demarcación rápida de sus territorios. Este nuevo entorno legal ha cambiado profundamente la situación de los derechos de propiedad en la región amazónica boliviana. Hoy, territorios indígenas conocidos también como Tierras Comunitarias de Origen (TCO) han sido establecidos, reconociéndose su derecho a la tierra y explotación de los recursos.

Aunque, en muchos casos, los ingresos económicos generados a través de la extracción de los productos del bosque no son suficientes para sostener las comunidades, la perspectiva empezó a cambiar. La agricultura de subsistencia, la caza y la pesca siguen siendo la base de las economías indígenas. La nueva legislación deja abierta la posibilidad a la explotación de madera comercial para estas comunidades.

El presente capítulo enfoca la vulnerabilidad del sistema socio-cultural de la comunidad indígena de Galilea, a orillas del río Beni. La base teórica del estudio es el concepto de los medios de vida sostenibles que permite concentrarse en los recursos disponibles de los pobladores y en las estrategias que utilizan para subsistir. Finalmente, el estudio contiene una exposición de la esperanza de los pobladores de Galilea sobre la futura explotación de madera comercial. El estudio concluye con las implicaciones de los principales resultados para el cambio socio-económico de la comunidad.

Las preguntas centrales de la investigación fueron: ¿Cuáles son las estrategias de subsistencia (livelihood strategies) utilizadas por los habitantes de Galilea, y cuáles son las fuerzas impulsoras detrás de estas estrategias? Estas preguntas específicas conducen a la permutación de las siguientes interrogantes: (1) ¿Cuáles son las causas, opciones y motivaciones que forman los medios de subsistencia de la gente? (2) ¿Cúal es el marco social en el que encajan las estrategias de subsistencia? (3) ¿Qué y cuánto produce la comunidad y qué productos se utilizan para el autoconsumo? (4) ¿Cuáles son los recursos que se utilizan para la producción, y qué métodos son utilizados? (5) ¿Son los modos de producción sostenibles?.

El trabajo de campo se realizó durante 36 días entre los meses de febrero y mayo del 2002, dividido en tres visitas. La investigación se centró en analizar la importancia de las actividades agroculturales y extractivas del ciclo productivo. La observación participativa fue el principal instrumento de la investigación. La metodología utilizada incluyó la participación en actividades cotidianas, trabajos comunitarios, así como discusiones en grupo y entrevistas semi-estructuradas e informales. 
Los datos cualitativos obtenidos en la presente investigación fueron validados y complementados por las experiencias y resultados de los trabajos de Henkemans (2001), Stoian (2000) y por la información disponible sobre las recientes investigaciones antropológicas de la cultura cavineña (García 1998a,b, Herrera 1998).

\section{ÁREA DE ESTUDIO}

Los Cavineños son un grupo indígena de aproximadamente 2,000 habitantes que pertenece a la familia lingüística Tacana. En Bolivia, sus comunidades están ubicadas en los departamentos del Beni y Pando. Desde el siglo XVIII la vida de los Cavineños estuvo estrechamente vinculada a las misiones que trataron de catequizarles.

La comunidad Galilea, situada en el Territorio Multiétnico II, es la más grande de las comunidades cavineñas. Cada uno de sus 36 hogares cultiva sus chacos familiares con arroz, maíz, plátano, y otros productos agrícolas. El territorio de la comunidad fue comprado en 1987 con el apoyo de la Misión Suiza, pasando a ser una de las pocas comunidades indígenas con título legal tangible. Su territorio abarca 8,500 hectáreas de bosque amazónico que se utiliza como recurso comunal (no existen parcelas individuales). El bosque es rico en flora y fauna que provee a los miembros de la comunidad muchos de los productos necesarios como la madera para combustible, carne o frutas silvestres. De gran importancia es la extracción y comercialización de la castaña. Siendo esta actividad una de las pocas alternativas para generar ingresos económicos.

Como la mayoría de las comunidades indígenas de la región, Galilea está claramente marginada del contexto regional. Los mercados están lejos y son de difícil acceso; la escasez de trabajo y la negligencia política en general, han generado condiciones de vida difíciles. La agricultura de subsistencia y la recolección de productos del bosque siguen siendo las actividades económicas básicas. Sin embargo, éstas apenas generan los ingresos necesarios para satisfacer las necesidades básicas.

\section{QUÉ ES UNA VIDA DIGNA}

El concepto de los medios de vida sostenibles se enfoca en mejorar la comprensión de los medios de vida y las estrategias económicas de los pobladores rurales. Además permite un análisis holístico y flexible de las causas, opciones y motivaciones que forman las estrategias en materia de medios de vida en las familias rurales. Por esa razón este concepto se relaciona con la antropología cultural y sus respectivos métodos. El concepto de los medios de vida sostenibles proviene de la teoría de desarrollo (Chambers y Conway 1992) y ha sido adoptado por varias organizaciones 
internacionales (P.ej., DFID, FAO, GTZ, UNDP). Considerando el aumento de la pobreza en las familias rurales, el concepto de los medios de vida sostenibles se basa en observar cómo se margina la población rural, que resulta en un aumento de la vulnerabilidad. Las familias campesinas son parcialmente capaces de asegurar su existencia con la producción para el mercado y para su propia subsistencia. Para sobrevivir en esta situación precaria, deben combinar una variedad de actividades económicas, sin embargo, negativas tendencias ecológicas, sociales, políticas o culturales y choques tales como la degradación de los recursos naturales, inundaciones o epidemias, ponen en peligro la supervivencia de estos pobladores. Por lo tanto, la meta fundamental del concepto de los medios de vida sostenibles es ayudar a las familias rurales a reducir su vulnerabilidad y consolidar los sistemas de medios de vida sostenibles (Derichs y Rauch 2000).

Los hogares se constituyen en la unidad central de análisis del concepto de los medios de vida sostenibles. Ellos son las instituciones autónomas de la producción y de consumo. El análisis de los sistemas de medios de vida sostenibles comienza con los activos que influyen en los medios de vida a los que los hogares pueden tener acceso. Esto se puede esquematizar como un pentágono de diferentes recursos (llamados capital humano, natural, financiero, social, y físico; ver Figura 7.1) los cuales dan, a los pobladores, la capacidad para elegir sus estrategias en materia de medios de vida (DFID 1999).

1. El capital humano se refiere a las aptitudes, conocimientos, capacidades laborales y buena salud que permiten a la gente entablar estrategias y lograr sus objectivos en materia de medios de vida.

2. El capital natural representa una amplia variedad de activos, desde las mercancías públicas intangibles como la biodiversidad o la atmósfera, hasta recursos divisibles como tierra, agua, árboles, etc.

3. El capital financiero incluye ahorros, créditos, y flujos regulares de la renta.

4. El capital social hace referencia a los recursos sociales que sirven de apoyo a los pobladores en la búsqueda de sus logros en materia de medios de vida (las redes y conexiones sociales, los grupos y organizaciones, o las relaciones de confianza, reciprocidad e intercambios).

5. Finalmente, el capital físico abarca la infraestructura (transporte, abastecimiento de aguas, energía, información, etc.) y los bienes de producción (herramientas, maquinaria, equipos).

Con estas cinco categorías es posible mostrar cuáles son las fortalezas y debilidades que tienen los medios de vida de las familias de Galilea. Con este conocimiento se puede investigar de qué manera los pobladores utilizan las estrategias en materia de medios de vida para compensar sus debilidades 


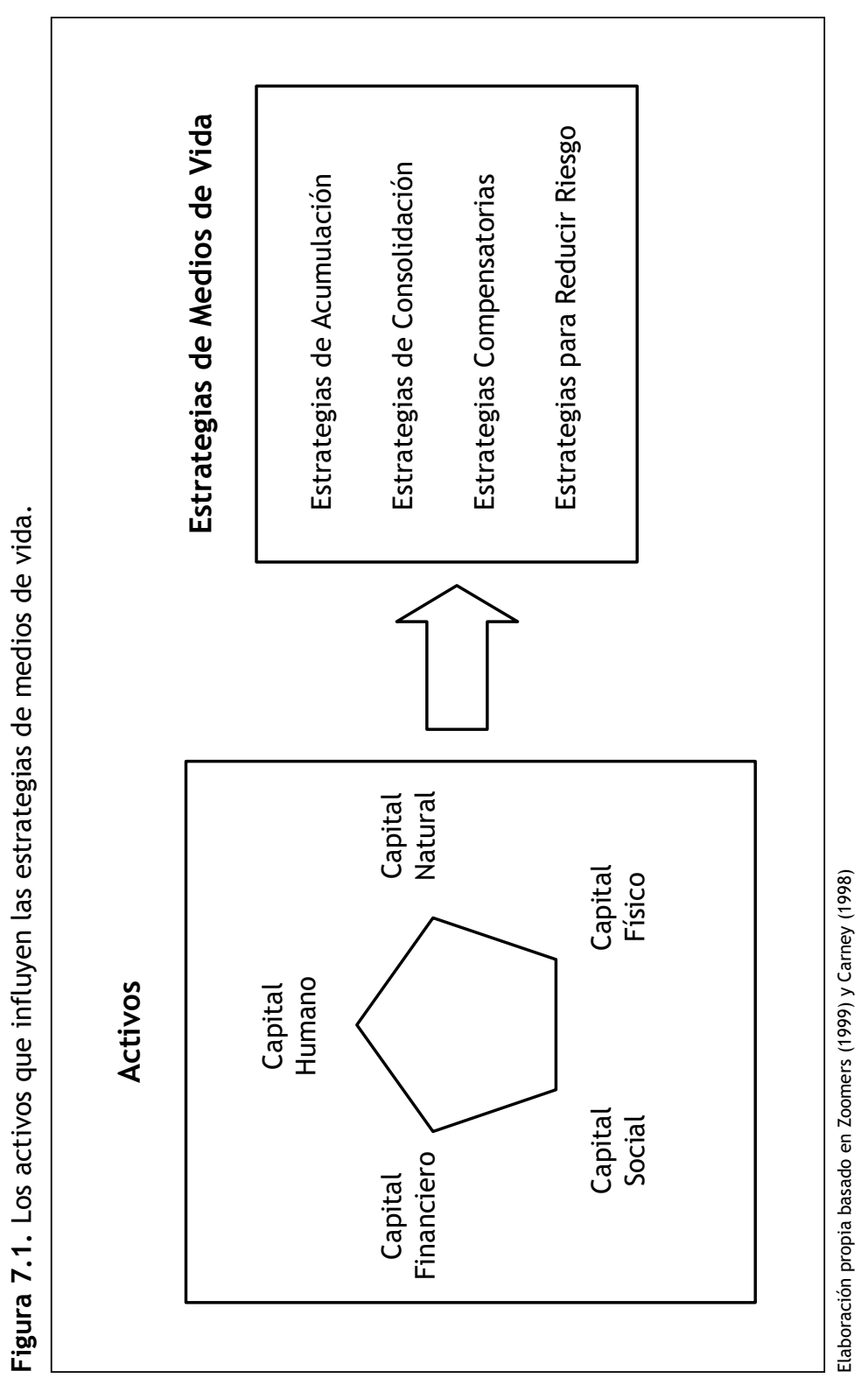


y aprovechar sus fortalezas. Con este fin Zoomers (1999) categoriza las estrategias en materia de medios de vida en una tipología elaborada en base a su experiencia en los Andes bolivianos. Esta tipología fue adaptada para encajar en el contexto de la Amazonía. Sus categorías principales son las siguientes:

1. Las estrategias de acumulación buscan establecer una base mínima de medios de vida y preparar esta base para una acumulación todavía más extensiva en el futuro.

2. Las estrategias de consolidación intentan estabilizar el bienestar de la familia y mejorar su calidad a corto plazo. Estas estrategias son empleadas particularmente por los hogares relativamente ricos que tienen excedentes para invertir.

3. Las estrategias compensatorias procuran hacer frente a una crisis temporal (mala cosecha, emergencia médica, pérdida de los medios de producción, etc.) o a una escasez estructural (P.ej., falta de mano de obra en familias incompletas).

4. Las estrategias para reducir el riesgo sirven para minimizar la inseguridad y el riesgo que se derivan del contexto de vulnerabilidad.

Un grupo particular en esta última categoría son las estrategias de diversificación, para las que se ha demostrado su importancia en el contexto de la comunidad de Galilea. Con las estrategias de diversificación, los hogares del pueblo tratan de aumentar su grado de seguridad, empleando una diversidad de prácticas (agricultura, explotación de los recursos naturales, trabajo asalariado, etc.). De esta manera se puede reducir el riesgo de una falta total de ingresos y de igual modo corrientes intra-anuales de renta, y la variabilidad inter-anual de la renta que está resultando de la inestabilidad de la producción agrícola y sus mercados.

\section{RESULTADOS}

\section{La diversidad de las estrategias en materia de medios de vida}

Este estudio analizó factores que explican un cierto grado de variaciones entre las familias de Galilea. A la heterogeneidad de los hogares contribuyen diferencias sutiles en las dotaciones de cada familia como la capacidad productiva, la integración en el mercado o el acceso a los medios productivos. Las metas y prioridades de cada familia se diferencian según estas circunstancias, y ellas adaptan y combinan sus estrategias para cubrir sus necesidades individuales. Con variante éxito, las familias intentan mejorar su estándar de vida usando estrategias de acumulación. Para estabilizar su situación usan estrategias de consolidación, y para asegurar su supervivencia adoptan el uso de estrategias compensatorias. Por otro lado, hay una variedad de factores (P.ej., igualdad de acceso al 
capital natural) que explican las características comunes de las formas de los medios de vida en Galilea. Una de las características más importantes es que los hogares tienden a no tener capital financiero para inversiones o para cubrir emergencias. Por lo tanto, los hogares deben confiar en otro tipo de capitales para compensar estas deficiencias (P.ej., en redes sociales o en los recursos del bosque). Consecuentemente, las familias viven en una situación potencialmente precaria e insegura en la cual ellas procuran aumentar su seguridad y reducir riesgos con las estrategias de diversificación (como la pérdida de rendimientos o de ingresos resultando de una mala cosecha, enfermedades, o migración).

Así, una producción diversa desempeña un papel importante en las estrategias de medios de vida de las familias de Galilea. Practicando la agricultura de roza y quema, la producción ganadera, pesca, caza y recolección de productos silvestres. Los pobladores de la comunidad utilizan una mezcla de actividades correlacionadas y complementarias (P.ej., la extracción de castaña para la venta en el mercado y la agricultura de subsistencia para la alimentación, o la caza como fuente de alimento y nivel social). Este ciclo complejo de producción permanentemente requiere de mano de obra en las actividades que tienden a culminar en ciertos momentos del ciclo anual (P.ej., las cosechas de arroz y castaña en el mes de abril). Además, muchos hogares presentan incapacidad productiva debido a que sus miembros migran o están enfermos. Por lo tanto, la disponibilidad de la mano de obra en las familias es un factor muy importante para el éxito en la diversificación.

\section{La importancia de la producción de subsistencia}

Los resultados de este estudio subrayan la importancia de la producción de subsistencia para las familias de Galilea, principalmente debido a la falta de opciones alternativas. Aunque, en comparación con otras comunidades indígenas de la región, la castaña es relativamente abundante y representa una porción significativa en los ingresos de cada hogar, su producción es naturalmente limitada y no puede sostener los ingresos de todas las familias de la comunidad.

Existen pocos productos alternativos con alto valor comercial puesto que debido a la infraestructura deficiente y a los mercados distantes, los productos agrícolas no se pueden vender a precios competitivos. Esto puede traducirse también como una realidad para otros productos provenientes de la caza, pesca y recolección de frutas silvestres.

Trabajar como jornalero es una actividad poco popular (especialmente entre las familias con miembros más ancianos) porque no existe trabajo en los alrededores de la comunidad y, como consecuencia, los trabajadores 
están forzados a emigrar a las barracas o a los centros urbanos, perdiendo así su enlace social y económico con la comunidad. Por ello, en Galilea se espera que la futura explotación de madera comercial beneficie considerablemente la economía de la comunidad. Sin embargo, desde el punto de vista legal, no ha sido posible iniciar la explotación de este recurso porque todavía no se ha aprobado el Plan de Manejo Forestal (PMF).

Por esta falta de alternativas, la agricultura de subsistencia es clave entre las actividades económicas de la comunidad, proporcionando la parte más importante del valor total de la producción agrícola por familia (entre US\$400 y US\$500 por familia). El valor de la producción de castaña, entre US\$280 y US\$530 por familia, no representa un ingreso estable. Bajo estas circunstancias, la agricultura de subsistencia conlleva una serie de ventajas a las familias del pueblo. Los recursos naturales de la comunidad se utilizan como recursos comunales, entonces, el acceso a la tierra agrícola es limitado exclusivamente por la capacidad productiva (mano de obra) de los hogares. Además, la agricultura presta pocos requisitos para la participación, pero rendimientos altos y un riesgo de subsistencia que es relativamente bajo.

Así, los habitantes de Galilea dependen de su capital natural para cubrir sus necesidades de medios de vida y para obtener ingresos económicos. En general, las actividades extractivas como la caza, pesca o recolección de frutas silvestres suplen las estrategias agrarias. En crisis (P.ej., mala cosecha) los hogares aumentan estas actividades para compensar las pérdidas en la agricultura. No obstante, para los pobladores de Galilea, la pesca y especialmente la caza significan mucho más que simples maneras de acumular recursos. Estas actividades son parte integral de la identidad masculina cavineña y están estrechamente vinculadas con el prestigio y estatus social de los hombres.

\section{La sostenibilidad de las estrategias en materia de medios de vida}

El uso de los recursos naturales en Galilea se caracteriza por una política de liberalismo. Con la excepción de la madera comercial, donde todavía existen restricciones burocráticas, el capital natural de la comunidad es propiedad comunal a la que todos tienen acceso. Sin mucha dificultad las familias pueden hacer sus chacos y, debido a sus habilidades y conocimientos especiales, adicionalmente pueden extraer los productos silvestres del bosque comunal.

Sin embargo, la presión sobre la base de los recursos está creciendo. Aunque no existen datos actualizados que estimen los cambios reales en los rendimientos de las actividades extractivas, la gente de Galilea observa que mantener sus medios de vida en base al extractivismo resulta cada vez más difícil. 
Los cambios en la pesca demuestran ser los más dramáticos. Los hogares no pueden compensar la casi exterminación de peces en uno de los lagos de la comunidad, y los pescadores están forzados a sobrexplotar los recursos restantes usando técnicas insostenibles (P.ej., pescando con redes).

En contraste con la caza y pesca, una explotación intensiva de la castaña no pone en peligro la futura regeneración de la especie. Sin embargo, la naturaleza limitada de este recurso, su calidad como producto comercial, y el precio que está bajando aumentan la competitividad entre los zafreros. Especialmente a las familias con escasa capacidad productiva les resulta cada vez más difícil extraer una cantidad de castañas suficiente para cubrir sus ingresos.

A pesar de la creciente presión sobre los recursos naturales, las familias de Galilea todavía no han impuesto reglas estrictas para influir el comportamiento extractivo de los habitantes de la comunidad. Las potenciales ventajas de una reglamentación no justifican los costos de establecer y hacer cumplir estas reglas según la percepción actual de los pobladores. Sin embargo, la futura explotación de madera comercial requerirá más restricciones y prácticas sostenibles de gerencia que todavía faltan en Galilea. Si en el futuro estas reglas serán ampliadas a otras actividades extractivas todavía no queda claro.

\section{Perspectivas de desarrollo}

Las perspectivas de desarrollo económico en Galilea se basan en gran parte en la explotación de madera comercial. Como ningún otro recurso, la madera significa la esperanza y la visión a futuro de la comunidad. Las autoridades de la comunidad estiman ingresos por la comercialización de madera entre US\$30,000 y US\$40,000. Si esta es una figura realista, este ingreso cambiará la situación económica de la comunidad.

Nilson Mayo, presidente de Galilea, resume sus esperanzas y habla de los planes de la comunidad para el futuro:

"Mi visión para el futuro [...] siempre es la madera, y creo que este año vamos a hacer algo, estábamos pensando lanzar un proyecto para poner un pequeño aserradero portátil aquí en el terreno. Aserrar y laminar la madera aquí, para luego en cada casa hacer paredes bonitas, el piso, canchones, bancos y mesas Esa es nuestra visión con nuestra propia madera, y un poco para la venta. Esa es una visión, y ojalá que lo logremos."

La mayoría de los pobladores tiene la esperanza de beneficiarse con la explotación de madera. Sin embargo, un grupo sigue siendo escéptico 
(especialmente las familias ya establecidas); para ellos los dirigentes comunitarios basan su discurso en sueños y aspiraciones que pueden, o no pueden transformarse en realidad. Hasta que ellos no vean resultados concretos, continúan confiando en estrategias de medios de vida "conservativas" para asegurar su futuro.

Similarmente, los adolescentes y hombres jóvenes de la comunidad prefieren basar sus visiones no solo en la explotación de madera sino también en estrategias de educación. Estas estrategias implican estar comprometidos activamente en la escuela, iglesia, y en otras actividades cívicas y políticas dentro de la comunidad, con el fin de obtener becas del Estado, de las misiones o de los partidos políticos nacionales. La comercialización de madera requerirá de mucho trabajo especializado, y con las becas los jóvenes tratan de prepararse para asumir estas responsabilidades.

\section{CONCLUSIONES}

Galilea es un ejemplo de comunidad indígena independiente y agroextractiva en el norte amazónico boliviano. Los resultados de este estudio demuestran que la producción de subsistencia, y no la producción para el mercado, es el centro de las actividades económicas de la comunidad. Contrario a una tipología propuesta por Stoian y Henkemans (2000), que agrupa a las comunidades según la fuente principal de ingresos económicos de sus pobladores, los resultados de este estudio sugieren que enfocarnos en los productos de mercado y en los valores económicos, significa implantar limitaciones severas para comprender los factores que conforman los medios de vida rurales.

Además, los resultados demuestran que los medios de vida de los habitantes de Galilea se caracterizan por tener un potencial de alto riesgo, que se originan por la falta de mano de obra para la producción y por la escasez de capital financiero. Para hacer frente a esta inseguridad, las familias adoptan actividades agrícolas y extractivas para la comercialización y también para su subsistencia, a fin de asegurar su futuro. Debido a la situación precaria en la cual se encuentran, no debe sorprender que algunos productos extractivos sean extraídos de manera insostenible.

A corto plazo, la comercialización de madera puede cambiar significativamente las estructuras económicas y sociales de la comunidad. Algunos de los problemas que la comunidad tiene que enfrentar son: (a) la falta de experiencia para negociar con las empresas madereras; (b) la tensión social debido a la distribución desigual de las ventajas en la explotación de madera, y (c) la degradación de sus recursos maderables. 
Con todas estas dificultades, Galilea, como otras comunidades indígenas de la región que enfrentan problemas similares, apreciaría la ayuda externa de proyectos para el desarrollo y conservación. Para generar un desarrollo social y ecológico sostenible, estos proyectos tendrían que centrarse no sólo en mejorar los ingresos económicos de los hogares sino también, por ejemplo, a través de la comercialización de madera. Este estudio ha demostrado que una de las grandes fuerzas de Galilea es la capacidad de sus familias para diversificar sus estrategias de medios de vida. Por lo tanto, la ayuda exterior debe consolidar las estrategias exitosas y eficaces que ya existen.

\section{NOTAS}

1 Barracas, grandes establecimientos productivos gomeros o castañeros. 2 Las leyes relevantes en este contexto son: Ley del Medio Ambiente 1333 (1992), Ley de la Participación Popular (1994), Ley de la Descentralización (1995), Ley 1257 (1996) que ratificó el convenio 169 de la OIT y que permite el establecimiento de Territorios Comunitarios de Origen; La Ley Forestal 1700 y la Ley INRA 1715 (1996) que regularon el manejo de los recursos naturales.

\section{REFERENCIAS}

Chambers, R. y Conway, R.1992. Sustainable Rural Livelihoods in Practice. Early Applications of Concepts in Rural Areas. En: Natural Resource Perspectives (42). London.

Carney, D. (ed.) 1998. Sustainable Rural Livelihoods. What Contribution Can We Make? DFID. London.

Derichs, A. y Rauch, T. 2000. LRE und der ,Sustainable Rural Livelihoods' Ansatz. En: Entwicklungsethnologie (9/2). pp. 60-78.

DFID. 1999. Sustainable Livelihoods Guidance Sheets. www.livelihoods.org García, A.E. (VAIPO) 1998a. Informe de identificación de necesidades y requerimientos espaciales. Tierra Comunitaria de Origen Cavineña. La Paz.

García, A.E. (PNUD). 1998b. Pueblo indígena Cavineño. La Paz.

Henkemans, A.B. 2001. Tranquilidad and Hardship in the Forest. Livelihoods and Perceptions of Camba Forest Dwellers in the Northern Bolivian Amazon. Riberalta.

Herrera, E. (VAIPO) 1998. Informe de caracterización de necesidades y requerimientos espaciales. Demanda Multiétnica: Ese-Ejja-TacanaCavineño. La Paz.

Stoian, D. 2000. Variations and Dynamics of Extractive Economies. The Rural-Urban Nexus of Non-Timber Forest Use in the Bolivian Amazon. Dissertación en la Universidad de Friburgo. 
Stoian, D. y Henkemans, A.B. 2000. Between Extractivism and Peasant Agriculture: Differentiation of Rural Settlements in the Bolivian Amazon. En: International Tree Crops Journal. Vol.10, no.4. pp.299-319. Aberdeen.

Zoomers, A. 1999. Linking Livelihood Strategies to Development. Experiences from the Bolivian Andes. Amsterdam. 


\title{
Capítulo 8
}

\section{Conflictos entre uso y protección de los recursos naturales, Reserva Nacional de Vida Silvestre Amazónica Manuripi}

\author{
Roberto Maldonado Kühne
}

\section{INTRODUCCIÓN}

La influencia del gobierno boliviano en la Reserva de Vida Silvestre Amazónica Manuripi (RNVSAM), analizada a través de instituciones formales, ha sido desde su fundación en 1973 hasta hace poco superficial. Esto ha generado que tareas como la de regular el acceso a la tierra o los derechos en el uso de Productos Forestales No Maderables (PFNMs), se realicen a través de instituciones informales, sin intervención del Estado, siendo los usuarios del bosque quienes protegen sus intereses de manera más eficiente.

Alrededor de 1990 el Estado ha iniciado esfuerzos para manejar y proteger la RNVSAM. Este esfuerzo coincide con reformas progresivas que tuvieron lugar en Bolivia durante los años 1993 y 1997, incluyendo los esfuerzos hacia la devolución de la tierra, ${ }^{1}$ la reforma agraria, la creación de una nueva Ley Forestal, la nueva Ley de Medio Ambiente, un estatuto general para áreas protegidas, etc. Tanto las reformas que consideran toda la amazonía boliviana, como la nueva administración de la reserva tienen un impacto significativo en la reserva. 
Las estructuras tradicionales, como las barracas que representan una forma de acceso a los recursos naturales, están siendo cuestionadas y en algunos casos cambiadas generando conflictos entre los diferentes usuarios del bosque. Cualquier organización que quiera mejorar las condiciones de vida de los habitantes así como proteger los recursos naturales de la reserva, tiene que conocer las instituciones locales así como comprender los conflictos existentes además de sus posibles consecuencias.

Se analizarán los diferentes usuarios del bosque, el acceso a los recursos naturales y finalmente las metas, relaciones y conflictos existentes entre los diferentes actores involucrados en la reserva a través de un análisis formal de las instituciones. El trabajo emplea el marco teórico de la "Nueva Economía Institucional". Este análisis permite comprender la situación actual de manejo del área así como predecir posibles influencias y decisiones futuras en torno al manejo de esta área y sus recursos.

El estudio incluyó trabajo de campo entre los meses de abril y julio del 2002, durante la época de sequía, periodo en el que los usuarios del bosque tienen más tiempo disponible y pueden ser entrevistados. Se realizaron entrevistas semi-estructuradas a los usuarios del bosque y a representantes de diferentes organizaciones tanto estatales como privadas que trabajan en la reserva. Además se organizaron dos viajes exploratorios al interior de la reserva y se participó en talleres de trabajo y una reunión comunitaria.

Para recopilar información, sobretodo datos en torno a conflictos, siempre se mantuvo una posición neutral, trabajando solo, sin acompañantes de la administración de la reserva o de otra organización. Además a veces fue necesario invertir varios días para que se pudiera establecer una relación de confianza. En el caso de conflictos las recomendaciones de Lederach (1992) fueron aplicadas, es decir evitar hablar de conflictos usando sinónimos menos negativos como pleitos, enredos o confusiones. La última consideración incluida es la propuesta por Atteslander (2000:138) quien sostiene que para obtener conclusiones, las informaciones obtenidas durante las entrevistas no deben ser usadas aisladamente sino que muchas veces es importante considerarlas en su conjunto.

Para levantar datos tanto en el área protegida como en las localidades de Cobija, Puerto Rico y Riberalta se usó entrevistas semi-estructuradas a usuarios del bosque $(n=52)$ y a representantes de organizaciones $(n=34)$ tanto estatales como privadas. La meta era lograr entrevistar a miembros de todas las comunidades así como a todos los barraqueros. Se entrevistaron a miembros de 7 de las 10 comunidades y a 18 de las 38 barracas. Para obtener mayor y mejor información, algunas personas fueron entrevistadas varias veces. Además se estudio fuentes escritas, tanto estatales como de 
ONGs. Se revisó cartas de denuncia de usuarios del bosque y se recopiló el libro de actas de los últimos tres años de una comunidad.

El capítulo tiene seis partes. Después de la introducción presenta información sobre el área de estudio. La tercera parte presente algunos conceptos teóricos a considerarse aquí. La cuarta parte contiene un análisis amplio de los actores que tienen que ver con el manejo de la reserva. Esta parte está seguida por una discusión de las amenazas para la reserva y la última sección concluye.

\section{ÁREA DE ESTUDIO}

La reserva Manuripi, ubicada en el norte amazónico boliviano, fue creada mediante el D.S. 11252 del 20 de diciembre de 1973. Entonces se llamaba Reserva Nacional Amazónica Manuripi - Heath y cubría aproximadamente 1.8 millones de hectáreas. Recién a inicios de los años 1990, por razones locales, nacionales y de política internacional empieza a funcionar la administración de la reserva (LIDEMA et al. 1992:2f). El Plan de Uso del Suelo del departamento de Pando (1996) propone la reducción del área de la reserva, adaptando sus márgenes a las condiciones naturales (ZONISIG 1996:7). Estas recomendaciones son institucionalizadas mediante el D.S. 25906 del 22 de Septiembre del 2000 que regula actualmente a la reserva. De este modo la reserva pasa a ser una Reserva Nacional de Vida Silvestre y su superficie es reducida a 750,000 hectáreas, finalmente cuenta con una administración y un cuerpo de guarda parques.

La reserva Manuripi cuenta con extensas áreas de bosque con poca intervención humana, predominando árboles de goma (Hevea brasiliensis) y castaña (Bertholletia excelsa), siendo la principal actividad económica la extracción de castaña (Herencia 2000:66).

La densidad media de árboles de castaña es de 1.86 árboles/ha según estudios de Herencia (2001b:56). Dentro de la reserva existen 564,426 ha de este tipo de bosque o 1 millón de árboles de castaña. Esto representa un potencial productivo de 1,3 millones cajas²/año de castaña (Herencia 2001b:56). Actualmente las barracas del río Manuripi producen 140,000 cajas/año, las barracas sobre el río Madre de Dios 70,000 cajas/año y las comunidades 10,000 cajas/año (Herencia 2001b:57). Por lo tanto sólo se aprovecha el $17 \%$ de la producción total. El $90 \%$ de la producción se vende en la ciudad de Riberalta.

La población de la reserva es casi en su totalidad mestiza. Según el censo de población y vivienda del 2001, en la reserva viven 1,541 habitantes. El $60 \%$ vive en las nueve comunidades libres ${ }^{3}$ (con personería jurídica), el $34 \%$ vive en barracas y el $6 \%$ vive individualmente (Herencia 2001b:14). Debido 
al alto grado de movilidad de la población estos datos fluctúan de año en año y dentro de un mismo año. La mayoría de las comunidades tienen acceso a los dos caminos que cortan la reserva mientras que la mayoría de las barracas se localizan a orillas de los ríos Madre de Dios y Manuripi que delimitan la reserva.

\section{DEFINICIONES: INSTITUCIONES Y CONFLICTOS}

North (1990:3) define instituciones como las reglas de juego dentro de una sociedad. Expresado más formalmente, son las limitaciones a las que las personas se someten voluntariamente para ínter relacionarse. De este modo instituciones pasan a ser reglas de juego y las organizaciones o personas los jugadores. Ambos se influencian mutuamente. De esta manera, esta teoría usa las instituciones existentes en una sociedad para entender las relaciones ínter personales (Vanberg en Mummert 1995:21). La naturaleza de estas relaciones puede ser política, social o económica.

Existen dos tipos de instituciones, las formales y las informales. Las instituciones formales son por ejemplo leyes y contratos. Las instituciones informales pueden ser tabúes, modales y tradiciones. Para Eger y Weise (en Mummert 1995:24) el mejor criterio para diferenciar los dos tipos es la forma en que se sanciona el no cumplimiento de una institución. A diferencia de las instituciones informales, en el caso de las formales el sistema de sanción está organizado, centralizado y estandarizado.

Según Imbusch y Zoll (1996:64) conflictos pueden ser definidos como hechos sociales, en los cuales por lo menos dos partes (individuos, grupos o estados) están envueltas y que se ocasionan por condiciones sociales diferentes $\mathrm{y} / \mathrm{o}$ por constelaciones de interés diferentes.

\section{ACTORES INVOLUCRADOS}

Para poder entender las instituciones y conflictos relacionados con los recursos naturales dentro de la reserva, es necesario presentar a los actores involucrados al igual que analizar sus metas e intereses.

\section{Actores estatales}

Administración de la Reserva. Cuenta con 17 empleados públicos de los cuales 13 son guarda parques. Debido al escaso personal, falta de capacitación y al hecho que la administración recién está trabajando hace dos años, aún no se cuenta con un plan de manejo participativo. Por estas razones la administración concentra sus actividades en inhibir la tala ilegal de madera sin visitar ni dar mayor acompañamiento a los usuarios del bosque. 
Es decir que la administración de la reserva aún no ha definido con claridad las modalidades y restricciones en el uso de los recursos naturales. Los usuarios del bosque saben que las actividades agropecuarias, la tala de árboles, caza y pesca sólo puede ser de subsistencia y que el extractivismo con fines comerciales es permitido. Lo que no saben es cuánta área, anualmente, pueden destinar para la tala y quema, cuántas cabezas de ganado se puede mantener y dónde están las diferentes zonas de manejo como la zona hábil para el extractivismo o la zona de protección permanente. Esto genera en los usuarios del bosque malestar y demandas compensatorias debido a las restricciones en el uso de los recursos. La administración, conjuntamente con los usuarios del bosque, esperan que con el plan de manejo de la reserva, actualmente en fase de concertación, se pueda definir operativamente las normas de uso y protección de los recursos naturales de la RNVSAM.

La ganadería es considerada por el director de la administración como muy problemática. Algunos barraqueros tienen más de 100 cabezas de ganado, y por lo tanto esta actividad ya no puede ser calificada como actividad tradicional o con fines de auto consumo. ${ }^{4}$

Respecto a la tala ilegal de madera, las pruebas indirectas encontradas son afirmaciones de diferentes oficiales estatales, usuarios del bosque, empleados de beneficiadoras en la ciudad de Riberalta y por último de algunos de los infractores. Otras pruebas son los caminos en tierras comunitarias hacia la frontera con el Perú y dos tractores "skidder" vistos en una barraca. Los barraqueros, con ayuda de algunos políticos departamentales, presionan al director de la reserva para autorizar la extracción de madera amparándose en el D.S. 26075 del 16 de febrero del 2001, decreto en el que se autoriza la extracción de madera dentro de áreas protegidas siempre y cuando el Servicio Nacional de Areas Protegidas (SERNAP) lo autorice.

Prefectura y municipios. La prefectura y los dos municipios afectados no cumplen con sus funciones de participar en el manejo del área, ignorándola o incluso persiguiendo metas contra producentes a la RNVSAM.

Instituto Nacional de Reforma Agraria (INRA). Debido a que en el año 2002 se esperaban los títulos de propiedad para aquellos pobladores legalmente establecidos dentro de la reserva, el INRA juega un papel importante en el manejo de la RNVSAM.

Superintendencia Forestal (SIF). Institución que controla la circulación de madera en los dos ríos limítrofes, el Manuripi y el Madre de Dios, además 
de regular las actividades forestales en la otra orilla de estos ríos. La SIF es vista por la mayoría de los barraqueros, sobre todo los asentados en Riberalta, como el órgano responsable de controlar el uso de madera en la reserva. Esta percepción no concuerda con la Ley Forestal 1700 ni con el Reglamento General de Áreas Protegidas D.S. 24781.

\section{Actores privados}

Asociación Campesina de Extractivistas Ecológicos de la Reserva Manuripi (ACEERM). Está en fase de reorganización, es la única organización comunitaria que representa los intereses de más de una comunidad. Junto con la ONG italiana Asociación de Cooperación Rural en África y América Latina (ACRA) está tratando de acceder a mercados verdes en Europa para la castaña ya que estos mercados pagan el doble del precio actual.

Asociación Agroindustrial de Recursos Naturales del Río Manuripi Pando (AARENARMAPA). Representa los intereses de los barraqueros del río Manuripi, esta asociación está bien organizada y tiene buenos contactos con la política departamental. Actualmente se está expandiendo hacia el río Madre de Dios.

Comunidades libres. El estado boliviano reconoce a las comunidades libres como unidad para otorgar títulos de propiedad, por ser consideradas como poblaciones originarias de la zona. Los derechos sobre tierras de las comunidades libres están reglamentados en los artículos 43 y 236-239 de la Ley INRA.

El INRA, basándose en una institución informal, entregará títulos de propiedad a las 10 comunidades libres (una comunidad no tiene personería jurídica) que habitan la reserva, a pesar de no cumplir con los requisitos de la ley INRA o de los dos decretos de la RNVSAM. El proceso incluye la comprobación del número de familias que viven o trabajan en una comunidad y el posterior otorgamiento de 500 hectáreas por familia ${ }^{5}$ (D.S. 225848 del 18 de julio del 2000). Se fijaron 500 ha/familia por ser aproximadamente el área necesaria para vivir de la extracción de la castaña. ${ }^{6}$ Esto se resume de la siguiente manera:

Área de una comunidad $(\mathrm{ha})=(\mathrm{n}$ familias legales $) * 500$ ha.

Como se puede ver en la Tabla 8.1, las comunidades procuran obtener la mayor cantidad de tierra posible usando dos estrategias: Presentan al INRA personas que no viven ni trabajan realmente en la comunidad y adicionalmente demandan áreas mayores a las que les corresponden de acuerdo al número de familias. Comparando datos propios de cuatro 
Tabla 8.1. Saneamiento de tierra (INRA) en comparación con demandas de cuatro comunidades

\begin{tabular}{|c|c|c|c|c|c|c|}
\hline Comunidad & $\begin{array}{c}\text { Familias } \\
\text { (INRA) }\end{array}$ & Familias & $\begin{array}{l}\text { Diferencia } \\
\quad \text { (Real) }\end{array}$ & $\begin{array}{l}\text { Saneamiento } \\
\text { (hectáreas) }\end{array}$ & $\begin{array}{c}\text { Tierra } \\
\text { demandada } \\
\text { (hectáreas) }\end{array}$ & Diferencia \\
\hline $\bar{A}$ & 14 & 8 & 6 & 7,000 & 11,638 & 4,638 \\
\hline B & 87 & 69 & 18 & 43,500 & 59,050 & 15,550 \\
\hline C & 36 & 34 & 2 & 18,000 & 24,532 & 6,532 \\
\hline D & 30 & 28 & 2 & 15,000 & 16,997 & 1,997 \\
\hline Total & 167 & 139 & 28 & $83,500^{*}$ & 112,218 & $28,717^{* *}$ \\
\hline
\end{tabular}

* Familias (INRA) * 500 ha

** Saneamiento - Tierra Demandada

Fuente: INRA y autor

comunidades con los datos del INRA se pueden verificar estas dos estrategias. En los datos observados se presenta al INRA la solicitud de tierras para 28 familias que no habitan en ninguna de las comunidades ni trabajan dentro de alguna, adicionalmente se demandan aproximadamente 30,000 ha más de las que corresponderían de acuerdo al número de familias presentado al INRA.

A nivel comunal se observó que la diferencia entre comunario y afiliado es una categorización problemática. A diferencia de los afiliados, los comunarios no tienen derechos dentro de la comunidad; es decir, el INRA va a considerarlos para determinar la superficie de cada comunidad, pero la comunidad no va a transferirles las 500 hectáreas asignadas por el INRA. En las comunidades donde este principio es aplicado, naturalmente se van a generar conflictos.

Barracas. Actualmente cada barraquero ocupa entre 1,000 y 80,000 ha de bosque y su principal función económica es la extracción de castaña. La Ley INRA define, que sólo usuarios tradicionales como campesinos y comunidades libres pueden habitar áreas protegidas. Las barracas son consideradas propiedades privadas (Ruiz, Capítulo 2) y su actividad extractivista no les otorga derechos formales dentro de la reserva. Sólo la pequeña superficie con fines agropecuarios los califica de campesinos y por lo tanto de usuarios tradicionales. De esta forma el INRA les va a otorgar títulos de propiedad sobre las pocas hectáreas plantadas o usadas para el ganado y no las 500 ha como en el caso de las comunidades. Respecto al resto de sus propiedades, dedicadas a la extracción de la castaña, el INRA va a medir la función económica del área en base a la nueva Ley Forestal. Es decir si pagan la patente forestal, si tienen un censo forestal, un Plan de Manejo, etc. (Herencia 2001a:37). Como ningún barraquero en Bolivia cumple estos requisitos, el INRA no va a otorgar títulos de propiedad sobre estas áreas. Esto es considerado injusto por los 
barraqueros argumentando que si cumplen los requisitos exigidos por la nueva Ley Forestal, sus costos de producción sobrepasarán los ingresos obtenidos por la extracción de castaña.

Por último cabe mencionar las localmente llamadas comunidades barracas, de las cuales existen tres en la reserva. Para el INRA se trata de comunidades, pero de facto son barracas. En este caso el barraquero adaptó su conducta a la reforma agraria, pretendiendo haberse creado una comunidad libre, para asegurar su propiedad. Es decir, aquí el barraquero no está perdiendo poder como en el caso de creación de una comunidad libre. Esta estrategia no está libre de conflictos porque no todos los actores la aceptan.

\section{Organizaciones No Gubernamentales}

Herencia. Única ONG reconocida oficialmente para trabajar dentro de la RNVSAM. Asesora a la administración de la reserva y a las comunidades ubicadas sobre la carretera al Chive. Además está elaborando, en base a estudios anteriores, el plan de manejo de la reserva junto con la administración.

ACRA. Quiere trabajar nuevamente con comunidades de la RNVSAM. Para obtener la autorización necesaria está usando dos estrategias: por un lado está pidiendo a ACEERM que solicite formalmente sus servicios de asesoramiento técnico y por otro lado quiere usar sus contactos con el gobierno italiano para que el SERNAP haga presión sobre la administración de la reserva.

La Tabla 8.2 muestra el tipo de relación que existe entre las organizaciones identificadas en el interior de la reserva. Estas relaciones pueden ser positivas $(+1)$, no existente $(0)$ o negativas $(-1)$. De esta forma se puede deducir entre qué actores se presentan relaciones institucionales o conflictos. La relación es presentada desde el punto de vista de ambas organizaciones.

\section{AMENAZAS PARA LA RESERVA NACIONAL DE VIDA SILVESTRE AMAZÓNICA MANURIPI}

Por falta de diálogo entre los diferentes actores las siguientes tres amenazas fueron observadas: Primero, la administración de la reserva sólo trabaja dentro de la reserva y por lo tanto no considera a los barraqueros que no habitan sus barracas viviendo en Riberalta, Puerto Rico o Cobija. Esto hace imposible el manejo de esta parte de la RNVSAM porque el director de la reserva sólo dialoga con los dueños de tierra considerando inútil trabajar con encargados que a veces son cambiados. Segundo, los comunarios 


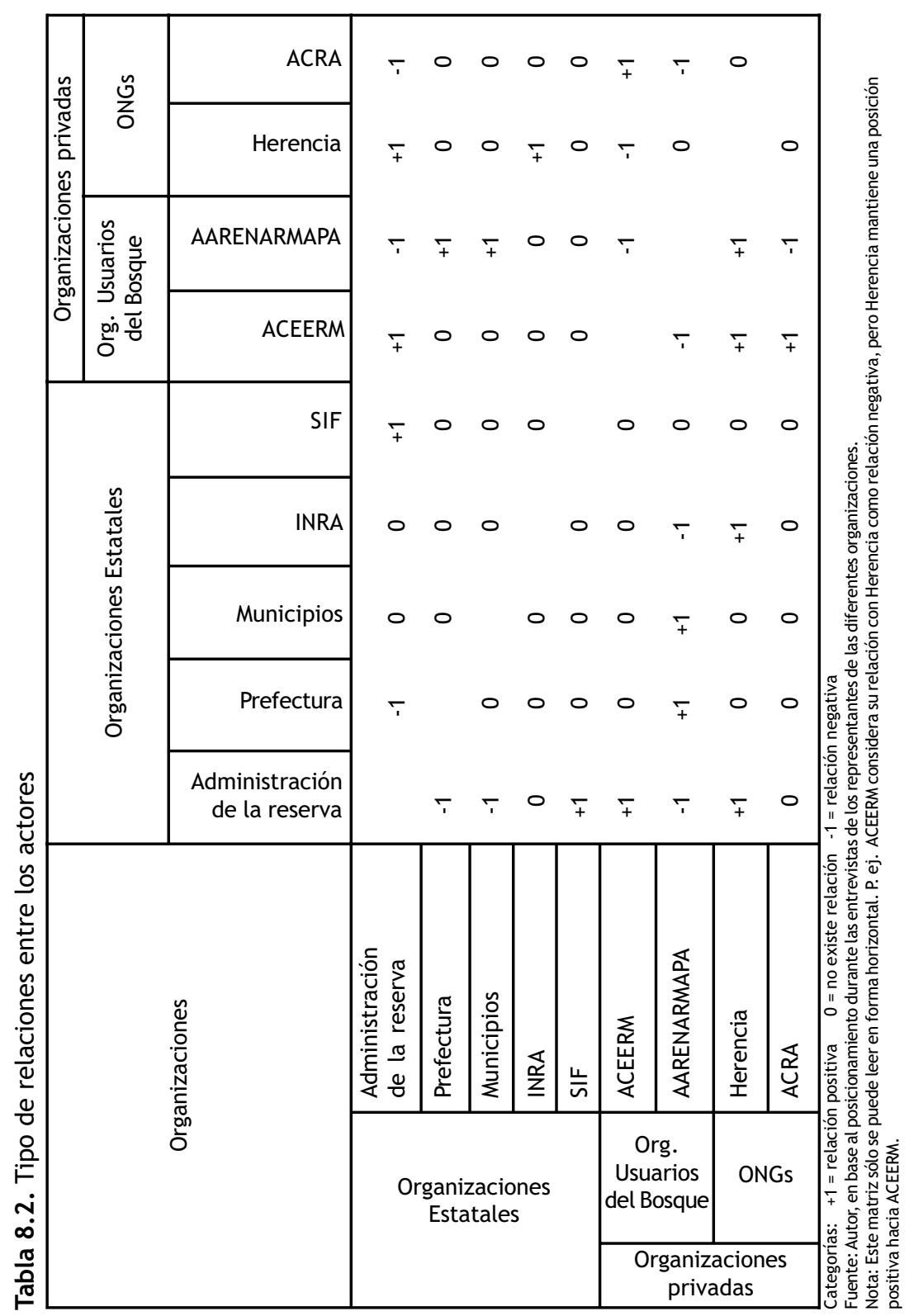


reclaman que tanto la administración como la ONG Herencia no participan regularmente de las reuniones comunales. El no aceptar sus invitaciones impide aclarar dudas y genera conflictos innecesarios. Tercero, algunos comunarios y afiliados no reconocen a sus líderes.

Respecto a carreteras, dos amenazas fueron identificadas: Primero, la construcción actual de la carretera bioceánica al norte de la RNVSAM puede convertirse en un conflicto si es que los $150,000 \mathrm{~m}^{3}$ de ripio, necesarios para su construcción, son extraídos de la comunidad el Chivé ubicada al sur de la reserva. El impacto ambiental a lo largo del camino hacia el Chive y para el Río Madre de Dios es inevitable en este caso. Segundo, la posible construcción de la carretera Cobija-Chivé-La Paz es considerada por los comunitarios y por el director de la reserva como una amenaza debido al temor de inmigraciones.

La inestabilidad política a nivel nacional genera tres amenazas para la reserva: Los comunarios temen que se revoque el D.S. que les asegura 500 hectáreas por familia. Segundo, los actores locales consideran posible la anulación del área protegida. Y por último, si se expande el área de coca plantada dentro de la reserva esto se puede convertir en un conflicto, como lo es en el Chapare y paulatinamente en el norte de La Paz (Los Tiempos del 20 de Noviembre del 2002).

La intensidad de relaciones institucionales así como relaciones conflictivas entre los diferentes actores se refleja en la Tabla 8.3, y es el resultado obtenido de las entrevistas realizadas a los diferentes representantes de las organizaciones y usuarios del bosque.

\section{DISCUSIÓN Y CONCLUSIONES}

El hecho que los barraqueros no obtendrán título de propiedad sobre sus áreas dedicadas a la extracción de castaña y que extensas áreas del norte boliviano van a ser tierras comunitarias, nos lleva a la situación que personas interesadas en controlar bosques para cosechar castaña o talar madera, ahora tratan de negociar con las comunidades en lugar de controlar directamente la tierra. Por otro lado, los barraqueros ante la eminente no titulación y posible desalojo de sus barracas en caso de no tener mejoras agropecuarias amenazan con las siguientes estrategias: a) Impugnar el estudio técnico jurídico del INRA, causando demoras en la titulación, b) No aceptar el fallo del INRA y defender sus propiedades, c) Deforestar sus propiedades para que el INRA reconozca estas mejoras como mejoras agropecuarias. 


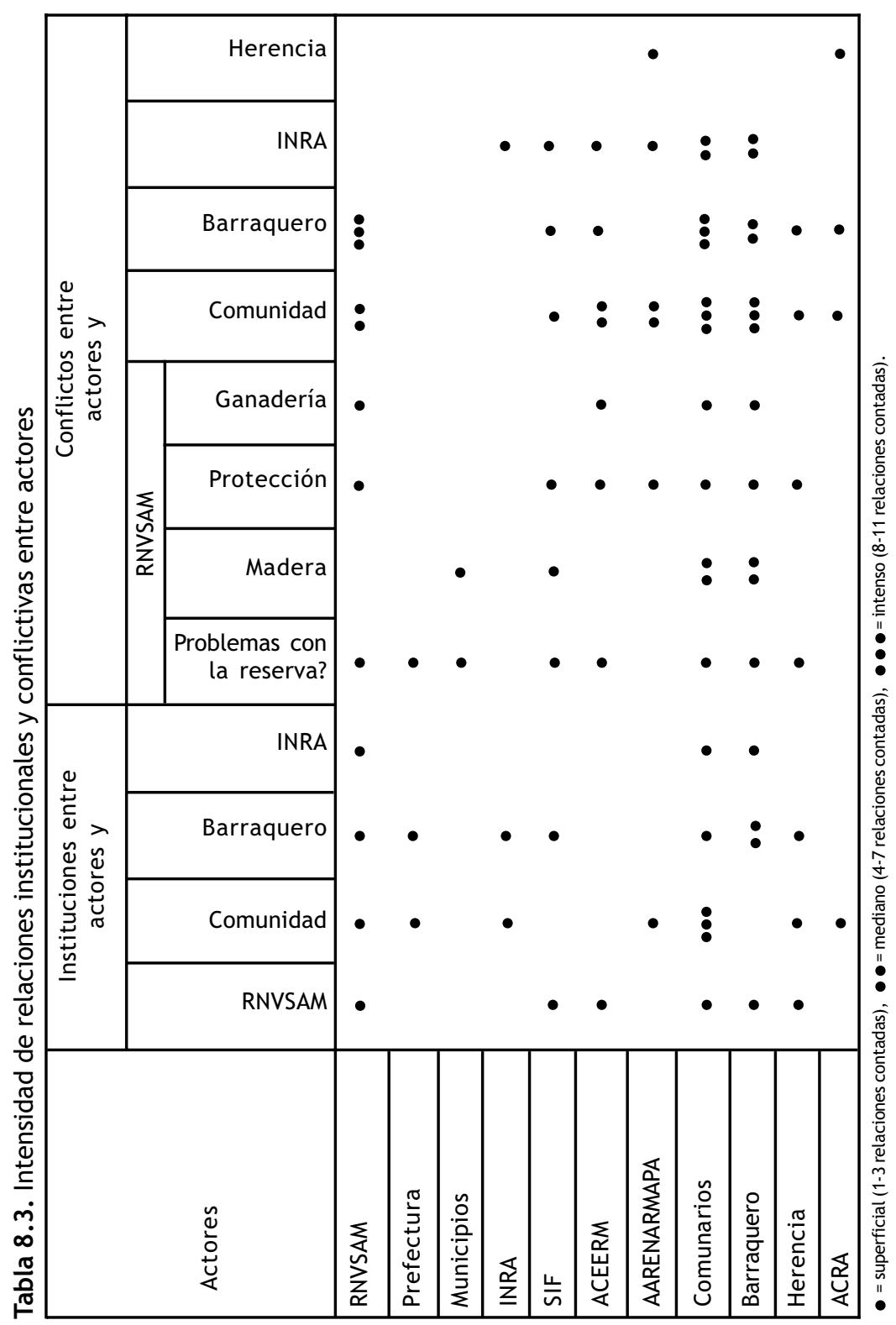


Los conflictos en torno a la tierra no se deben tanto al título de propiedad sino al acceso a la castaña. Dos aspectos prueban esta conclusión. Primero, los usuarios del bosque afectados no pelean por hectáreas de bosque sino por caminos castañeros o cantidad determinada de castaña. Y segundo, el resto de los recursos naturales como caza, jatata, materiales de construcción, plantas medicinales etc. no son razón de conflicto ya que muchas veces el mismo lugar es usado por más de un usuario del bosque.

Como debilidad se identificó la falta de un espacio para articular y solucionar conflictos entre la administración y los usuarios de la reserva. Este espacio de diálogo y negociación también es necesario para manejar de forma participativa a la RNVSAM. De acuerdo a Gumbo (1999) se deben usar estructuras ya existentes. En el caso de la reserva se consideran apropiados dos espacios para dialogar y negociar. Primero las reuniones comunales así como las reuniones de la AARENARMAPA y segundo el comité de gestión. En el caso de las reuniones, la debilidad se debe a que las diferentes organizaciones invitadas por los usuarios del bosque no asisten.

El comité de gestión es el órgano establecido por ley para representar a todos los usuarios de un área protegida. Actualmente se está creando tal comité y por lo tanto el autor hace las siguientes recomendaciones: Para que todos los usuarios del bosque estén representados, la administración de la reserva debe hacer esfuerzos para incluir a los barraqueros que no habitan el área. Por otro lado la representatividad de las comunidades también tiene que ser garantizada. Esto quiere decir que los representantes comunales tienen que ser elegidos democráticamente y que las organizaciones involucradas tienen que considerar también a las comunidades que no se encuentran sobre la carretera al Chivé.

\section{NOTAS}

${ }^{1}$ Devolución: Difiere de una descentralización porque no solo competencias administrativas son transferidas a instancias subordinadas del sistema administrativo de un país, sino también legitimidad política (Rondinelli et al. 1983:14-15 en Stoian 2000:46).

${ }^{2}$ Caja: Unidad de medida para nueces de castaña en cascara. La caja de madera $(51 * 27 * 35 \mathrm{~cm})$ contiene alrededor de 22 a $26 \mathrm{~kg}$. (Stoian 2000:xii).

3 Definición: Comunidad libre es un asentamiento rural capaz de acordar por fuerza propia acuerdos institucionales que regulan el uso de recursos naturales. Generalmente los miembros de una comunidad libre trabaja sus parcelas independientemente (Stoian 2000:184f).

${ }^{4}$ Según datos de Herencia (2001b:51), los barraqueros son dueños de casi el 70\% de las 1,200 cabezas existentes en la reserva. 
${ }^{5}$ Este decreto define 500 ha como mínimo pero no aclara la superficie máxima. Una institución informal solucionó este problema. En la reunión del Comité de Saneamiento del Norte Amazónico del 20 de febrero del 2002, donde participaron representantes de campesinos, ONGs y el director nacional del INRA, se acordó fijar como superficie máxima 560 ha.

${ }^{6}$ La prefectura es considerada un actor, porque ésta es la opinión de todos los actores entrevistados. Según los artículos 16 y 24 del Reglamento General de Áreas Protegidas D.S. 24781 del 31 de julio de 1997, esto es incorrecto. Estos artículos definen que la categoría de manejo reserva de vida silvestre puede ser departamental o nacional. El artículo 39 de este D.S. aclara que las prefecturas sólo son responsables a nivel departamental para reservas departamentales de vida silvestre, no para reservas nacionales de vida silvestre como la RNVSAM.

\section{REFERENCIAS}

Gumbo, F. 1999. Conflict management and forest disputes. Is there a path out of the woods? Harare, Zimbabwe. (sin publicar)

Herencia. 2000. Diagnóstico de los recursos forestales en la RNVSAM. Con énfasis en la castaña (Bertholletia excelsa). Cobija, Bolivia. (sin publicar)

Herencia. 2001a. Análisis de los marcos legales para la consolidación propietaria en la Reserva Nacional de Vida Silvestre Amazónica Manuripi y las posibilidades legales de uso de los recursos forestales. Cobija, Bolivia. (sin publicar)

Herencia. 2001b. Diagnóstico de sistemas socioeconómicos y ocupación del espacio. Cobija, Bolivia. (sin publicar)

INE - Instituto Nacional de Estadística www.ine.gov.bo (03 de Agosto del 2002).

LIDEMA; CORDEPANDO PL-480. 1992. Plan para el desarrollo integrado de la Reserva Nacional Amazónica Manuripi-Heath (Fase II) La Paz, Bolivia.

Los Tiempos - www.lostiempos.com (20 de noviembre del 2002).

Maldonado, R. 2002. Natural Resource Management in a Tropical Protected Area. Conflicts between use and protection in the Reserva Nacional de Vida Silvestre Amazónica Manuripi - RNVSAM, Bolivia. Tesis de licenciatura Universidad Albert Ludwig. Freiburg, Alemania (sin publicar).

Mummert, U. 1995. Informelle Institutionen in ökonomischen Transformationsprozessen. Nomos-Verlag-Gesellschaft, Baden-Baden, Alemania.

North, D.C. 1990. Institutions, institutional change and economic performance. Cambridge University Press, Cambridge, Gran Bretaña.

North, D.C. 1992. Institutionen, instituioneller Wandel und Wirtschaftsleistung. Mohr, Tübingen, Alemania. 
Stoian, D. 2000. Variations and dynamics of extractive economies: the rural- urban nexus of non-timber forest use in the Bolivian Amazon. Tesis de doctorado Universidad Albert-Ludwig. Freiburg, Alemania (en prensa).

ZONISIG - Proyecto de Zonificación Agroecológica y Establecimiento de una Base de Datos y Red de Sistema de Información Geográfica en Bolivia (1996): Plan de uso del suelo del Departamento de Pando. La Paz, Bolivia. 


\section{Capítulo 9}

\section{Extracción forestal, procesos migratorios y deforestación en el norte amazónico boliviano}

Victor Llanque

\section{INTRODUCCIÓN}

En el norte amazónico boliviano conviven pobladores con diferencias culturales muy marcadas, el sustento de estos pobladores se basa en la extracción de productos forestales. La región cuenta con una gran variedad de plantas y especies animal. La deforestación tropical incontrolable no sólo pone en peligro la conservación de la biodiversidad, sino que también es una amenaza a la sobrevivencia de las comunidades locales que dependen directamente de este ecosistema. Los políticos, científicos y el público en general están cada vez más preocupados con la deforestación tropical y sus consecuencias negativas. Existe la necesidad de entender los factores directos e indirectos que conllevan a la deforestación tropical y sus consecuencias, para poder asegurar la continuidad de este ecosistema. Para contribuir con estas metas, este capítulo analiza la relación entre la extracción de productos forestales, los procesos migratorios, y el impacto de las actividades de poblaciones en el bosque del norte amazónico boliviano. El estudio abarca el departamento de Pando y la Provincia de Vaca Diez en el departamento del Beni. 
Este capítulo no sólo investiga las relaciones causales directas entre la extracción de productos forestales, procesos migratorios y deforestación; también analiza otros factores que afectan estas relaciones. Una percepción muy sencilla de esta relación es que las áreas forestales remotas proporcionan oportunidades para aprovechar este recurso a grupos que son privados de este derecho en su lugar de origen. Estos grupos migran hacia las regiones forestales, y sus actividades tienen un impacto sobre el bosque. Cuando uno, sin embargo, mira los casos específicos con más detalle, el cuadro se muestra mucho más complejo. Es necesario entender mejor estos casos específicos para poder comprender la compleja relación entre procesos migratorios, bienestar poblacional, y la condición del bosque tropical. Este capítulo analiza las relaciones causales entre la extracción de productos forestales, procesos migratorios y los cambios en la condición del bosque en el norte amazónico boliviano.

El capítulo se divide en seis secciones, incluyendo esta introducción. La sección dos presenta la historia económica de la explotación forestal en el norte amazónico boliviano, y cómo ésta ha influido en las primeras migraciones. La siguiente sección analiza los procesos modernos de migración en el norte amazónico boliviano. La sección cuatro proporciona las explicaciones de estos procesos modernos de la migración. La sección cinco analiza cómo estas migraciones han afectado la condición del bosque en el norte amazónico boliviano y la sección seis concluye.

\section{EXTRACCIÓN DE PRODUCTOS FORESTALES Y LA HISTORIA DE MIGRACIONES}

Grupos indígenas dispersos habitaban originalmente el norte amazónico boliviano, subsistiendo a través de la caza, pesca, y extracción de productos forestales (CIDOB 1979a, citado en Stoian 2000). Estos grupos indígenas cruzaron regularmente las fronteras con Perú y Brasil, mostrando una alta movilidad geográfica, generando sobre el bosque un impacto muy bajo (Lockhart y Schwartz 1989, citado en Stoian 2000). Desde el siglo XIX, se incrementa aceleradamente los niveles poblacionales de la región debido a la explotación de los productos forestales. Primero, los emigrantes vinieron a extraer la quinina (Cinchona spp), una medicina para la malaria. La explotación del caucho (Hevea brasiliensis) que tuvo su auge entre 1880 y 1920 trajo un gran número de migrantes al norte amazónico boliviano. Cuando el caucho asiático es aceptado en el mercado internacional, la región amazónica se ve duramente afectada y como consecuencia de esto también se ve afectada la migración hacia la región. Los grandes empresarios controlaban grandes áreas forestales bajo una propiedad llamada barraca, estas grandes áreas incluían bosques y un lugar para la acumulación de caucho. Allí vivían los trabajadores, compraban sus necesidades básicas en tiendas y llevaban el caucho que recolectaban a los depósitos. 
Con la aceptación del caucho asiático en los mercados internacionales, la economía del norte amazónico boliviano cambió basándose ahora en la recolección de castaña (Bertholletia excelsa), mientras que la extracción del caucho continuó pero en menor escala. Muchos de los trabajadores que vivían en las barracas se trasladaron a otros lugares "comunidades libres". Algunas de estas comunidades se localizaron en los mismos lugares de las barracas, pero otras fueron establecidas en lugares más convenientes para los nuevos pobladores. La extracción del caucho nuevamente toma importancia en la región durante la Segunda Guerra Mundial, cuándo las Fuerzas Aliadas no podían contar con el abastecimiento de Asia. La nueva crisis del caucho, después de la Segunda Guerra Mundial, generó nuevamente una intensa migración dentro de la región por la reorganización de la extracción de productos forestales. La caída de las exportaciones de caucho en Bolivia, y la Reforma Agraria en 1952 dieron un nuevo impulso a la migración de personas desde las barracas hacia las comunidades libres. La Tabla 9.1 muestra información oficial sobre datos demográficos para ilustrar la movilidad interna de poblaciones en el norte amazónico boliviano durante el periodo 19762001.

\section{LAS MIGRACIONES MODERNAS}

\section{La inmigración hacia el norte amazónico boliviano}

El norte amazónico boliviano no está muy densamente poblado, comparado con el resto del país, cuenta con aproximadamente 169,000 habitantes en el departamento de Pando y la Provincia de Vaca Diez. Esto tiene como resultado una densidad poblacional de 2 habitantes por $\mathrm{km}^{2}$, siendo la densidad poblacional de Bolivia del $7.6 / \mathrm{km}^{2}$ (Tabla 9.2). Más del $60 \%$ de la población regional ahora vive en sólo tres centros urbanos, Riberalta (54\%), Guayaramerín $(27 \%)$ y Cobija $(17 \%)$. Hasta finales de la década de 1990, el número total de inmigrantes en las tierras bajas bolivianas era relativamente bajo, sin embargo los porcentajes de migrantes son bastante significativos (Tabla 9.3). La población de inmigrantes en esta región aumentó en un 8.1\% hasta 1992.

Los flujos de migrantes desde otras regiones del país no eran muy significativos en las áreas rurales, eran más importantes en los centros urbanos. La población rural ha crecido sobretodo de acuerdo a la tasa de crecimiento interna, sugiriendo una mínima inmigración extra-regional en estas áreas. Los migrantes de otras regiones que vienen a cultivar o vivir en las áreas rurales son atraídos hacia las áreas de la colonización identificadas así por el gobierno (Beni Alto, La Paz, y Santa Cruz). En el norte amazónico boliviano el desarrollo de la frontera agrícola depende de las iniciativas del sector privado, aunque no se inició ningún esfuerzo mayor 


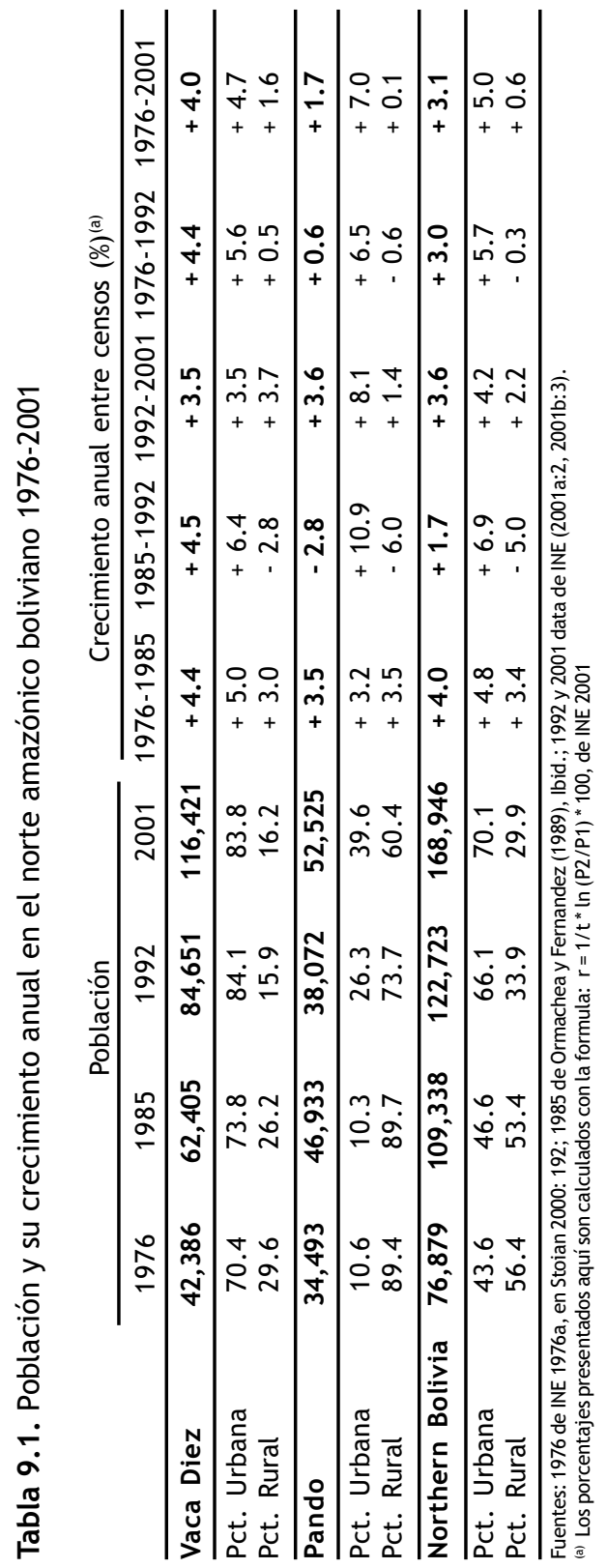




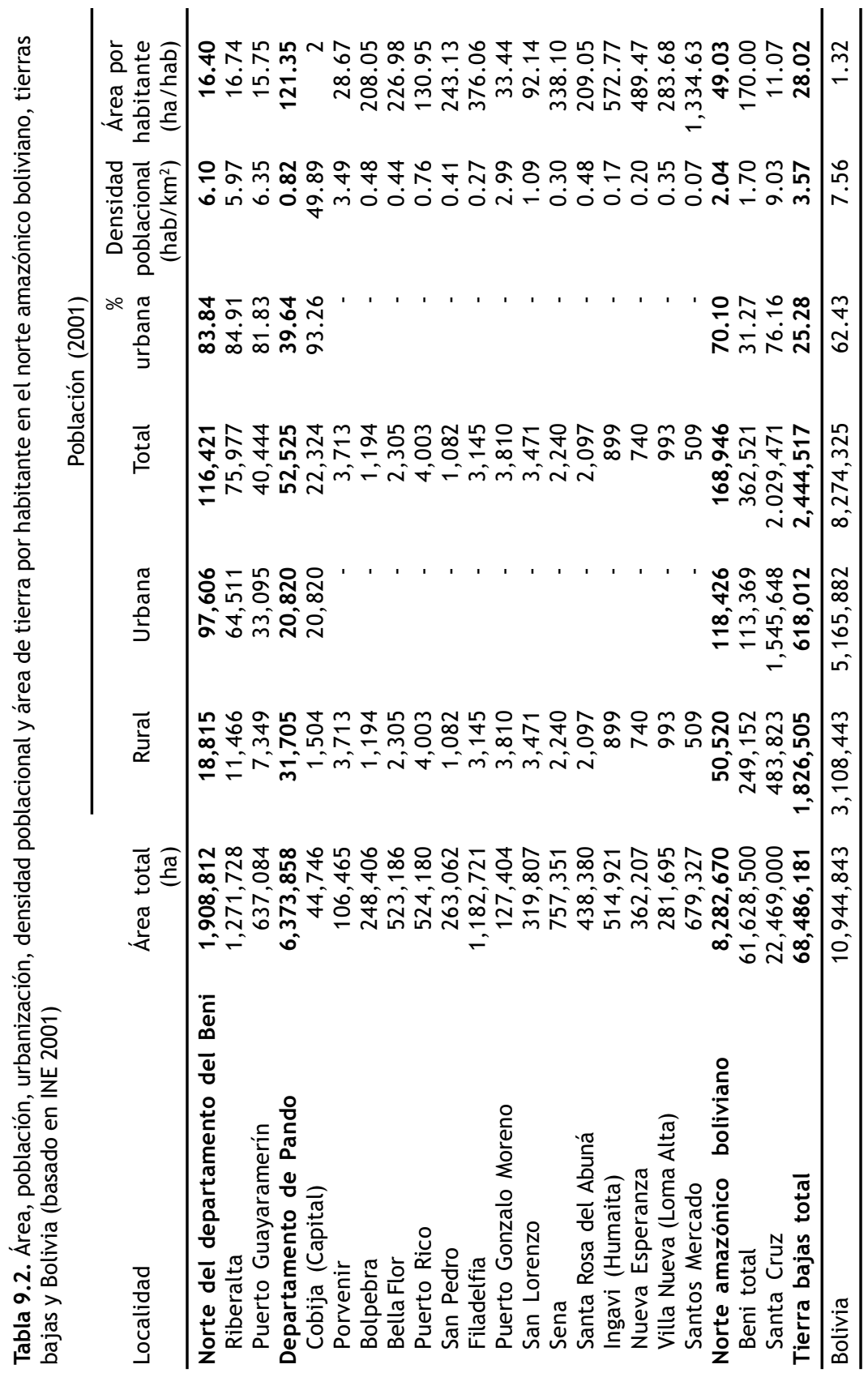




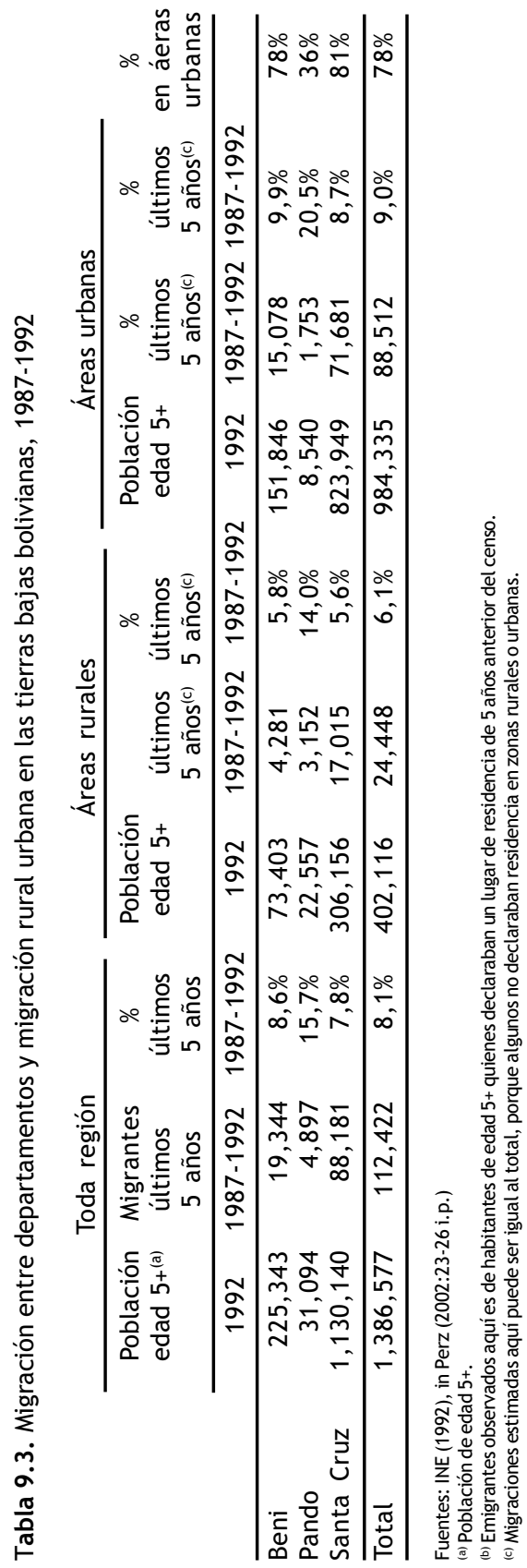


de colonización desde la época del caucho (Stoian 2000). La mayoría de inmigrantes extra-regionales se asientan en los centros urbanos de esta región. Este tipo de migración ha sido especialmente intenso una vez terminada la carretera que conectó el norte amazónico boliviano con el resto del país en 1986. En años recientes migraciones hacia la ciudad de Cobija, la capital de Pando, localizada en la frontera con Brasil, han aumentado fuertemente. Comerciantes de los Andes vienen hacia la región a comercializar sus productos en el mercado local y para beneficiarse del acceso directo a la frontera brasileña. Esto se refleja en el alto porcentaje de nuevos inmigrantes en la región entre 1987 y 1992 (Tabla 9.3). En la Provincia de Vaca Diez, estas poblaciones se asentaron en Riberalta y Guayaramerín. Riberalta es un mercado importante en si mismo, que atrae muchos comerciantes. Guayaramerín está en la frontera con Brasil y sirve como camino de importación para los productos industrializados de Brasil.

\section{La migración intra-regional}

La migración dentro de la región presenta un cuadro más complejo. La recolección de castaña y caucho continuaron como las principales actividades económicas hasta finales de la década de 1980. Estas actividades combinadas proporcionaron una ocupación para recolectores prácticamente durante todo el año. La eliminación de los subsidios que daba Brasil para el caucho durante la mitad de los años 1980, y que beneficiaba también a los productores de caucho boliviano, al igual que la hiperinflación boliviana explican el decline de las exportaciones del caucho. Desde entonces la extracción de productos forestales era limitada a la recolección de castaña. Desde que la extracción de productos forestales no proporcionó una ocupación completa, los habitantes forestales no vieron otra alternativa que mudarse cada vez más hacia comunidades libres o hacia centros urbanos de la región. Un inventario de comunidades realizado en 1997 por Stoian (2000) en zonas de extracción de caucho y castaña y en comunidades libres, reveló que entre los años 1986-1997, el 81\% de las barracas habían experimentado emigración, el $16 \%$ tenían poblaciones estables, y que sólo el $3 \%$ había experimentado inmigración hacia las barracas. Durante estos años el $63 \%$ de las comunidades libres experimentaron inmigración, el 31\% experimentaron emigración, y el $6 \%$ tenían una población estable. Entre los años 19921997 , en promedio las barracas perdían el $34.6 \%$ de su población debido a emigración, mientras que la población en las comunidades libres aumentó en un $47.5 \%$ (cifras ajustadas por el crecimiento interno). Combinando las pérdidas o ganancias de la migración de barracas y comunidades libres, la población de los asentamientos investigados creció en un $10.7 \%$ durante los años 1992-1997. La inmigración fue más intensa en los centros periurbanos de Riberalta que crecieron en un $84 \%$ durante este período. 
El departamento de Pando y la Provincia de Vaca Diez experimentaron una alta urbanización, especialmente después de 1985. El pueblo de Riberalta experimentó la inmigración más alta entre los años 1980-1987, cuando su población tuvo un crecimiento del $6.7 \%$ anual. Como resultado de estos cambios migratorios, el año 1985 marca un punto clave para el departamento de Pando. Antes de este año la población de Pando crecía 3.5\% anualmente. Después de 1985 y hasta el año 1992 la tasa de crecimiento anual fue negativa $(-2.8 \%)$ como resultado de la emigración, principalmente de sus áreas rurales. Además, mientras que las áreas rurales de Pando crecían negativamente en $-6.0 \%$, las áreas urbanas en este departamento y en la Provincia de Vaca Diez crecían anualmente en un $10.9 \%$ y $6.4 \%$ respectivamente. La urbanización, sin embargo, se veía en Riberalta desde antes de 1985. Entre los años 1976-1985 el crecimiento anual ya considerablemente alto fue del $5.0 \%$.

Otro proceso migratorio muy intenso en la región es la migración estacional de Riberalta hacia las barracas antes y después de la época de cosecha de castaña. Actualmente, entre 5,000 y 6,000 recolectores de castaña (zafreros), toman parte en la cosecha entre los meses de noviembre y marzo. En este periodo los zafreros migran al bosque y permanecen allí durante tres meses aproximadamente.

Durante los años 1992-2001 el éxodo rural al igual que el proceso de urbanización ha disminuido. Durante este período, las poblaciones rurales en Vaca Diez y Pando han aumentado en un $3.7 \%$ y $1.4 \%$ respectivamente. Las tasas anuales de crecimiento demográfico urbano disminuyeron de 6.4\% entre los años 1985-1992 a 3.6\% entre los años 1992-2001 en Vaca Diez, y de $10.9 \%$ a $8.1 \%$ en Pando.

\section{Las causas inmediatas de la migración intra-regional}

Los factores que influyen en la migración se dividen en dos grupos. Son factores de atracción de la región a donde se migra, y son factores de empuja, que originan la salida de personas de sus lugares. Ambos factores explican la migración rural-urbana, urbana-rural, y rural-rural en la región (Llanque 2003). Las bajas oportunidades de trabajo después de la crisis del caucho de medianos 1980 fue el principal factor para que los habitantes forestales abandonaran sus asentamientos rurales. La perspectiva de más oportunidades de empleo en Riberalta, como resultado de la expansión de la industria de procesamiento de castaña (Bojanic 2001), fue el factor principal que atrajo a los habitantes forestales a este pueblo. Cobija y Guayaramerín atrajeron a emigrantes urbanos quienes trataban de beneficiarse del intensivo comercio fronterizo. Factores de empuja y de atracción también explican la migración rural-rural desde barracas hacia comunidades libres. Mientras que la falta de empleo en las barracas después 
que las diferentes crisis de caucho empujó a recolectores de castaña a salir de las barracas, la oportunidad de combinar actividades agrícolas y la recolección estacional de castaña atrajo a estos emigrantes a las comunidades libres.

Al mismo tiempo, sin embargo, los servicios que se proporcionan en las ciudades y comunidades independientes influyeron (factor de atracción). Los inmigrantes en las comunidades libres y ciudades regionales son atraídos por los servicios de salud y educación. Las oportunidades de educación y la asistencia médica fueron muy bajas en las barracas. De todos los ex recolectores de caucho entrevistados el $7.1 \%$ no tuvo ninguna educación, mientras que cerca del $41 \%$ no terminó la escuela primaria (Llanque 2003).

\section{Las causas subyacentes de la migración moderna}

La sección previa describió las causas inmediatas de la migración. Sunderlin y Resosudarno (1996) proponen, que existen causas subyacentes fundamentales que provocan estas causas inmediatas. Las políticas macroeconómicas y políticas específicas pueden ser consideradas como estos tipos de causas. Bolivia tuvo tres principales generaciones de reformas: en la década de 1950, 1980 y 1990, que explican la situación actual del país y en parte las tendencias generales de la migración y la deforestación relacionada.

El primer cambio se dio en 1952, cuándo políticas económicas bolivianas cambiaban de un enfoque de exportaciones de minerales a una estrategia más social que apuntó a diversificar la estructura económica así como a sustituir las importaciones. El gobierno boliviano impulsó la producción agraria en las regiones bajas para reemplazar las importaciones de alimento y resolver la presión demográfica que se vio en los Andes (Pacheco 1998:152). Este proceso fue acompañado de una Reforma Agraria asignando tierra para la agricultura, construcción de caminos, programas de colonización hacia las tierras bajas tropicales, créditos y otros subsidios para la producción agrícola en las tierras bajas tropicales. Como resultado de estas medidas la migración y deforestación se intensificó gradualmente, especialmente en las regiones orientales del país con los núcleos de Cochabamba y Santa Cruz. No obstante, este proceso no fue masivo ya que la producción agrícola fue orientada a un pequeño mercado interno. Estos cambios no tuvieron un impacto significativo en el norte boliviano. Ninguna de estas políticas estuvo enfocada a desarrollar el sector forestal, ya que este no se consideró como una prioridad dentro de la estrategia de la diversificación productiva. Sin embargo, la reforma agraria estimuló la migración interna en el norte amazónico boliviano como fue descrito anteriormente. 
El 29 de agosto de 1985 Bolivia adoptó su Nueva Política Económica (NEP) con el objetivo de estabilizar la hiperinflación. La NEP aplicó los ajustes estructurales típicos de un sistema neoliberal: la liberalización casi total de mercados de bienes, crédito, capital y trabajo, por la eliminación del control de precios internos y la abolición de los límites cuantitativos para el comercio internacional. Además, se disminuyó la inversión del Estado y las subvenciones. Este nuevo modelo macroeconómico dependió de la producción para la exportación por un nuevo sector privado dinámico (IDH, 2003). Los ajustes estructurales estimularon las exportaciones no tradicionales por medio de reducción de impuestos y la mejora de caminos entre otras medidas. Estos cambios tuvieron un impacto profundo sobre la expansión agrícola y los procesos migratorios en la región. Generando especialmente la migración hacia la parte oriental de Bolivia, es decir, hacia la región de Santa Cruz, llegando la expansión agrícola y deforestación a esta región (Pacheco y Mertens 2003). Como resultado de estos cambios, la deforestación en las tierras tropicales bajas aumentó drásticamente después de la década de 1980.

Durante la década de los años 1990 una tercera generación de reformas contrarrestó parcialmente las consecuencias de las políticas económicas neoliberales, tomando en cuenta aspectos de medio ambiente, sociales y económicos. El establecimiento del Ministerio de Desarrollo Sostenible y la Pausa Ecológica, limitaron la expansión de actividades forestales. La Ley Ambiental (1992), y la Ley de Participación Popular (1994), al igual que la nueva Ley del Instituto Nacional de Reforma Agrária (1996) y la Ley Forestal (1997) son productos de esta tercera generación de reformas. Como resultado de esta reforma, entre los años 1950 y 1995 el porcentaje de tierras bajo cultivo en los trópicos aumentó del 15\% al $58 \%$ del área nacional cultivada (Figura 3). De esta área tropical cultivada, cerca del $80 \%$ es aprovechado por las compañías que producen principalmente soja para exportaciones, mientras que las demás son aprovechadas por campesinos que practican principalmente la agricultura de subsistencia.

Estas políticas han tenido pequeños impactos pero muy notables en la región norte de Bolivia. Sin considerar el efecto de la reforma agraria de los años 1950, el programa de construcción de caminos durante la década de los años 1980 dio accesibilidad al norte amazónico boliviano. Esto, hasta cierto punto explica la llegada de inmigrantes extra-regionales, en su mayor parte comerciantes, y la expansión de la industria de procesamiento de castaña. El último era uno de los factores que atrajo a migrantes intraregionales a las ciudades. La tercera generación de reformas tiene impacto en el norte amazónico boliviano desde finales de la década de 1990. La propiedad de tierras y el acceso a bosques se redefinen por los cambios que resultan de la nueva Ley Forestal y Ley INRA (Ruiz, Capítulo 2). Es muy 
Figura 9.1. Cambios de la proporción del área cultivada en los Andes y trópicos bolivianos durante el periodo 1950-1995

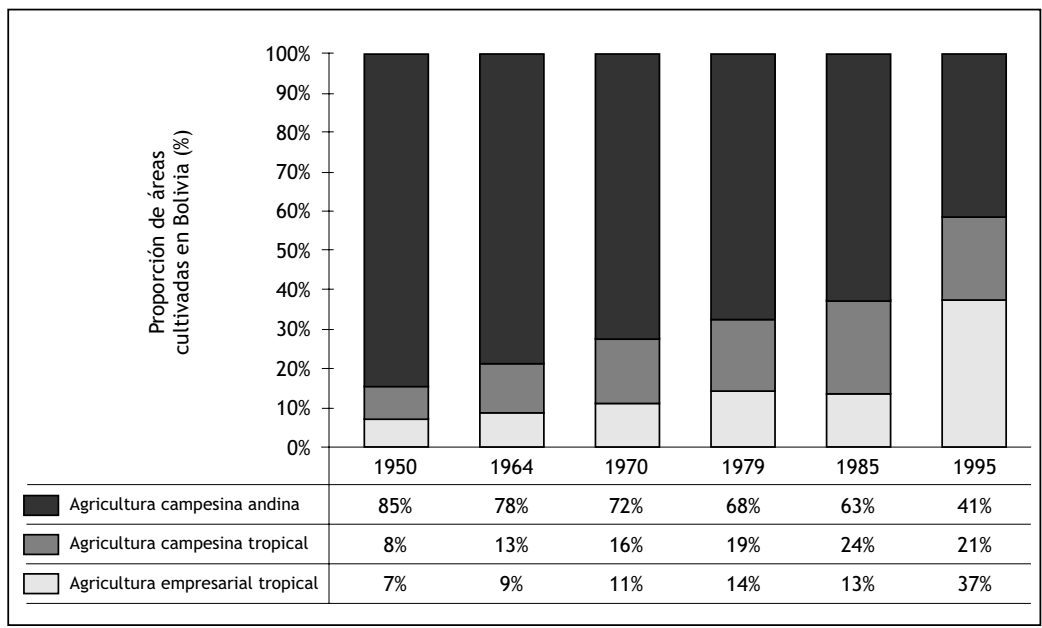

probable que estos cambios lleguen a ser un factor atractivo para inmigrantes extra-regionales hacia el norte amazónico boliviano.

\section{LOS IMPACTOS DE LA MIGRACIÓN SOBRE EL BOSQUE}

El impacto directo de emigrantes sobre el bosque en el norte amazónico boliviano ha cambiado con el tiempo. La pérdida del bosque era más intensa alrededor de barracas durante las épocas de producción del caucho. Una vez paralizada la producción de caucho, la presión en el bosque cambió hacia los nuevos asentamientos, donde muchos recolectores de caucho se desplazaron, incluyendo dentro de sus actividades económicas la agricultura de subsistencia. Además, muchos dueños de barracas empezaban a criar ganado en sus propiedades. Desde los años 1990, la tala de madera tiene cada vez más importancia en la región (Bojanic 2001) y un nuevo grupo de agricultores medianos practican la agricultura comercial a pequeña escala para abastecer con alimentos a las ciudades regionales. Últimamente, habitantes urbanos afectan cada vez más el bosque, cuando intentan obtener materiales de construcción para sus residencias, pero también porque aumentan la demanda de productos agrícolas y forestales.

Para el primer grupo, el principio fundamental para su agricultura es la seguridad alimenticia, aunque la producción comercial aumenta. La deforestación es inevitable para este grupo de personas si ellos quieren 
sobrevivir. El promedio de área cultivada por familia ha aumentado durante los últimos años: entre 1980 y 1990 el área cultivada en los departamentos del Beni y Pando aumentó de 18,000 a 33,000 hectáreas y de 3,000 a 15,000 hectáreas, respectivamente (Torrico 1983, INE 1999a, b, citados en Henkemans 2001). La agricultura en esta región se basa en un sistema de agricultura de roza y quema. Los chacos deforestados se distribuyen escasamente y se les deja descansar por largos períodos después de dos años de uso intensivo. Las actividades agrícolas de este grupo no son muy intensivas e implican una conversión forestal relativamente menor. Las tasas de conversión del bosque son más altas cerca de la frontera brasileña (Káiser 1993, citado en Henkemans 2001). La conversión a gran escala para propósitos comerciales tiene un potencial relativamente bajo, como consecuencia de la baja fertilidad de la tierra.

Los dueños de barracas continúan con la extracción de castaña entre los meses de noviembre y marzo todos los años, trayendo a recolectores estacionales de las principales ciudades de la región. El resto del año, la mayor parte de ellos se dedican a la crianza de ganado y extracción de madera. La crianza de ganado es muy intensiva cerca de Cobija, en Pando. Es también muy intensa a lo largo de los nuevos caminos que conectan Cobija con Riberalta y Riberalta con Guayaramerín. La costosa conversión del bosque a pasto para la crianza de ganado es una desventaja cuando se compara esta actividad con la realizada en las sabanas naturales al sur de la región. La crianza de ganado ha aumentado significativamente durante los últimos años, en parte como resultado de la necesidad de demostrar el uso económico de tierras forestales para obtener título de propiedad.

Los datos sobre la deforestación para esta región fueron conocidos durante los primeros años de la década de 1990. La Tabla 9.4 muestra información sobre la deforestación en las tierras bajas de Bolivia, y el norte amazónico, entre las décadas de 1980 y 1990. Entre 1975 y 1993, el área forestal de Bolivia disminuyó de $565,000 \mathrm{~km}^{2}$ a 534,000 km² (GEOBOL 1978, en Pacheco 1998, MDSMA 1995). Durante este periodo, aproximadamente $30,242 \mathrm{~km}^{2}$ de los bosques bolivianos fueron deforestados a una tasa de 1,680 km² por año. Entre 1985 y 1990, la tasa anual más alta de deforestación se vio en el departamento de Santa Cruz $\left(340 \mathrm{~km}^{2}\right.$ por año aproximadamente), mientras que el departamento de Pando perdió 49 $\mathrm{km}^{2}$ de la cobertura boscosa por año en el mismo período. El departamento del Beni perdió sólo 1.6\% de su bosque hasta el año 1990, y el norte amazónico boliviano sólo perdió $2.6 \%$ de su bosque en el mismo periodo (Usipales 2001). Estos datos probablemente variaron durante la década de 1990, entre otros a causa de las expansiones de producción de ganado en el departamento de Pando. 


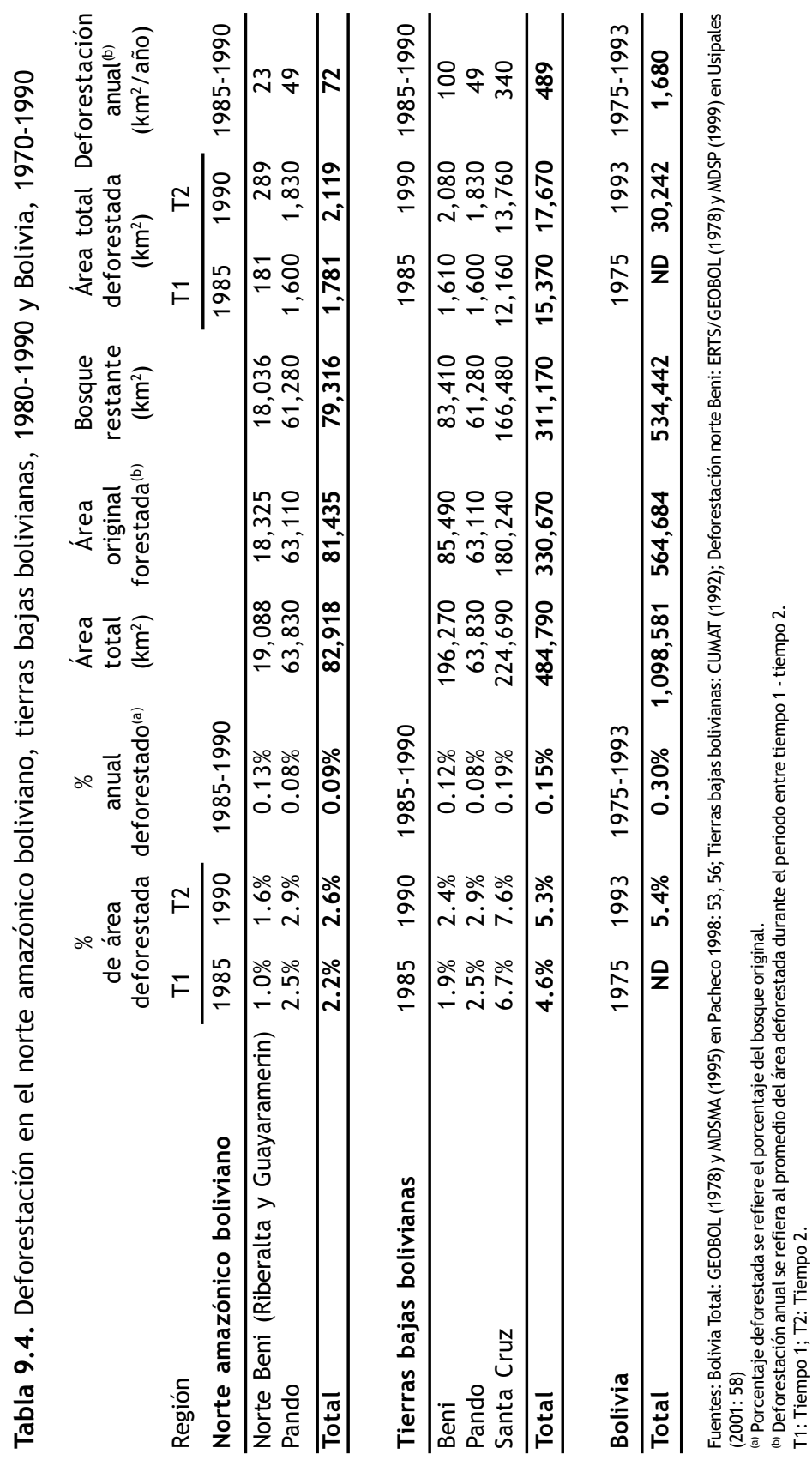


A pesar de la falta de datos más recientes, estas figuras demuestran que la correspondencia entre la pérdida del bosque, la migración rural, y la migración urbana es moderada. La columna de la derecha en la Tabla 9.3 muestra el porcentaje de inmigrantes que se asentaron en las áreas urbanas. Durante las décadas de 1980 y 1990, el proceso de urbanización en las tierras bajas de Bolivia aumentó, convirtiendo esta región en una frontera bastante urbana. En el norte amazónico boliviano, el proceso de urbanización implicó que la mayoría de los emigrantes se asienten en los centros urbanos, generando quizás sólo una presión indirecta sobre el bosque. Sin embargo, comparando los datos nacionales, el porcentaje más alto de inmigrantes que se asentaban en áreas rurales se vio en Pando. Esto está de acuerdo con las tasas más altas de deforestación en el departamento de Santa Cruz, que es claramente el más urbanizado.

\section{CONCLUSIONES}

La migración en el norte amazónico boliviano ha tenido cuatro características principales: (1) la migración de personas extra-regionales hacia la región, (2) la migración desde áreas rurales en la región hacia centros urbanos en la región, (3) la migración desde centros urbanos hacia áreas rurales en la región, y (4) en la migración entre áreas rurales en la región. Los diferentes tipos de migración han jugado un papel importante en el tiempo y cada uno de los cuatro tipos de la migración puede ser relacionado a una combinación relativamente clara y particular de las actividades forestales y no forestales. Factores externos influyeron en estos procesos migratorios. La migración hacia el norte amazónico boliviano fue de mayor importancia cuando los productos forestales llegaron a tener una gran demanda en el mercado internacional. Los factores internacionales, como el abastecimiento de caucho desde Asia, dedpués de la Segunda Guerra Mundial, y la eliminación de subsidios al caucho por Brasil influyeron en la viabilidad para el aprovechamiento de los productos forestales y modos de cooperación, y esto influyó fuertemente en la migración intra-regional.

Los factores que definen la migración, y la migración misma en el norte amazónico boliviano, serán probablemente muy dinámicos en los próximos años. Dos factores claves son la expansión de Cobija como el centro político y económico en la región, y el camino bioceánico que muy pronto conectará Brasil y Perú, y que pasa muy cerca de la región. Esto crea una condición enteramente nueva para el norte amazónico boliviano. Otro factor es la redistribución de tierras forestales entre indígenas y campesinos (Ruiz, Capítulo 2, Hentschel, Capítulo 5, Garzón, Capítulo 6). Queda claro que estos factores definirán la migración en el futuro cercano. Es menos claro cómo los factores más localizados influyen en los procesos de migración. Las tendencias iniciales sugieren que muchos emigrantes se moverán hacia 
Pando o Cobija. Además, es muy probable que lleguen nuevos emigrantes extra-regionales buscando nuevas oportunidades. El impacto de estas nuevas migraciones es difícil de predecir.

A pesar de que los procesos particulares de migración descritos aquí son típicos para una región de extracción no exhaustiva de productos forestales (caucho y castaña) semejantes procesos de migración multidireccional son comunes en otras regiones tropicales donde el uso local de los recurso es relacionado de alguna manera a mercados más grandes (Limachi et al. 2004).

En el caso del norte amazónico boliviano es notable la conexión entre los procesos de migración y la deforestación. Parte de las mayores migración en las regiones forestales tenían poco impacto sobre el bosque, y más bien, las subsiguientes migraciones rural-urbanas tuvieron como resultado una presión aumentada sobre el bosque. Esto es sobretodo el resultado de un cambio en actividades económicas mayores de las personas que emigraron, desde un enfoque de colección de productos forestales hacia un enfoque en la producción comercial agrícola. De esto se puede concluir que sólo la migración hacia una región forestal no puede explicar una presión incrementada sobre el bosque. Depende del tipo de uso de los recursos que coincide con una cierta tendencia de migración, y de procesos migratorios subsiguientes y más localizados. Bajo ciertas circunstancias, movimientos fuera del bosque pueden implicar un cambio en el uso de los recursos que puede tener como resultado una presión aumentada sobre el bosque.

\section{REFERENCIAS}

Bojanic, A.J. 2001. Balance is Beautiful: Assessing Sustainable Development in the Bolivian Amazon. PROMAB Seria Científica 4. Programa de Manejo de Bosques de la Amazonia Boliviana (PROMAB), Universidad de Utrecht.

Carr, M. 1997. New Patterns: Process and Change in Human Geography. Gran Británica, Thomas Nelson and Sons Ltd.

Chispin, J. y Jegede, F. 1998. Population, Resources and Development. Londres, Collins.

Codrington, S. 2002. Planet Geography. Published by Solid Star Press. Adelaide, Australia.

Henkemans, A. B. 2001. Tranquilidad and Hardship in the Forest: Livelihoods and Perceptions of Camba Forest Dwellers in the Northern Bolivian Amazon. PROMAB Seria Científica 5. Programa de Manejo de Bosques de la Amazonia Boliviana (PROMAB), Universidad de Utrecht.

INE (Instituto Nacional de Estadística). 2001. Censo Nacional de Población y Vivienda 2001. Beni: Resultados Departamentales. La Paz: INE. 
INE 2001. Censo Nacional de Población y Vivienda 2001. Pando: Resultados Departamentales. La Paz: INE.

Informe de Desarrollo Humano en Bolivia (IDHB). 2002. Programa de las Naciones Unidas para el Desarrollo (PNUD), La Paz.

IPHAE (Instituto para el Hombre, Agricultura y Ecología) 2003. Departamento de Apoyo al Fortalecimiento Organizativo y Tenencia de la Tierra. Riberalta: IPHAE.

Kaimowitz, D. y Angelsen A. 1998. Economic Models of Tropical Deforestation: A Review. Yakarta, Centro para la Investigación Forestal. Llanque Zonta, V. 2003. Driving Forces of Rural-Urban Migration in the Northern Bolivian Amazon Region. Flekke, Red Cross Nordic United World College.

Pacheco Balanza, P. 1998. Estilos de Desarrollo, Deforestación y degradación de los Bosques en la Tierras Bajas de Bolivia. La Paz: Centro para la Investigación Forestal Internacional/ Centro de Estudios para el Desarrollo Laboral y Agrario/ TIERRA.

Pacheco Balanza, P. 1992. Integración Económica y Fragmentación Social: El Intinerario de las Barracas en la Amazonía Boliviana. La Paz: Centro de Estudios para el Desarrollo Laboral y Agrario (CEDLA).

Pacheco Balanza, P. 1998a. Magnitud y Causas de la Deforestación y Degradación de los Bosques en Bolivia. Www.wrm.org.uy/ deforestation/LAmerica/Bolivia.html.

Pacheco, P. y Mertens, B. 2003. Land use change and agriculture development in Santa Cruz, Bolivia. Bois et Forêt des Tropiques.

Perz, S. 2002. Migrant Characteristics, and Land Use/Land Cover Change in the Pan-Amazon Basin: A Comparative Analysis of Brazil, Bolivia and Peru. Presentado al Symposium "In, Out, In, Out: Populations, Migrations, and the Social Ecology of Tropical Forests", Japan Center for Area Studies, Osaka.

Stoian, D. 2000. Variations and Dynamics of Extractive Economies: the Rural-Urban Nexus of Non-timber Forest Use in the Bolivian Amazon. Tesis de Doctorado, Universidad de Freiburg.

Usipales 0. 2001. Incidencia de la Ganadería en la Deforestación del Bosque Tropical de Tierra Firme en el Municipio de Riberalta. Tesis de graduación, Universidad Técnica del Beni (UTB), Riberalta. 
Desde mediados de los años 1990 Bolivia inició una reforma política y legal teniendo como eje central la promulgación de un paquete de leyes. Incluye tres leyes que están afectando fuertemente al sector forestal y la participación de la población rural, en el norte amazónico boliviano. La Ley de Participación Popular (1994), la Ley del Servicio Nacional de Reforma Agraria (Ley INRA), y la nueva Ley Forestal (1996). Estas leyes están reconfigurando totalmente quién se aprovecha económicamente de los bosques de Bolivia, y cómo se hace esto. El nuevo régimen legal de Bolivia ha resultado en una democratización del sector.

Este libro presenta nueve capítulos que analizan el impacto del paquete de reformas sobre la población forestal en el norte amazónico boliviano. Los estudios son el resultado de un proyecto de investigación llevado a cabo por el Centro para la Investigación Forestal Internacional (CIFOR), el Instituto de Política Forestal y Ambiental, Sección de Mercados y Mercadeo de la Universidad de Friburgo, el Programa de Manejo de Bosques de la Amazonía Boliviana (PROMAB) y el Centro de Investigación y Promoción del Campesinado (CIPCA).

El nuevo régimen legal tiene un impacto importante en el norte amazónico boliviano. El marco legal, el enfoque de este libro, es sólo un elemento que influye sobre el impacto que tiene el aprovechamiento de los recursos forestales. Este libro observa aspectos muy positivos del nuevo régimen legal, pero también deficiencias estructurales. Los ajustes del régimen legal tienen que ser acompañados por medidas más amplias, creando capacidad y disposición adecuada de los diferentes actores para implementar un mejor manejo forestal, permitido por un régimen legal adecuado a las condiciones de la región.
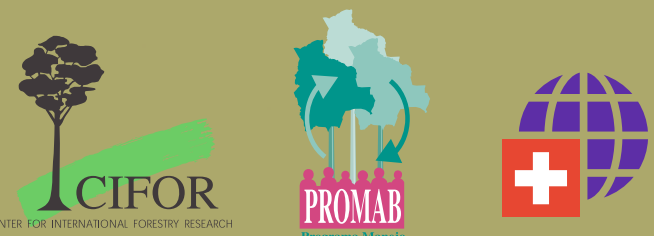

Bundesministerium für wirtschaftliche Zusammenarbeit und Entwicklung 